UNIVERSIDADE DE SÃO PAULO

ESCOLA DE ENFERMAGEM

ALINE ALE BERALDO

ADESÃO AO TRATAMENTO DA TUBERCULOSE: AÇÕES DESENVOLVIDAS PELOS SERVIÇOS DE ATENÇÃ̃O BÁSICA EM CAMPINASS - SP

RIBEIRÃO PRETO

2015 


\section{ADESÃO AO TRATAMENTO DA TUBERCULOSE: AÇÕES DESENVOLVIDAS PELOS SERVIÇOS DE ATENÇẪO BÁSICA EM CAMPINAS - SP}

Tese apresentada ao Programa Interunidades de Doutoramento em Enfermagem da Escola de Enfermagem da Universidade de São Paulo e Escola de Enfermagem de Ribeirão Preto da Universidade de São Paulo para obtenção do título de Doutor em Ciências.

Linha de pesquisa: Sociedade, Saúde e Enfermagem

Orientador: Tereza Cristina Scatena Villa 
Autorizo a reprodução e divulgação total ou parcial deste trabalho, por qualquer meio convencional ou eletrônico, para fins de estudo e pesquisa, desde que citada à fonte.

Beraldo, Aline Ale

ADESÃO AO TRATAMENTO DA TUBERCULOSE: AÇÕES DESENVOLVIDAS PELOS SERVIÇOS DE ATENÇÃO BÁSICA EM CAMPINAS - SP. Escola De Enfermagem De Ribeirão Preto Universidade De São Paulo, 2015.

105 p.: il.; $30 \mathrm{~cm}$

Tese de Doutorado, apresentada à Escola de Enfermagem de Ribeirão Preto/USP.

Orientador: Tereza Cristina Scatena Villa

1. Tuberculose. 2. Adesão ao Tratamento. 3. Serviços de Saúde. 4. Atenção Básica. 
BERALDO, Aline Ale

ADESÃO AO TRATAMENTO DA TUBERCULOSE: AÇÕES DESENVOLVIDAS PELOS SERVIÇOS DE ATENÇÃO BÁSICA EM CAMPINAS - SP

Tese apresentada ao Programa Interunidades de Doutoramento em Enfermagem da Escola de Enfermagem da Universidade de São Paulo e Escola de Enfermagem de Ribeirão Preto da Universidade de São Paulo para obtenção do título de Doutor em Ciências.

Aprovado em / /

\section{Comissão Julgadora}

Prof. Dr.

Instituição:

Prof. Dr.

Instituição:

Prof. Dr.

Instituição:

Prof. Dr.

Instituição:

Prof. Dr.

Instituição: 


\section{DEDICATÓRIA}

Aos Meus Pais Osmar e Sandra e irmãos Ana Carolina e Rodrigo, por todo o incentivo e apoio de sempre, sem vocês nada teria sido possível! Amo vocês!! 


\section{Agradecimentos}

A minha orientadora Profa ${ }^{a} r^{a}$ Tereza Cristina Scatena Villa, por todas as oportunidades vivenciadas, reflexões, aprendizado, e através da sua liderança sempre nos ensinando como enfrentar desafios, também pela grandiosa oportunidade de Fazer e continuar fazendo parte do GEOTBB.

Ao Prof. Dr. Antônio Ruffino Netto, por todas as oportunidades, pela paciência em nos ensinar diante de cada dificuldade, e nos mostrar como seguir em frente, também por dividir conosco a sabedoria profissional, mas principalmente o que levar para a vida. 


\section{Agradecimentos}

A Todos os professores do GEOTB, e em especial à Profa ${ }^{a} r^{a}$ Aline Aparecida Monroe, por todo aprendizado e generosidade, tenho aprendido muito com você; Ao Prof. Dr. Reinaldo Antônio da Silva-Sobrinho, pelo aprendizado e parceria em todos esses anos; A Profa $\mathscr{D r}^{a}$ Lúcia Marina Scatena por toda a contribuição e aprendizado, principalmente com os Métodos Estatísticos ao longo da Pós Graduação;

Muito obrigada, professores!

As amigas Beh, Eli e Isa, por continuar fazendo parte da minha vida, pela amizade.

A Paty, por estar sempre presente, por todos os conselhos, o carinho e amizade.

A Rubia, por todos os ensinamentos, paciência e amizade.

A cada amigo da "TROPA", aqueles que não estão mais presentes fisicamente, por estarem seguindo suas carreiras, mas sempre no coração, Amelinha, Anne, Érika, Rei e Tiemi, e aquelas que continuam no desenvolvimento das teses, dissertações e Pós-Doc, Gabi, Laurinha, Lívia, Maria Eugênia, Nathy H. e Nathy C. e Ru muito obrigada por toda a colaboração, companfia e aprendizado de sempre! 
A Bia (in memoriam), por todo o trabalho conjunto, aprendizado, pelas maravilhosas histórias que a "TROPA" viveu e nunca mais esquecerá. Você faz muita falta!!

A todos os participantes do GEOTBB, GEOquali e GEOaids, por toda a construção conjunta, e todo o aprendizado que me foi proporcionado. Muito obrigada!

A FAPESP pelo apoio financeiro para o desenvolvimento dessa pesquisa.

A Escola de Enfermagem de Ribeirão Preto e todos os funcionários, que tornaram possívelo desenvolvimento dessa pesquisa.

Ao Programa Interunidades de Doutoramento em Enfermagem da Escola de Enfermagem e Escola de Enfermagem de Ribeirão Preto, em especial a FCávia, por todo o apoio, suporte e gentileza de sempre.

Aos profissionais de saúde e gerentes dos serviços de Atenção Básica (CS), e também aos doentes de Tuberculose do município de Campinas, sem vocês essa pesquisa não poderia ter sido realizada.

A Maria Alice Satto, e Rosalice Carvalho de Castro, ex e atual coordenadora do Programa de Controle da Tuberculose por todo o apoio, carinho e profissionalismo que sempre tiveram comigo.

As enfermeiras Fabiana, Yara, Nidia, Sirlei e Valdete das Vigilâncias em Saúde Distritais do Município de Campinas por toda a disponibilidade em colaborar com o desenvolvimento da Pesquisa.

Muito obrigada a todos vocês por fazerem parte dessa construção!!! 


\section{RESUMO}

BERALDO, A.A. Adesão ao Tratamento da Tuberculose: ações desenvolvidas pelos serviços de Atenção Básica em Campinas - SP. 2015. 105f. [Tese] - Escola de

Enfermagem de Ribeirão Preto, Universidade de São Paulo, Ribeirão Preto, 2015.

O objetivo do presente estudo foi analisar as ações desenvolvidas na atenção básica para promover adesão ao tratamento da tuberculose na percepção dos doentes e profissionais de saúde em Campinas-SP. Trata-se de um estudo epidemiológico descritivo do tipo inquérito, que foi conduzido no município de Campinas. A população de estudo foi composta por enfermeiros e técnicos/auxiliares de enfermagem que acompanharam casos de tuberculose nos últimos 12 meses anterior à coleta de dados (agosto de $2012 \mathrm{a}$ maio de 2013) e doentes de tuberculose que estavam em tratamento no período de coleta de dados citado, ou que haviam terminado o tratamento em até 30 dias, e se enquadravam nos critérios de inclusão: idade igual ou superior a 18 anos, em tratamento há 3 meses ou mais, fora do sistema prisional. Foi utilizado um questionário estruturado com 16 questões com resposta dicotômica (sim e não), relacionadas as ações oferecidas na Atenção Básica para promover a adesão ao tratamento de tuberculose, que são correspondentes na percepção dos doentes e profissionais de saúde. Tais questões foram elaboradas com base no "Adherence to long-term therapies: evidence for action", "Manual de Recomendações para o Controle da tuberculose", da série de artigos "Melhores práticas para o cuidado de doentes com tuberculose", e estudos anteriores que abordam os aspectos de maior relevância para a adesão e para a não adesão ao tratamento da tuberculose. Para a análise dos dados foi utilizado o teste qui-quadrado para comparação de proporções e teste exato de Fisher quando os critérios (Valores esperado, $\mathrm{E}_{\mathrm{ij}}>1,80 \%$ dos $\mathrm{E}_{\mathrm{ij}} \geq 5, \mathrm{~N} \geq 20$ ) não foram atendidos. Quanto aos resultados, foram entrevistados 183 profissionais da equipe de enfermagem e 165 doentes de tuberculose. As seguintes ações não tiveram associação entre as percepções de doentes e profissionais: orientação sobre o que é tuberculose; orientação quanto à importância de comparecer às consultas mensais; orientação sobre a realização de exames de controle; orientação sobre como deve tomar os remédios da tuberculose; encorajamento para continuar o tratamento da tuberculose; orientação para procurar pelo serviço de saúde quando tem dúvidas sobre o tratamento; orientação para observar se os sintomas melhoram durante o tratamento; orientação sobre a conduta a ser tomada se os sintomas piorarem; orientação sobre os hábitos de uma vida mais saudável (alimentação adequada, prática de exercícios físicos, evitar o uso de bebida alcoólica e cigarro) e convite para participar de algum grupo de doentes de tuberculose. E estas outras ações tiveram associação: orientação para buscar informações em livros e/ou internet sobre a doença; oportunidade para opinar sobre o tratamento; agendamento de consultas mensais para o acompanhamento do tratamento da tuberculose; entrega de informações escritas sobre o tratamento; orientação para que os familiares façam exames para a tuberculose e tempo suficiente para você falar sobre as dúvidas e/ou preocupações. Através da análise das percepções de doentes e profissionais de saúde, compreende-se que a Atenção Básica do município de Campinas vem oferecendo ações para a adesão ao tratamento da tuberculose. Entende-se isso como um avanço, no entanto, ainda há deficiências na promoção de autonomia dos doentes pelos serviços de saúde, participação do doente nas decisões do tratamento, investigação dos contatos, bem como na oferta de ações extramuros e voltadas a uma assistência familiar e comunitária que poderiam ajudar ainda mais na adesão ao tratamento.

Palavras-chave: Tuberculose, Adesão ao Tratamento, Serviços de Saúde, Atenção Básica. 


\begin{abstract}
BERALDO, A.A. Adherence to Tuberculosis Treatment: actions developed by

Primary Health care services in Campinas - SP. 2015. 105f. [Thesis] - Ribeirão Preto

College of Nursing - University of Sao Paulo, Ribeirao Preto, 2015.
\end{abstract}

The aim of this study was to analyze the actions undertaken in primary health care to promote adherence to tuberculosis treatment in the perception of patients and nursing staff in Campinas-SP. It is a descriptive epidemiological study of the survey type, which was conducted in Campinas. The study population consisted of nursing staff who accompanied cases of tuberculosis in the 12 months prior to data collection (August 2012 to May 2013) and tuberculosis patients who were undergoing treatment at the collection period Data cited or had completed treatment within 30 days, and met the inclusion criteria: aged 18 years, in treatment for three months or more, out of the prison system. It used a structured questionnaire with 16 questions with dichotomous answers (yes and no), relating the shares offered in primary health care to promote adherence to treatment of tuberculosis, which are relevant in the perception of patients and health professionals. These questions were designed based on "Adherence to long-term therapies: evidence for action", "Recommendations Manual for the Control of Tuberculosis", the series "Best practices for the care of patients with tuberculosis," and previous studies addressing the most relevant aspects for membership and nonadherence to tuberculosis treatment. For data analysis were used the chi-square test to compare proportions and Fisher's exact test when criteria (expected values, Eij $>1,80 \%$ of Eij $\geq 5, N \geq 20$ ) were not met. As for the results, they interviewed 183 professionals of the nursing staff and 165 sick with tuberculosis. The following actions have had no association between perceptions of patients and professionals: guidance on what is TB; guidance on the importance of attending monthly visits; guidance on performing tests of control; guidance on how to take the medication for TB; encouragement to continue TB treatment; orientation to seek for health services when they have doubts about the treatment; orientation to see if symptoms improve during treatment; guidance on the action to be taken if symptoms worsen; guidance on the habits of a healthier lifestyle (proper nutrition, physical exercise, avoid using alcohol and cigarettes) and invitation to join some group of TB patients. And these others actions were associated: Opportunity to opine on the treatment; Scheduling monthly visits for monitoring of tuberculosis treatment; Provide written information about treatment; Guidance for families to do tests for tuberculosis; Enough for you to talk about the questions and / or concerns time. By analyzing the perceptions of patients and health professionals, it is understood that the primary care of the Campinas municipality has offered shares to adherence to tuberculosis treatment. It is understood this as a breakthrough, however, there are still shortcomings in the promotion of autonomy of patients by health services, patient participation in treatment decisions, investigation of contacts as well as in the provision of extramural activities and aimed at a family assistance and community that could further help in treatment adherence.

Key Words: Tuberculosis, Medication Adherence, Health Services, Primary Health Care. 


\section{RESUMEN}

BERALDO, A.A. La adherencia al tratamiento antituberculoso: medidas adoptadas por los servicios de atención primaria en Campinas - SP. 2015. 105f. Tesís - Escuela de Enfermería de Ribeirão Preto, Universidad de São Paulo, Ribeirão Preto, de 2012.

El objetivo del estudio fue analizar las acciones emprendidas en la atención primaria para promover la adhesión al tratamiento de la tuberculosis en la percepción de los pacientes y los profesionales de la salud en Campinas-SP. Se trata de un estudio epidemiológico descriptivo de tipo encuesta, que se realizó en Campinas. La población de estudio consistió de enfermeras y asistentes técnicos / enfermería que acompañaron a los casos de tuberculosis en los 12 meses anteriores a la recolección de datos (agosto 2012-mayo 2013) y los pacientes con tuberculosis que fueron recibiendo tratamiento en el período de recolección Los datos citados o habían completado el tratamiento dentro de 30 días, y se reunió con los criterios de inclusión: mayores de 18 años en tratamiento por tres meses o más, fuera del sistema penitenciario. Se utilizó un cuestionario estructurado con 16 preguntas con respuestas dicotómicas (sí y no), que relaciona las acciones ofrecidas en la atención primaria para promover la adherencia al tratamiento de la tuberculosis, que son relevantes en la percepción de los pacientes y los profesionales de la salud. Estas preguntas fueron diseñados sobre la base de "La adherencia a los tratamientos a largo plazo: Evidencia para la acción", "Manual de Recomendaciones para el Control de la Tuberculosis", la serie "Las mejores prácticas para el cuidado de pacientes con tuberculosis", y estudios previos abordar los aspectos más relevantes para la adhesión y la falta de adherencia al tratamiento de la tuberculosis. Para el análisis de los datos se utilizó la prueba de chi-cuadrado para comparar proporciones y la prueba exacta de Fisher cuando criterios (valores esperados, Eij $>1$, el 80\% de Eij $\geq 5, \mathrm{~N} \geq 20$ ) no fueron satisfechas. En cuanto a los resultados, se entrevistaron a 183 profesionales del personal de enfermería y 165 enfermos de tuberculosis. Las siguientes acciones han tenido asociación entre las percepciones de los pacientes y los profesionales: una guía sobre lo que es la tuberculosis; orientación sobre la importancia de asistir a las consultas mensuales; orientación sobre la realización de las pruebas de control; orientación sobre cómo tomar los medicamentos para la tuberculosis; estímulo para continuar el tratamiento de la tuberculosis; orientación para la búsqueda de los servicios de salud cuando tienen dudas sobre el tratamiento; orientación para ver si los síntomas mejoran durante el tratamiento; orientación sobre medidas que deben adoptarse si los síntomas empeoran; orientación sobre los hábitos de un estilo de vida saludable (alimentación adecuada, ejercicio físico, evitar el uso de alcohol y tabaco) y la invitación a participar en algún grupo de pacientes con tuberculosis. Y estas otras acciones fueron asociados: orientación para buscar información en libros y / internet sobre la enfermedad; oportunidad de opinar sobre el tratamiento; programar visitas mensuales para monitorear el tratamiento de la tuberculosis; entrega de información escrita sobre el tratamiento; orientación a los miembros de la familia para hacer las pruebas para la tuberculosis y el tiempo suficiente para que usted hable sobre las preguntas y / o preocupaciones. Mediante el análisis de las percepciones de los pacientes y los profesionales de la salud, se entiende que la atención primaria del municipio de Campinas ha ofrecido acciones a la adherencia al tratamiento de la tuberculosis. Se entiende esto como un gran avance, sin embargo, todavía hay deficiencias en la promoción de la autonomía de los pacientes por los servicios de salud, la participación del paciente en las decisiones del tratamiento, la investigación de contactos, así como en 
la prestación de las actividades extraescolares y dirigidas a una asistencia familiar y la comunidad que podrían ayudar más en el cumplimiento.

Palabras claves: Tuberculosis Adherencia al Tratamiento, Servicios de Salud, Atención Primaria. 


\section{LISTA DE FIGURAS}

Figura 1 As cinco dimensões da Adesão ao Tratamento.

Figura 2 Mapa das Redes de Atenção à Saúde, e respectivos Departamento Regional de Saúde e 33 Regiões de Saúde do Estado de São Paulo, 2013. Organograma da Secretaria Municipal de Saúde de Campinas - SP,

Figura 3 2013.

Figura 4 Regiões Distritais de Saúde em Campinas-SP, 2013.

Figura 5 Fluxo do doente durante o acompanhamento dos casos com diagnóstico de tuberculose

Figura 5 pelos tipos de serviços de saúde do Município, Campinas-SP, 41 2013. 


\section{LISTA DE TABELAS}

Distribuição de frequências da descrição do perfil sociodemográfico, clínico e hábitos de

Tabela 1 vida dos doentes de tuberculose, Campinas-SP, 2013

Distribuição de frequências do perfil sociodemográfico e profissional dos profissionais de saúde que acompanharam os casos de tuberculose em tratamento, Campinas-SP, 2013.......

Tabela 2

Tabela 3 Distribuição de frequência da organização da assitência aos doentes de tuberculose

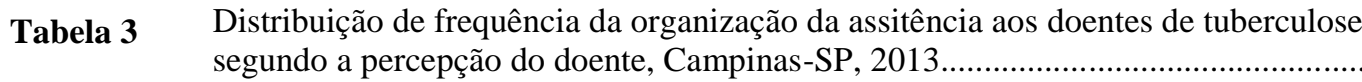
Distribuição de frequência das ações desenvolvidas pelos serviços de atenção básica para

Tabela 4 adesão ao tratamento de tuberculose na percepção dos doentes e profissionais de saúde, Campinas-SP, 2013. 


\section{LISTA DE QUADROS}

Variáveis relacionadas às ações desenvolvidas pelos serviços de atenção básica para adesão ao tratamento

tuberculose...

Artigos, segundo o ano de publicação, periódico, autores, país, tipo e população de estudo,

QUADRO 2 enfoque (adesão, não adesão ou adesão + não adesão), através das características relacionadas às dimensões da Organização Mundial da Saúde (OMS, 2003), 2014 


\section{LISTA DE APÊNDICE}

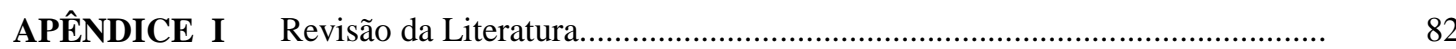

APÊNDICE II Formulário Estruturado - Caracterização dos Doentes e o Tratamento da 96

APÊNDICE III Formulário Estruturado - Caracterização dos Profissionais de Saúde que 97

Formulário Estruturado - Questionário para análise das Ações desenvolvidas

APÊNDICE IV pelos serviços de Atenção Básica para Adesão ao Tratamento da Tuberculose - Percepção dos Doentes.

APÊNDICE V Formulário Estruturado - Questionário para análise das Ações desenvolvidas pelos serviços de Atenção Básica Para Adesão ao Tratamento da Tuberculose - Percepção dos Profissionais de Saúde.

APÊNDICE VI Termo de Consentimento Livre e Esclarecido - Doente...................................... 100

APÊNDICE VII Termo de Consentimento Livre e Esclarecido - Profissionais de Saúde............ 101 


\section{LISTA DE ANEXOS}

ANEXO I

ANEXO II

ANEXO III

ANEXO IV
Autorização do município de Campinas para a realização da pesquisa com os doentes de tuberculose.

Autorização do município de Campinas para a realização da pesquisa com os profissionais de saúde.

Aprovação do Comitê de Ética em Pesquisa da Escola de Enfermagem de Ribeirão Preto - Universidade de São Paulo - EERP/USP - Doentes.

Aprovação do Comitê de Ética em Pesquisa da Escola de Enfermagem de Ribeirão Preto - Universidade de São Paulo - EERP/USP - Profissionais de Saúde. 


\section{LISTA DE ABREVIATURAS}

ACS Agentes Comunitários de Saúde

aids Acquired immune deficiency syndrome

APAE Associação dos Pais e Amigos do Excepcional

CAPS Centros de Apoio Psicossocial

CEO Centros de Especialidades odontológicas

Cinahl Cumulative Index to Nursing and Allied Health Literature

CNES Cadastro Nacional de Estabelecimentos de Saúde

$\mathrm{CNPq} \quad$ Conselho Nacional de Desenvolvimento e Pesquisa

CoViSA Coordenadoria da Vigilância em Saúde

CS Centros de Saúde

DOTS Directly Observed Treatment Short Course

DP Desvio Padrão

DRS Departamento Regional de Saúde

EERP Escola de Enfermagem de Ribeirão Preto

ESF Equipe de Saúde da Família

FMRP Faculdade de Medicina de Ribeirão Preto

GEOTB Grupo de Estudos Epidemiológico-Operacional em Tuberculose

HC Hospital das Clínicas

HIV Human Immunodeficiency Virus

IBECS Indice Bibliográfico Español de Ciencias de la Salud

IBGE Instituto Brasileiro de Geografia e Estatística

IDHM Índice de Desenvolvimento Humano Municipal

IQ Intervalo Interquartil

LILACS Literatura Latino-Americana e do Caribe em Ciências de Saúde

MEDLINE Literatura Internacional em Ciências da Saúde

MESH Medical Subject Headings

OMS Organização Mundial da Saúde

PCT Programa de Controle da Tuberculose

PMCT Programa Municipal de Controle da Tuberculose

PNCT Programa Nacional de Controle da Tuberculose

PUCCAMP Pontifícia Universidade Católica de Campinas 
REDE-TB Rede Brasileira de Pesquisa em Tuberculose

RRAS Rede Regional de Atenção à Saúde

SAD Centros de Apoio Psicossocial

SAMU Serviço de Atendimento Médico de Urgência

SciELO Scientific Electronic Library Online

SUS Sistema Único de Saúde

TB Tuberculose

TBWEB Sistema de Informação do controle dos doentes de TB do Estado de São Paulo

TDO Tratamento Diretamente Observado

UNICAMP Universidade Estadual de Campinas

VISA Vigilância em Saúde Distrital 


\section{SUMÁRIO}

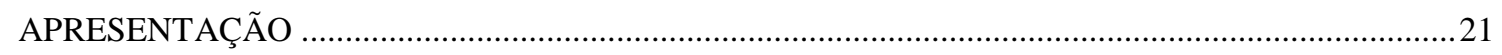

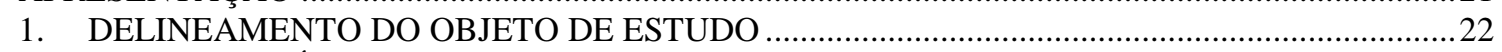

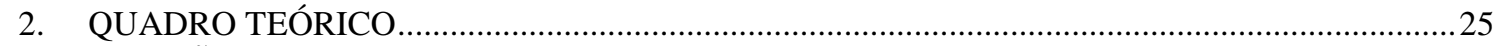

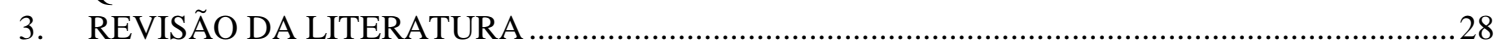

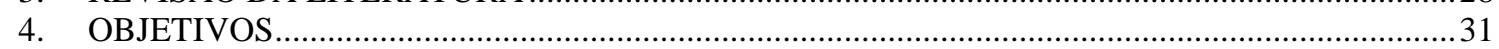

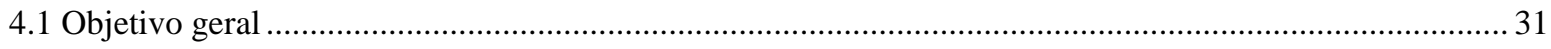

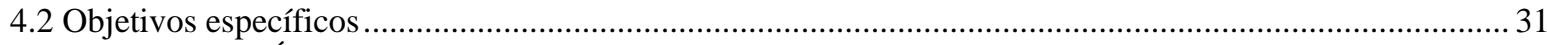

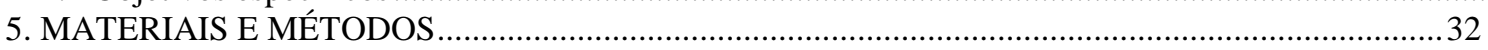

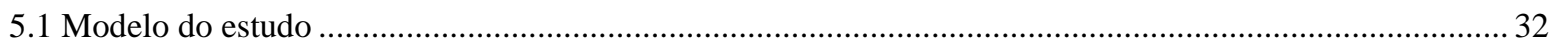

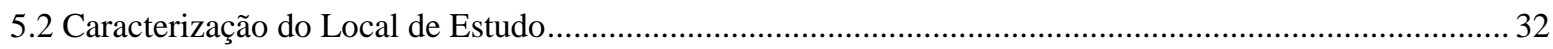

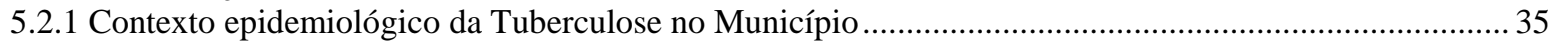

5.2.2 Atendimento à Tuberculose pelos diferentes tipos de Serviços de Saúde do Município................................. 35

5.2.3 Disponibilidade de laboratórios para a realização de exames de diagnóstico e controle da

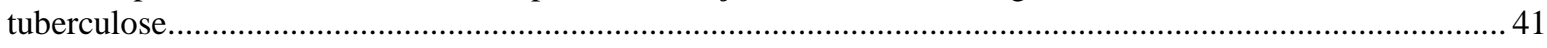

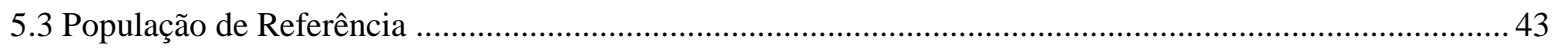

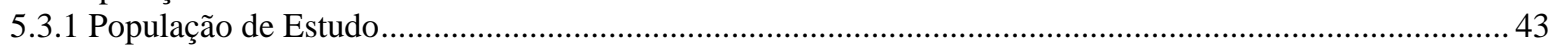

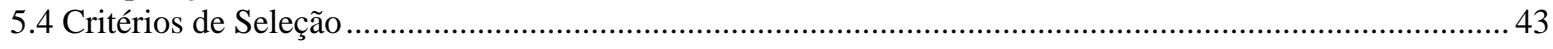

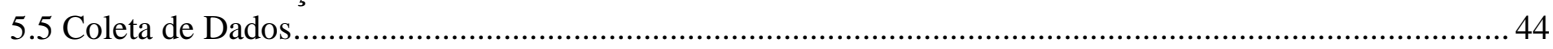

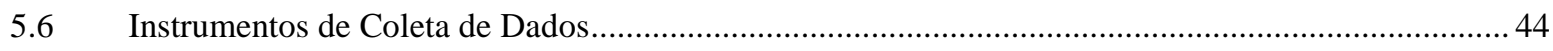

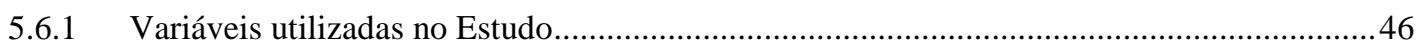

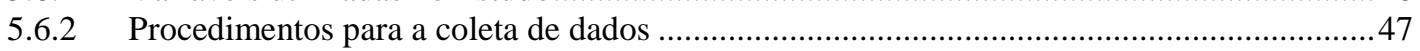

5.6.3 Aspectos observados durante a Coleta de Dados................................................................49

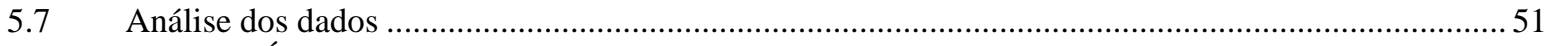

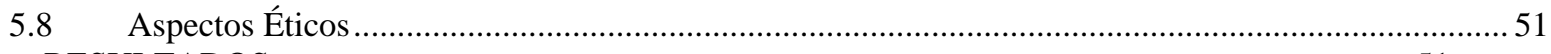

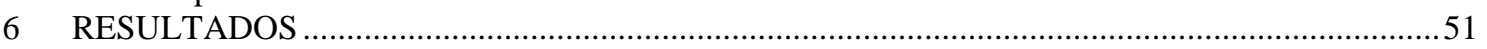

6.1 Caracterização do perfil sociodemográfico, clínico e hábitos de vida dos doentes de tuberculose em

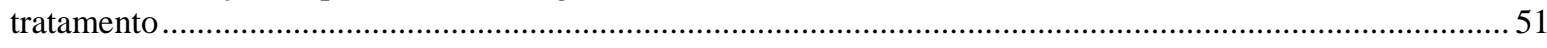

6.2 Caracterização dos profissionais de saúde da atenção básica que acompanham os casos de tuberculose, segundo variáveis demográficas e profissionais.............................................................................53

6.3 Caracterização da organização da assistência aos doentes de tuberculose segundo a percepção dos

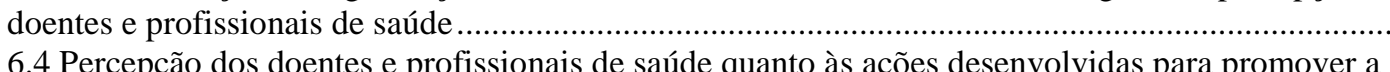
adesão ao tratamento da tuberculose.

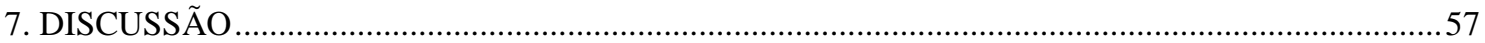

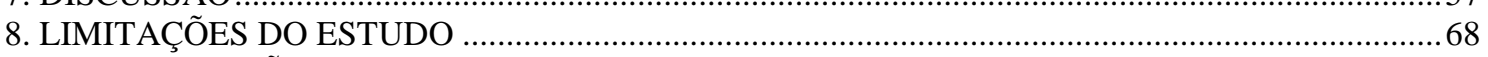

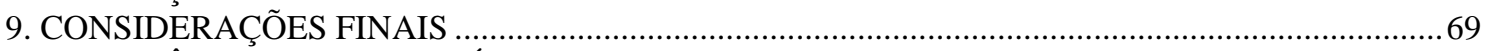

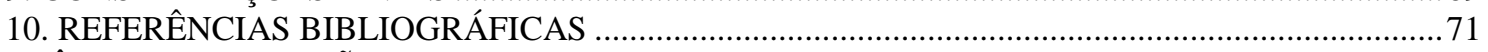

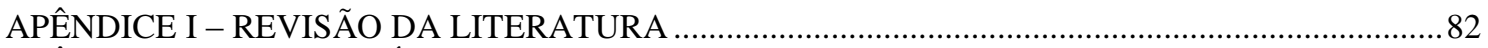

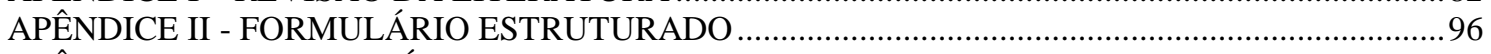

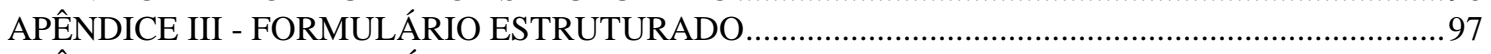

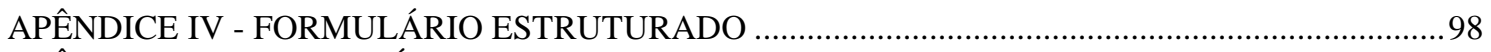

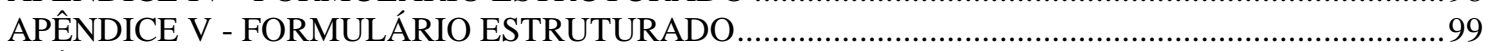

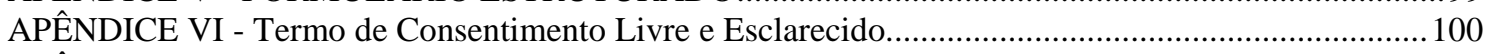

APÊNDICE VII - Termo de Consentimento Livre e Esclarecido ................................................................ 101

ANEXO I - Autorização do município de Campinas para a realização da pesquisa com os doentes de

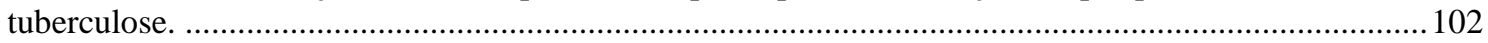

ANEXO II - Autorização do município de Campinas para a realização da pesquisa com os profissionais

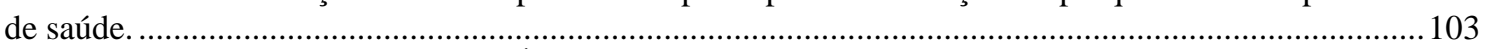

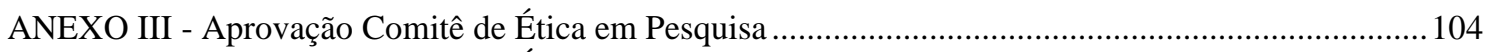

ANEXO IV - Aprovação Comitê de Ética em Pesquisa............................................................................ 105 


\section{APRESENTAÇÃO}

Este estudo foi realizado no município de Campinas-SP, considerado prioritário para o controle da tuberculose, parte integrante do projeto Multicêntrico financiado pelo CNPq Edital MCT/CNPq 14/2010 (processo 475907/2010-8), intitulado: “Estratégia DOTS no tratamento da tuberculose: desempenho da Atenção Básica em municípios da região Sul, Sudeste e Nordeste do Brasil", desenvolvido pelo "Grupo de Estudos Epidemiológico-Operacional em Tuberculose" (GEOTB) ${ }^{2}$.

Este grupo vem desenvolvendo pesquisa de forma integrada com pesquisadores da Rede Brasileira de Pesquisa em Tuberculose (REDE-TB), entidades governamentais (coordenação estadual, municipal do Programa de Controle da Tuberculose, gerentes e profissionais dos serviços de saúde da rede básica), instituições de ensino superior estadual e federal, alunos de graduação e pós-graduação, centros de pesquisa e agências de cooperação internacional.

\footnotetext{
${ }^{1}$ Coordenado por: Prof $^{\mathrm{a}}$. Dri ${ }^{\mathrm{a}}$. Tereza Cristina Scatena Villa ${ }^{2}$ Líderes: Prof. Dr. Antônio Ruffino Netto e $\operatorname{Prof}^{\mathrm{a}} \operatorname{Dr}^{\mathrm{a}}$ Tereza Cristina Scatena Villa; www.eerp.usp.br/geotb
} 


\section{DELINEAMENTO DO OBJETO DE ESTUDO}

A endemia da tuberculose (TB) representa um dos mais graves e persistentes problemas contemporâneos de Saúde Pública em todo o mundo (CAVALCANTI et al., 2006; HIJJAR, 2005; RUFFINO-NETTO, 2002; LIMA et al., 1997). Sabe-se que esta epidemia foi agravada pela negligência, tanto por parte de gestores, como profissionais de saúde, bem como pela própria população por ter sido considerada "extinta".

Diante deste cenário, medidas para o controle da TB foram deixadas em segundo plano e, neste sentido, o abandono do tratamento da TB representa um dos aspectos técnicos que desafiam o efetivo controle da doença, posto que traz implicações para a saúde pública e para a saúde do próprio indivíduo (NGAMVITHAYAPONG-YANAI et al, 1998).

No ano 2000, a Organização Mundial da Saúde (OMS) elaborou metas para o "Desenvolvimento do Milênio" e o combate a certas doenças, entre elas a TB, originando a iniciativa chamada Stop TB, que estabeleceu para até o ano de 2015 a redução da incidência e de óbitos por TB em 50\%, a partir de então, a TB foi colocada entre as prioridades das políticas públicas no Brasil, sendo pactuada com os gestores estaduais e municipais a necessidade de detecção de pelo menos $70 \%$ dos casos de TB bacilíferos, assim como o aumento da taxa de cura para pelo menos $85 \%$ e a taxa de abandono menor que 5\%. Para o cumprimento dessa meta, o Programa Nacional de Controle da TB (PNCT) fortaleceu e descentralizou a estratégia de Tratamento Diretamente Observado (TDO).

Anteriormente, o PNCT já havia elegido 230 municípios prioritários que concentravam a maioria dos casos de TB do país, dentre eles o município de Campinas, segundo critérios epidemiológicos e dados operacionais (GOLUB et al.; DYE, 2005; SANTOS, 2007). Neste momento, o controle da doença foi considerado como 
responsabilidade dos municípios e as ações de controle foram reconhecidas como competência da Atenção Básica (BRASIL, 2001; 2004), para melhoria do acesso ao diagnóstico e tratamento da doença (WHO, 2006).

Sendo uma das propostas a de expandir o TDO para $100 \%$ das unidades de saúde dos municípios prioritários e para pelo menos $80 \%$ dos usuários bacilíferos desses municípios até 2007 (FERREIRA, SILVA, BOTELHO; MUNIZ et al., 2005). Assim, o Brasil tem atingido às metas de detecção de casos propostas pela OMS (70\%), mas não tem atingido as taxas de cura estipulado em $85 \%$, para os casos novos bacilíferos. Segundo o Ministério da Saúde, em 2012, o país apresentou 70.047 mil casos de TB e coeficiente de incidência de 36,1/100.000 habitantes, foram detectados $82 \%$ dos casos, e houve $70,6 \%$ de cura, e 10,3\% de abandono entre os casos de TB pulmonar bacilífera (BRASIL, 2013; 2014); no entanto, estas taxas são heterogêneas quando se leva em consideração a extensão territorial do país com suas diversidades regionais, culturais e sociais. No município de Campinas, a taxa de cura entre os casos novos de TB foi de 80,4\% em 2012 e a taxa de abandono de 9,06\% (CENTRO DE VIGILÂNCIA EPIDEMIOLÓGICA ALEXANDRE FLEMING, 2013).

Deste modo, considera-se importante a adoção de estratégias pelos serviços de atenção básica que visam à adesão ao tratamento, na qual se constitui de um processo dinâmico e multifatorial, envolvendo aspectos comportamentais, psíquicos e sociais e que requer decisões e responsabilidades compartilhadas entre o usuário do serviço, a equipe de saúde e a rede social de apoio, com abordagem que atenda às singularidades dos indivíduos, para uma melhor qualidade de vida (WHO, 2003; 2008; SOUZA et al., 2009).

Dessa maneira, a adesão ao tratamento pode ser baseada em abordagens relacionadas ao campo pessoal do paciente ou à fatores ambientais externos, ou seja, 
transcende a clínica tradicional e envolve a forma como o paciente concebe a doença e como vive a organização dos serviços de saúde (TERRA, BERTOLOZZI, 2008). A adesão compreende não apenas a ingestão medicamentosa, se faz também com os comportamentos de saúde por parte do doente e da equipe de saúde que propiciam a compreensão quanto à corresponsabilidade de ambos perante o tratamento.

Reconhece-se hoje que a eficácia dos medicamentos não é suficiente para assegurar a cura de uma doença, dentre elas a TB, devendo ser valorizado o comportamento do doente no processo de cura, o qual constitui, provavelmente, o mais importante fator de sucesso terapêutico (COSTA et al., 1998). Nesta perspectiva, a adesão ao tratamento inclui fatores terapêuticos e educativos relacionados aos doentes, os quais envolvem o reconhecimento e aceitação de suas condições de saúde, uma adaptação ativa a estas condições, a identificação de vulnerabilidades no estilo de vida, bem como o cultivo de hábitos e atitudes que proporcione um melhor cuidado em saúde.

Além disso, a adesão inclui fatores relacionados aos profissionais, como ações de saúde centradas na pessoa e não exclusivamente nos procedimentos, que aliam orientação; informação; adequação dos esquemas terapêuticos ao estilo de vida do doente; esclarecimentos; suporte social e emocional. Portanto, a atitude acolhedora do profissional que cuida, respalda o paciente para novas atitudes perante o adoecimento, e o medicamento é mais um recurso terapêutico na promoção da saúde (SILVEIRA, RIBEIRO, 2005).

Há também aspectos ligados à instituição de saúde, cuja finalidade é promover e estimular ações que contribuam para que os indivíduos envolvidos possam caminhar em direção à eficácia e à qualidade do tratamento. Por se tratar de um processo no qual os sujeitos estão em contato com uma variedade de aspectos que influenciam sua continuidade ou a descontinuidade, facilitar a adesão ao tratamento não são tarefas 
fáceis; são desafios que sofrem oscilações e demandam atenção contínua (SILVEIRA, RIBEIRO, 2005).

Diante disso, a atenção à TB implica lidar com uma doença considerada como condição crônica, que exige habilidades específicas para um atendimento diferenciado, por se tratar de uma doença de longa duração, cujo planejamento das ações deve incluir os aspectos socioeconômico-cultural do doente e o estabelecimento de vínculo e corresponsabilização entre o profissional de saúde/ equipe do serviço de saúde, doente, família e comunidade (WHO, 2003).

\section{QUADRO TEÓRICO}

O comportamento humano e o estilo de vida, têm uma destacada importância no processo saúde e doença, juntamente a outros aspectos, como os sociais, biológicos, ambientais (FLÓREZ-ALARCÓN, 2005) e econômicos. E desempenham papel importante no que tange as doenças, bem como a adesão e cumprimento pelos pacientes dos tratamentos de saúde.

Em se tratando da TB, atualmente, a adesão dos doentes ao tratamento é considerada o maior desafio para o controle e a eliminação desta doença no campo da saúde pública (PICON et al., 1993; WHO, 1997; BERGEL, GOUVEIA, 2005; SÁ et al., 2007), porquanto a não adesão tem como consequência altos índices de incidência, mortalidade e TB multiresistente (SUMARTOJO, 1993).

Pensando no conceito de adesão ao tratamento, embora inicialmente a definição se restringisse a adesão medicamentosa (WHO, 2003), em 2003, a OMS ampliou o conceito, a partir da junção da definição de dois autores Haynes (1979) e Rand (1993), como "O grau em que o comportamento de uma pessoa representado pela ingestão do 
medicamento, seguimento da dieta, mudanças no estilo de vida, correspondem com as recomendações de um profissional de saúde”.

Ainda segundo a OMS (2003), a adesão é entendida como um fenômeno multidimensional determinado pela interação de cinco conjuntos chamados de "dimensões" (Figura 1):

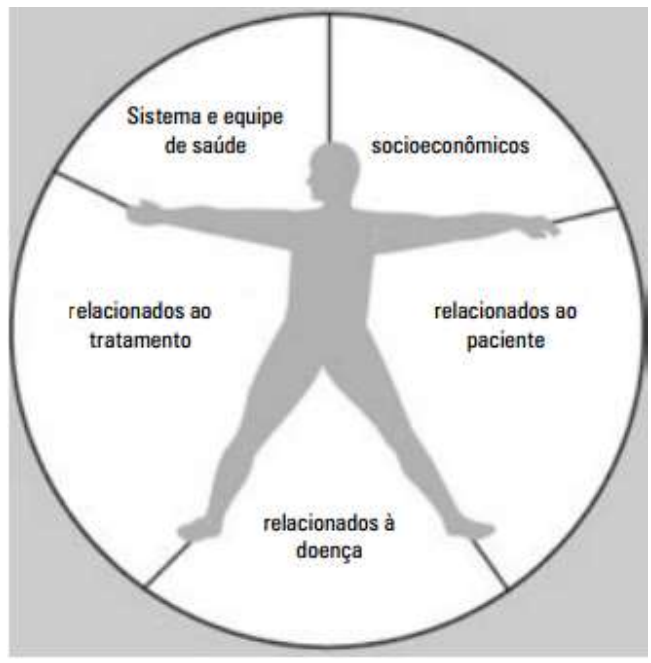

Figura 1. As cinco dimensões da Adesão ao Tratamento. Fonte: Adaptado WHO, 2003.

\section{- Dimensão relacionada ao paciente}

Envolvem os recursos, conhecimentos, atitudes, crenças, percepções e expectativas do paciente, satisfação, vínculo com a equipe/serviço.

\section{- Dimensão Socioeconômica}

Diz respeito ao sexo, idade, renda, escolaridade, vínculo empregatício, custo com transporte, se o indivíduo é morador de rua, estado civil, os quais podem influenciar na adesão ao tratamento.

\section{- Dimensão relacionada à doença}

São requisitos específicos ligados à gravidade dos sintomas, progressão da incapacidade (física, psicológica, social e profissional), gravidade da doença e da 
disponibilidade de tratamentos eficazes, bem como as comorbidade, tais como a coinfecção HIV/AIDS e o consumo de álcool e drogas.

\section{- Dimensão relacionada ao Tratamento}

Dentre os aspectos relacionados ao tratamento que influenciam a adesão, destacam-se àqueles relacionados com a complexidade do regime terapêutico, duração do tratamento, às falhas de tratamento anteriores, frequentes mudanças no tratamento, à iminência dos efeitos benéficos e efeitos colaterais, disponibilidade de apoio clínico para tratá-los.

\section{- Dimensão Sistemas e Equipes de saúde}

Envolve o conhecimento e formação de profissionais de saúde na gestão da doença, profissionais de saúde que trabalham sobrecarregados, falta de incentivos, falta de feedback sobre o desempenho destes profissionais, consultas curtas, dificuldade da equipe em fornecer conhecimento acerca da doença para o doente e familiares, dificuldade em estabelecer o apoio com a comunidade e capacidade de autocuidado, falta de conhecimento sobre a adesão, e intervenções eficazes para melhorá-lo.

Nesse sentido, o conceito multidimensional da OMS sobre a adesão ao tratamento será utilizado para a discussão desta pesquisa. A utilização deste conceito possibilitará uma melhor compreensão da análise das percepções de doentes e profissionais de saúde quanto às ações que são desenvolvidas na atenção básica para promover a adesão ao tratamento da TB, visto que são os sujeitos que vivenciam essas práticas, podendo trazer subsídios para a compreensão mais abrangente dessa problemática, sendo estas orientadas de forma a assegurar o tratamento, culminando na adesão ao tratamento e cura da doença. Pois, apesar de os doentes de TB terem acesso aos tratamentos após a obtenção do diagnóstico da doença, muitos não aderem. $\mathrm{O}$ problema poderia ser atribuído à forma como os serviços de saúde e equipes se 
organizam; como prestam/oferecem as ações para promover a adesão ao tratamento, bem como na forma como o doente enfrenta a doença, e se corresponsabiliza pelo tratamento, levando em consideração os aspectos sociais, demográficos, econômicos, clínicos e epidemiológicos.

\section{REVISÃO DA LITERATURA}

Foi realizado um levantamento bibliográfico, nas bases de dados eletrônicas, LILACS (Literatura Latino-Americana e do Caribe em Ciências de Saúde), MEDLINE (Literatura Internacional em Ciências da Saúde), Cinahl (Cumulative Index to Nursing and Allied Health Literature), Scopus, IBECS (Índice Bibliográfico Español de Ciencias de la Salud) e na biblioteca virtual SciELO (Scientific Electronic Library Online).

Foram utilizados os descritores Tuberculosis, Medication Adherence, Treatment Refusal, Patient Dropouts, Patient Compliance, Treatment Failure e Adherence, contidos nas bases DECS (Descritores em Ciências da Saúde) e MESH (Medical Subject Headings), para identificar as evidências científicas quanto à adesão ao tratamento da TB.

A questão utilizada para orientar a revisão foi: Quais as evidências científicas acerca dos aspectos relacionados às dimensões (paciente; sociodemográficas; doença; tratamento; e Sistemas e Equipes de Saúde) da OMS (Conceito Multidimensional da OMS (2003)), relacionadas à adesão e não adesão ao tratamento da TB?

Foram incluídas pesquisas originais, de origem nacional e internacional, cujos resumos estivessem disponíveis nas bases de dados e biblioteca virtual selecionadas, publicados nos idiomas português, espanhol ou inglês, no período de 2008-2012. Desta forma, revisões da literatura, teses, dissertações, cartas, editoriais, artigos de reflexão e de debates foram excluídos, assim como pesquisas duplicadas em uma ou mais bases de 
dados. Foram considerados como critério de exclusão os estudos que abordassem a adesão ao tratamento da TB infantil.

Com o levantamento foram identificados 323 artigos, nas seis bases de dados eletrônicas, posteriormente excluídas as repetições $($ Medline $=19 ;$ CINAHL $=2$; SCOPUS $=5 ;$ LILACS $=3 ;$ IBECS $=1 ;$ Scielo $=0$ ), totalizando 293 artigos, destes, quatro foram excluídos por serem revisões da literatura $($ Medline $=2 ;$ LILACS $=1$; Scielo $=1)$, restando 289 artigos.

Após a exclusão, foi realizada a leitura dos resumos dos artigos, e destes foram excluídos $233($ Medline $=123 ;$ CINAHL = 9; SCOPUS = 60; LILACS = 9; IBECS = 9; SciELO =4), por não responderem à questão que orientou a revisão.

O procedimento resultou em 56 estudos elegíveis, os quais foram lidos na íntegra. Destes, 31 artigos responderam à questão que orientou a revisão, sendo que o ano de 2012 foi o que apresentou maior frequência de publicações $(25,8 \%)$.

O periódico que mais publicou artigos na temática do estudo foi o International Journal of Tuberculosis and Lung Disease (16,1\% dos artigos). Em relação ao local do estudo, $32,3 \%$ das produções foram realizados no continente africano, 25,8\% na América do Sul, sendo que o Brasil foi o país que figurou com maior frequência entre os locais de estudo (22,5\% dos artigos); $22,5 \%$ na Ásia, $12,9 \%$ na Europa, e 3,2\% na América do Norte. Os doentes de TB constituíram a população de estudo da maioria dos artigos selecionados $(80,6 \%)$, no entanto, familiares, comunidade, profissionais de saúde e gestores foram incluídos em apenas 19,4\% dos artigos.

Com relação ao delineamento dos estudos, predominou as pesquisas que utilizaram a abordagem quantitativa, $11(35,5 \%)$ de pesquisas feitas de forma Transversal, seguidos dos estudos de Coorte, 5 (16,1\%), e Caso Controle 4 (12,9\%). 
Outro delineamento encontrado foram as Pesquisas Qualitativas, com 11 (35,5\%) dos artigos.

Sobre o Método Quantitativo feito de forma Transversal, nove dos onze artigos, abordaram a percepção dos doentes; dois desses artigos, a percepção dos doentes e profissionais de saúde, sendo que um deles abordou também a percepção de gestores. Em se tratando dos estudos de Coorte, os cinco artigos abordaram a percepção dos doentes, assim como os quatro estudos de Caso Controle.

Nos estudos com Método Quantitativo feito de forma Transversal e Coorte, foram observados aspectos relacionados à Dimensão Sociodemográfica. Na percepção de doentes sobre a adesão os aspectos foram: ter maior nível escolar e sexo feminino; quanto a não adesão: sexo masculino, idoso, desemprego, analfabetismo ou menor nível escolar, divórcio ou viúvo, despesas financeiras com o tratamento, distância até o serviço de saúde, perda de tempo de trabalho e ser morador de rua. Quanto à percepção dos profissionais sobre a não adesão: distância até o serviço de saúde, despesas financeiras com o tratamento e menor nível escolar.

Nos estudos Caso Controle, predominou aspectos relacionados à Dimensão do Doente, sobre a adesão os aspectos foram: conhecimento sobre TB, morar próximo ao serviço de saúde; sobre a não adesão: falta de conhecimento sobre TB, não residir com familiares, distância até o serviço de saúde.

Quanto à Pesquisa Qualitativa, dos onze artigos, sete estão relacionados à percepção dos doentes, e dos outros quatro artigos, três abordaram a percepção de doentes, profissionais, gestores e familiares e o quarto artigo abordou a percepção de doentes, profissionais e comunidade.

Os aspectos abordados neste tipo de estudo, estiveram relacionados à Dimensão do Doente, sendo que na percepção dos doentes sobre a adesão, foram o apoio familiar 
e o conhecimento da doença; a não adesão: estigma, preconceito, falta de vínculo com os profissionais de saúde, falta de apoio familiar, falta de compromisso do doente com o próprio tratamento, falta de conhecimento sobre TB, tratamento longo, distância até o serviço de saúde. Sobre a percepção dos profissionais, quanto à adesão: vínculo com os enfermeiros; e sobre a não adesão: falta de compromisso do doente com o tratamento, falta de conhecimento sobre a doença e o tratamento.

Vale destacar que as Pesquisas Qualitativas abordaram outros aspectos, como o estigma, preconceito, vínculo, e o compromisso do doente com o próprio tratamento.

O Apêndice 1 mostra um quadro, com a síntese dos aspectos observados nos artigos, segundo à adesão, não adesão ao tratamento, e as dimensões da OMS (2003).

Com a revisão da literatura entre os anos de 2008 a 2012, não foi identificado artigo que abordou as ações de controle da TB na atenção básica para promover adesão ao tratamento da TB, o que justifica a realização do presente estudo.

\section{OBJETIVOS}

\subsection{Objetivo geral}

Analisar as ações desenvolvidas na atenção básica para promover a adesão ao tratamento da tuberculose na percepção dos doentes e profissionais de saúde em Campinas-SP.

\subsection{Objetivos específicos}

1. Caracterizar os doentes de tuberculose em tratamento, segundo o perfil sociodemográfico, clínico e hábitos de vida;

2. Caracterizar os profissionais de saúde da atenção básica que acompanham os casos de tuberculose, segundo variáveis demográficas e profissionais; 
3. Caracterizar a organização da assistência aos doentes de tuberculose segundo a percepção dos doentes e profissionais de saúde;

4. Identificar e analisar associação entre as percepções dos doentes e profissionais de saúde e às ações desenvolvidas para promover a adesão ao tratamento da tuberculose.

\section{MATERIAIS E MÉTODOS}

\subsection{Modelo do estudo}

Trata-se de um estudo epidemiológico descritivo do tipo inquérito, que foi conduzido no município de Campinas.

\subsection{Caracterização do Local de Estudo}

Campinas está situada à $100 \mathrm{~km}$ da capital Paulista, apresenta uma área de $794,43 \mathrm{Km}^{2}$ de extensão, economia baseada na indústria, (como exemplos: tecnologia da informação, telecomunicações, equipamentos óticos, médicos, material de transporte etc) e prestação de serviços.

Em 2013, apresentou população estimada de 1.144.862 habitantes, densidade populacional de 1.359,60 habitantes por $\mathrm{km}^{2}$, em área predominantemente urbana (IBGE, 2014). Considerando o setor Saúde, o município é parte integrante da Rede Regional de Atenção à Saúde (RRAS) entre as dezessete estruturadas no estado de São Paulo, sendo a de Campinas denominada RRAS 15, constituída por quarenta e dois municípios (Figura 2).

As RRAS são uma nova configuração, estabelecida a partir do Pacto de Gestão de 2007, que tem por objetivo organizar os fluxos de usuários na melhoria do acesso e na qualidade da atenção à saúde, entre os serviços de saúde com diferentes densidades tecnológicas disponível nos municípios (SECRETARIA MUNICIPAL DE SAÚDE DE CAMPINAS; SECRETARIA ESTADUAL DE SAÚDE DO ESTADO DE SÃO 
PAULO, 2012). No caso da TB, o município presta assistência para pacientes com TB multirresistente em uma das Policlínicas da cidade, sendo referência para doentes do município e de outras regiões.

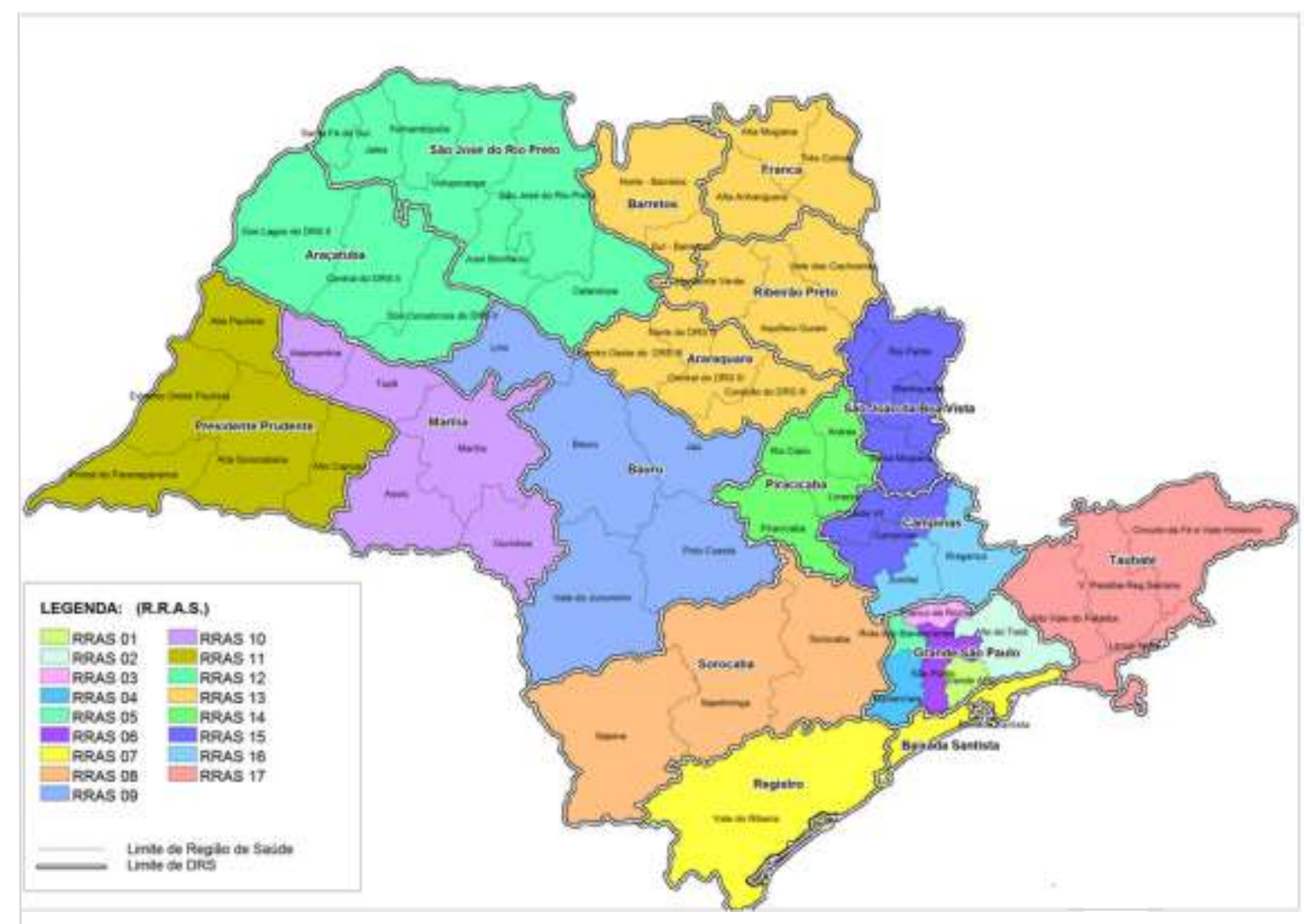

Figura 2. Mapa das Redes de Atenção à Saúde, e respectivos Departamento Regional de Saúde e Regiões de Saúde do Estado de São Paulo, 2013

Fonte: Secretaria da Saúde do Estado de São Paulo, 2013.

A cidade conta ainda com o Departamento Regional de Saúde (DRS) VII, que é uma unidade administrativa que tem por função comandar/ ordenar na área regional, atividades da Secretaria de Estado da Saúde e promover a articulação entre os quarenta e dois municípios que compõe o DRS VII.

Quanto à configuração do Sistema Único de Saúde (SUS) do Município, este consiste em uma complexa rede de Serviços de Saúde (unidades de saúde próprias, conveniadas e contratadas no nível primário, secundário e terciário de atenção) e instâncias de Gestão e Controle Social, sendo o município, responsável pela integração 
entre os serviços de hierarquia estadual ou federal, e referência regional, recebendo a demanda da Região nos diferentes níveis de atenção (Atenção secundária e terciária).

Os serviços de saúde estão descentralizados nos cinco distritos de saúde (Norte, Sul, Leste, Sudoeste e Noroeste), tendo estes, a função de coordenador das ações de saúde, nas áreas de abrangência definidas, com a presença da Vigilância em Saúde Distrital (VISA), cujas equipes habitualmente dividem o mesmo espaço físico com os Distritos de Saúde e têm a atribuição da vigilância em saúde em áreas de abrangência coincidentes com a divisão dos Distritos de Saúde, vinculados a Coordenadoria da Vigilância em Saúde (CoViSA), que segundo a Secretaria Municipal da Saúde, tem por função, criar e constituir estratégias de implantação e implementação de ações de Vigilância em Saúde, articulando os diferentes níveis do sistema, incluindo as áreas de Vigilância Epidemiológica, Sanitária e Ambiental. Ambas vinculadas aos demais setores da Secretaria Municipal da Saúde hierarquicamente como mostrado na figura 3.

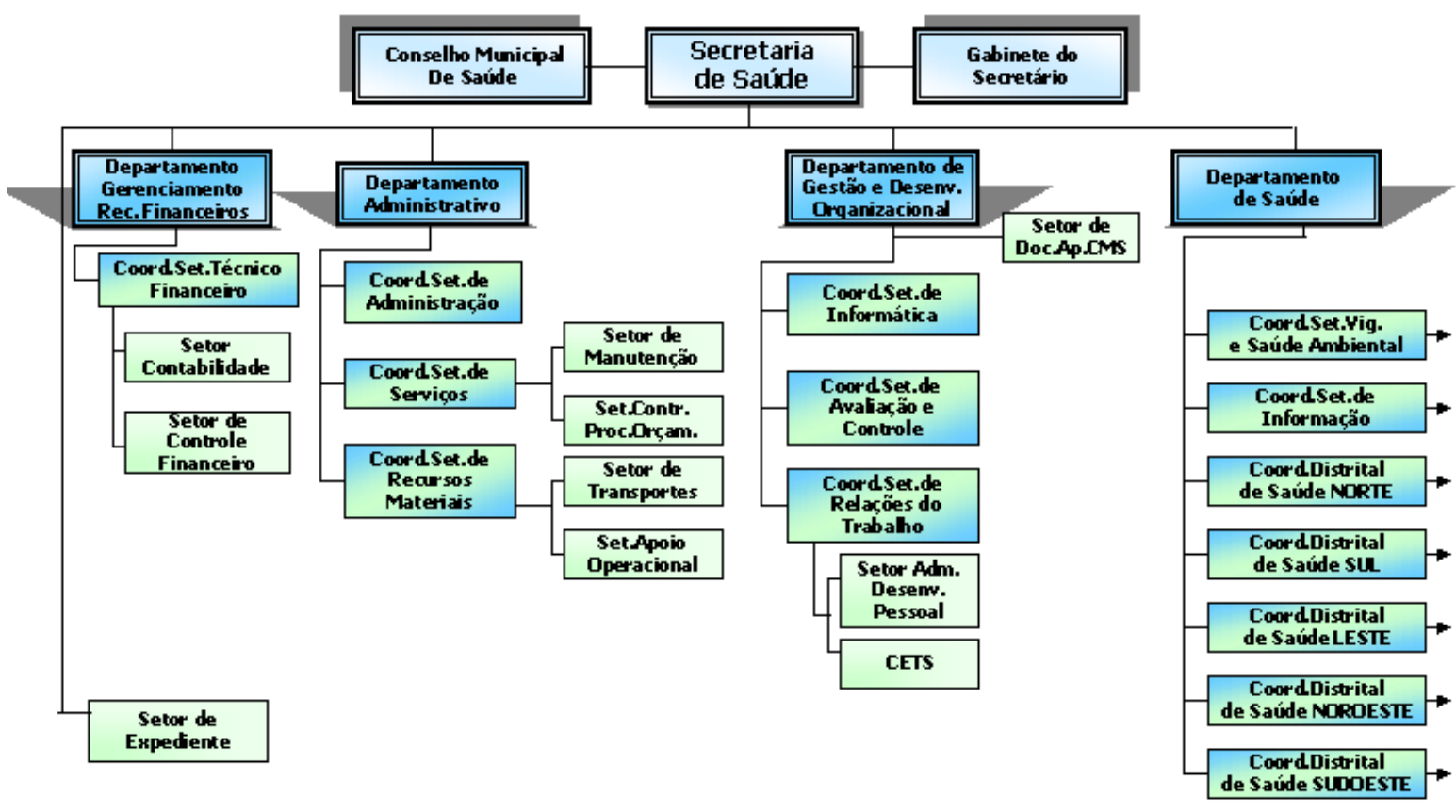




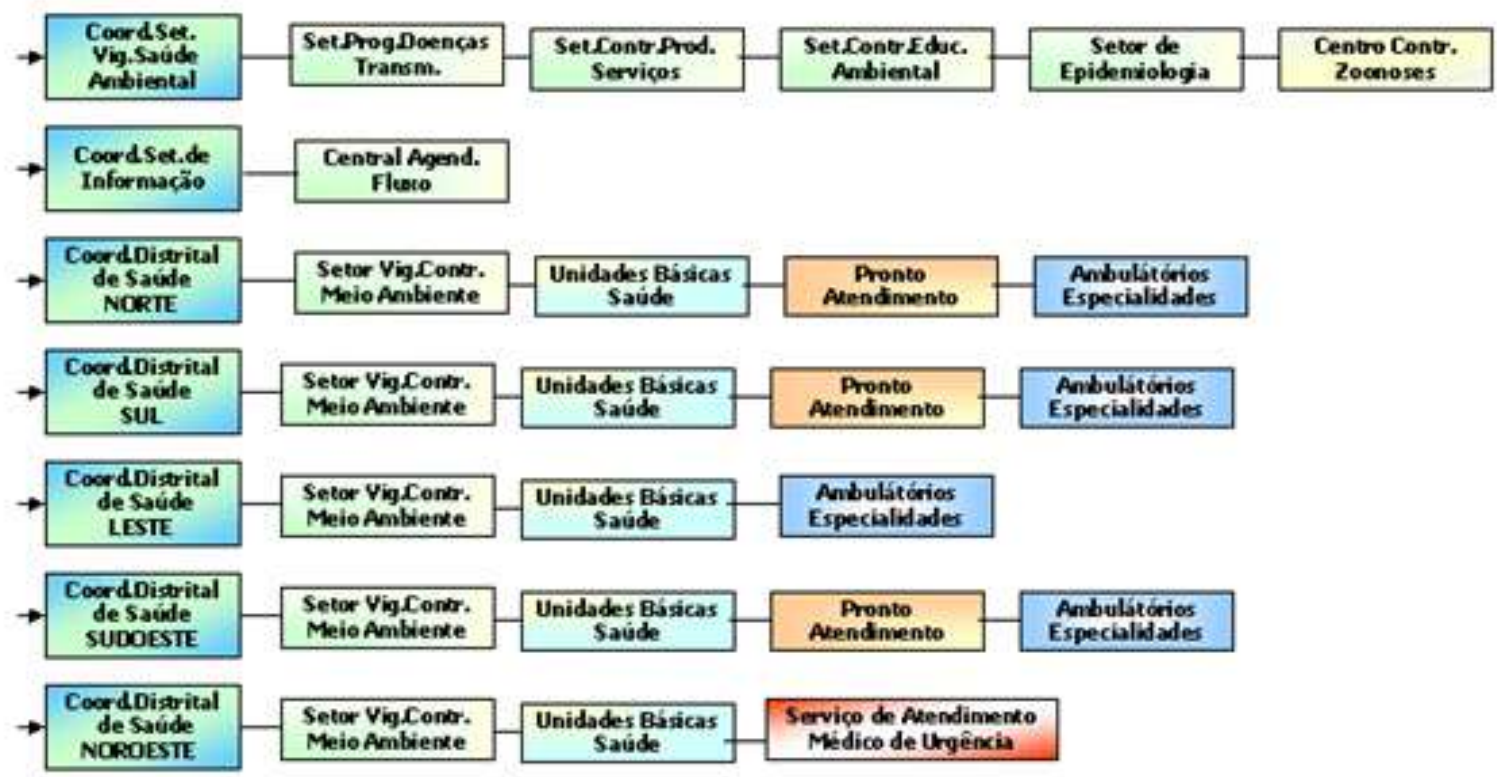

Figura 3. Organograma da Secretaria Municipal de Saúde de Campinas - SP, 2013.

\subsubsection{Contexto epidemiológico da Tuberculose no Município}

Campinas é considerado um dos 44 municípios prioritários no controle da TB do Estado de São Paulo (BRASIL, 2011), nos últimos anos (2006-2010), apresentou uma média de 290 casos novos de TB por ano, com uma taxa de incidência média de todas as formas 27,0 casos novos por 100.000 habitantes, $76 \%$ de taxa de cura, $4,8 \%$ da taxa de óbito, e uma média de 54\% de Sintomáticos Respiratórios examinados, entre 2003 e 2004. Em 2013, foram notificados 300 casos novos de TB, um coeficiente de incidência de todas as formas de 26,2 casos por 100.000 habitantes, $82,3 \%$ de cura entre os casos novos, $8,3 \%$ de abandono, $4,7 \%$ de óbito por TB e 3,7\% de óbito não TB. Sendo avaliados 5870 (53\%) dos Sintomáticos Respiratórios no ano de 2012. (SALA DE SITUAÇÃO DO ESTADO DE SÃO PAULO; TB WEB, 2015).

5.2.2 Atendimento à Tuberculose pelos diferentes tipos de Serviços de Saúde do Município

\section{CENTROS DE SAÚDE}


São sessenta e três Centros de Saúde (CS), (Figura 4), sendo um deles dividido em duas estruturas físicas em bairros vizinhos (Oziel e Monte Cristo), do qual é gestor, o mesmo profissional. Segundo informações da Secretaria Municipal de Campinas, há o dimensionamento de um CS para aproximadamente 20.000 habitantes, com equipes multiprofissionais, como médicos (clínicos, pediatras, ginecologistas-obstetras), enfermeiros (atuando nas áreas da mulher, criança e adulto), auxiliares/ técnicos de enfermagem, dentistas, auxiliares de consultório dentário. Segundo dados do CNES 2012, há uma média de 155 ESF no município.

Os CS são responsáveis pela atenção básica à saúde e alguns procedimentos de média complexidade. Possuem território e população bem definidos, gerenciam informações dos nascimentos, óbitos, doenças de notificação compulsória, perfil de atendimento ambulatorial. Constroem mapas de recursos, barreiras, e a partir dessas informações e de protocolos assistenciais pactuados no SUS Campinas planejam e programam ações de saúde, contando com suporte e retaguarda de equipes técnicas distritais e centrais da Secretaria Municipal de Saúde.

Quanto à atenção a TB, são estes serviços que realizam a busca de sintomáticos respiratórios; exames de apoio diagnóstico, ou encaminham para outros serviços, como no caso da realização de raios-X; consultas médicas e de enfermagem; tratamento diretamente observado (TDO); fornecimento dos medicamentos; encaminhamento para outros serviços/setores quando necessário; contando com a retaguarda das equipes das VISAs. E foram estes os serviços de escolha para realizar as entrevistas com doentes e o oferecimento de incentivos, pelo Programa de Controle da Tuberculose (PCT) do município é composto por um kit café da manhã, constando um suco ou leite achocolatado em caixinha e bolacha ou bolo em porção individual. 
No caso do vale transporte, no município, há uma Lei $n^{\circ} 8616$, de 04 de dezembro de 1995, Decreto $\mathrm{n}^{\circ} 14.572$, de 23 de dezembro de 2003, artigo $2^{\text {o }}$ que assegura o vale transporte para "pessoa com patologia de interesse coletivo cujo sucesso do tratamento esteja vinculado à regularidade do seu comparecimento à unidade de saúde, tais como tuberculose, hanseníase, AIDS, patologias relacionadas à saúde mental, renais crônicos, neoplasias, insuficiência cardíaca congestiva $e$ patologias pulmonares crônicas, em graus avançados, por meio de fornecimento de cartão com número de viagens suficiente para garantir o seu tratamento”. Portanto, para que o doente seja contemplado com esse benefício, o médico precisa emitir uma solicitação para concessão de isenção tarifária, que o doente deve levar junto com outros documentos pessoais e comprovação de endereço para obter o passe gratuito.

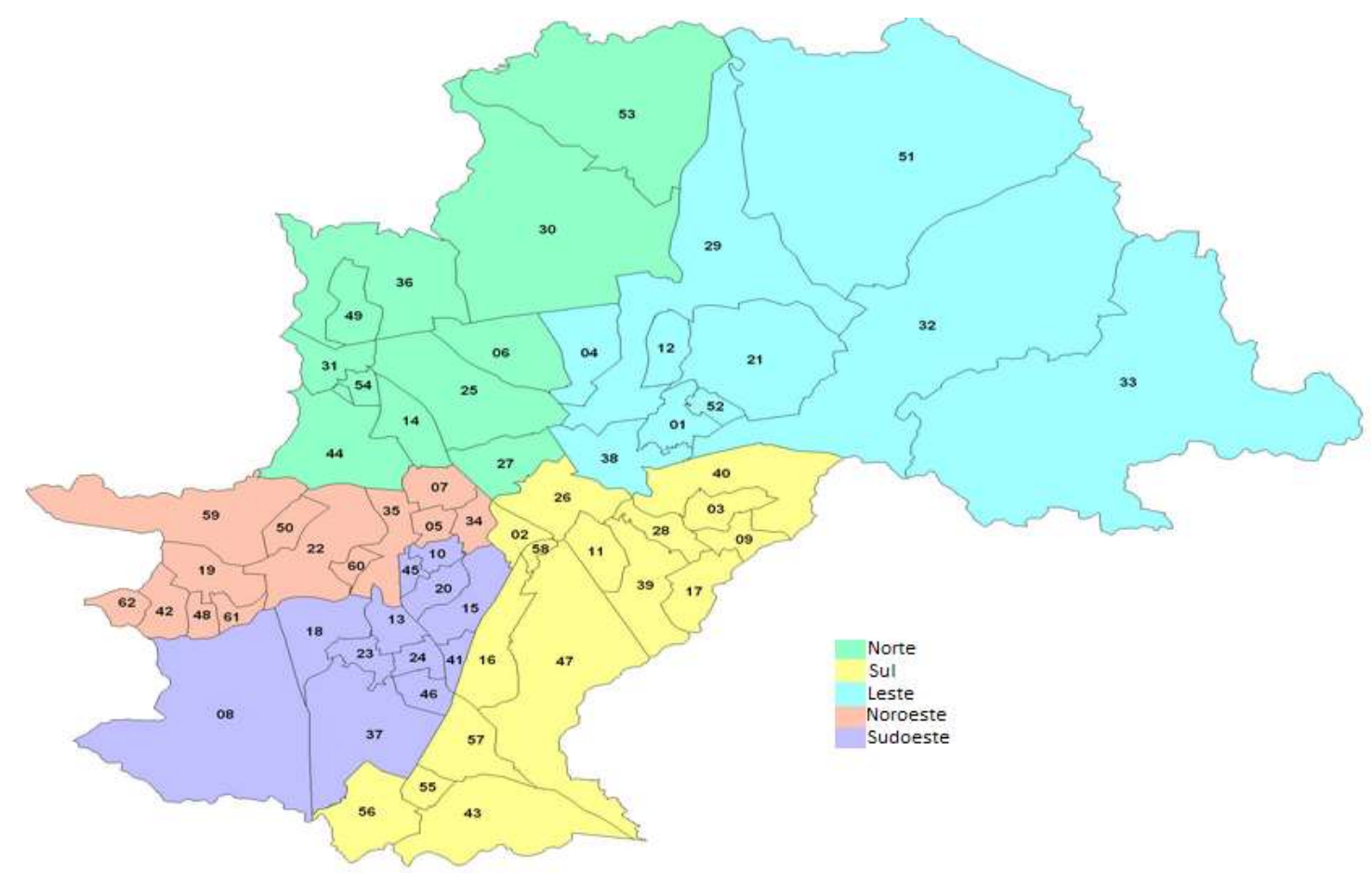

Figura 4. Regiões Distritais de Saúde em Campinas-SP, 2013.

Fonte: Secretaria Municipal de Saúde, 2013.

\section{UNIDADES DE REFERÊNCIA}


São cerca de vinte e quatro unidades de referência com atendimento especializado, referenciado, sendo duas Policlínicas (I e II), que são unidades de saúde secundárias que concentram ambulatórios de aproximadamente 30 especialidades médicas. Há ainda Centros de Referência, com equipes multiprofissionais que têm como papel a atenção à Saúde focada a grupos específicos, tais como: Ambulatório CEASA (atendimento na saúde do trabalhador para todos os trabalhadores do Ceasa e Mercado de Flores, e de pronto atendimento aos que transitam por esses locais), os Centros de Especialidades Odontológicas (CEO), os Centros de Apoio Psicossocial (CAPS) da área de Saúde Mental, Infanto-Juvenil, Álcool e Drogas, e unidades dedicadas à Reabilitação Física, Saúde do Trabalhador, Saúde do Idoso, Doenças Sexualmente Transmissíveis e AIDS. Três Serviços de Atendimento Domiciliar (SAD) (sul, leste-norte e noroeste-sudoeste).

Além disso, conta com atendimento ambulatorial do "Hospital Municipal Dr. Mário Gatti”, “Complexo Hospitalar Ouro Verde”, Hospital e Maternidade Dr. Celso Pierro (Pontifícia Universidade Católica de Campinas (PUCCAMP)), como Fonoaudiologia, Terapia Ocupacional, Fisioterapia, Psicologia, Odontologia, entre outros, e com o Ambulatório do Hospital das Clínicas da UNICAMP (Universidade Estadual de Campinas).

O atendimento aos doentes de TB é realizado na Policlínica II, com acompanhamento de casos de multidroga-resistência de Campinas e Região; no Centro de Referência HIV-aids são acompanhados os casos de coinfecção TB-HIV/aids, onde há Agentes Comunitários de Saúde (ACS) responsáveis para observar o TDO; e os ambulatórios dos hospitais "Hospital Municipal Dr. Mário Gatti”; "Complexo Hospitalar Ouro Verde"; Hospital e Maternidade Dr. Celso Pierro Ambulatório do Hospital das Clínicas da Unicamp, são acompanhados os casos de maior gravidade, em 
associação com outras comorbidades. Nestes serviços são realizados exames de raios$\mathrm{X}$.

\section{HOSPITAIS}

Os cinco principais hospitais são: "Hospital Municipal Dr. Mário Gatti”; “Complexo Hospitalar Ouro Verde”; Hospital e Maternidade Dr. Celso Pierro; Hospital das Clínicas da UNICAMP e Maternidade de Campinas.

Oferecem atendimento 24 horas por dia, com alta densidade tecnológica (utilização de recursos tecnológicos de apoio diagnóstico e terapêutico que compreende cuidados de prevenção, tratamento e recuperação, serviços complementares de diagnóstico e tratamento, nas mais diversas especialidades em saúde).

Quanto à assistência a TB, teoricamente são nesses locais que ocorrem as internações nos casos em que há complicação da doença, quando a doença se encontra em estágios mais avançados, no entanto, também é realizado o diagnóstico dos casos de TB.

\section{URGÊNCIA E EMERGÊNCIA}

O sistema é composto pelas quatro unidades de Pronto Atendimento, presentes em quatro dos distritos sanitários de saúde (São José, Anchieta, Campo Grande e Centro), o Serviço de Atendimento Médico de Urgência (SAMU), o Pronto Socorro do Hospital Municipal "Dr. Mário Gatti” e o Pronto Socorro do Complexo Hospitalar Ouro Verde, além de serviços conveniados e contratados, em especial o Pronto Socorro do Hospital das Clínicas e do CAISM da UNICAMP, Hospital e Maternidade Celso Pierro, e a Maternidade de Campinas (urgências obstétricas). Estes serviços têm funcionamento de $24 \mathrm{~h}$ e atendem demanda espontânea. 
Apesar de o sistema priorizar os CS como serviço de acesso inicial ao usuário, muitas vezes o diagnóstico ocorre nestes serviços, onde também ocorre a realização dos exames de raios-X.

\section{CONSULTÓRIOS PARTICULARES}

Nesses locais os usuários recebem atenção especializada, a depender da necessidade de saúde, usufruindo de atendimento com profissionais especializados, apoio diagnóstico e terapêutico.

Nestes serviços são realizados exames diagnósticos (raios-X) e, após confirmação da doença, o tratamento pode ser acompanhado por esse especialista. No entanto, a notificação do caso deve ser realizada por um CS ou pela VISA, no distrito de saúde, na qual o consultório está inserido. A dispensação do medicamento é realizada pelo sistema público.

Segundo a Secretaria Municipal de Saúde, o município conta com aproximadamente quinze prestadores de serviços conveniados, entre eles, a Maternidade de Campinas, Hospital e Maternidade Celso Pierro - PUCCAMP; Hospital Municipal "Dr. Mario Gatti”, Serviço de Saúde "Dr. Cândido Ferreira"; Real Sociedade Portuguesa de Beneficência; Associação dos Pais e Amigos do Excepcional - APAE; Centro "Dr. Antonio Carlos Corsini”; Fundação Síndrome de Down; Clínica de Psicologia da PUCCAMP; Ambulatório de Fisioterapia da PUCCAMP; Ambulatório de Terapia Ocupacional da PUCCAMP; Clínica de Odontologia da PUCCAMP; Complexo Hospitalar Ouro Verde; Fundação Penido Burnier; Instituto Raskin.

A figura 5 mostra o fluxo do doente, quando este recebe o diagnóstico e inicia o tratamento da TB. 


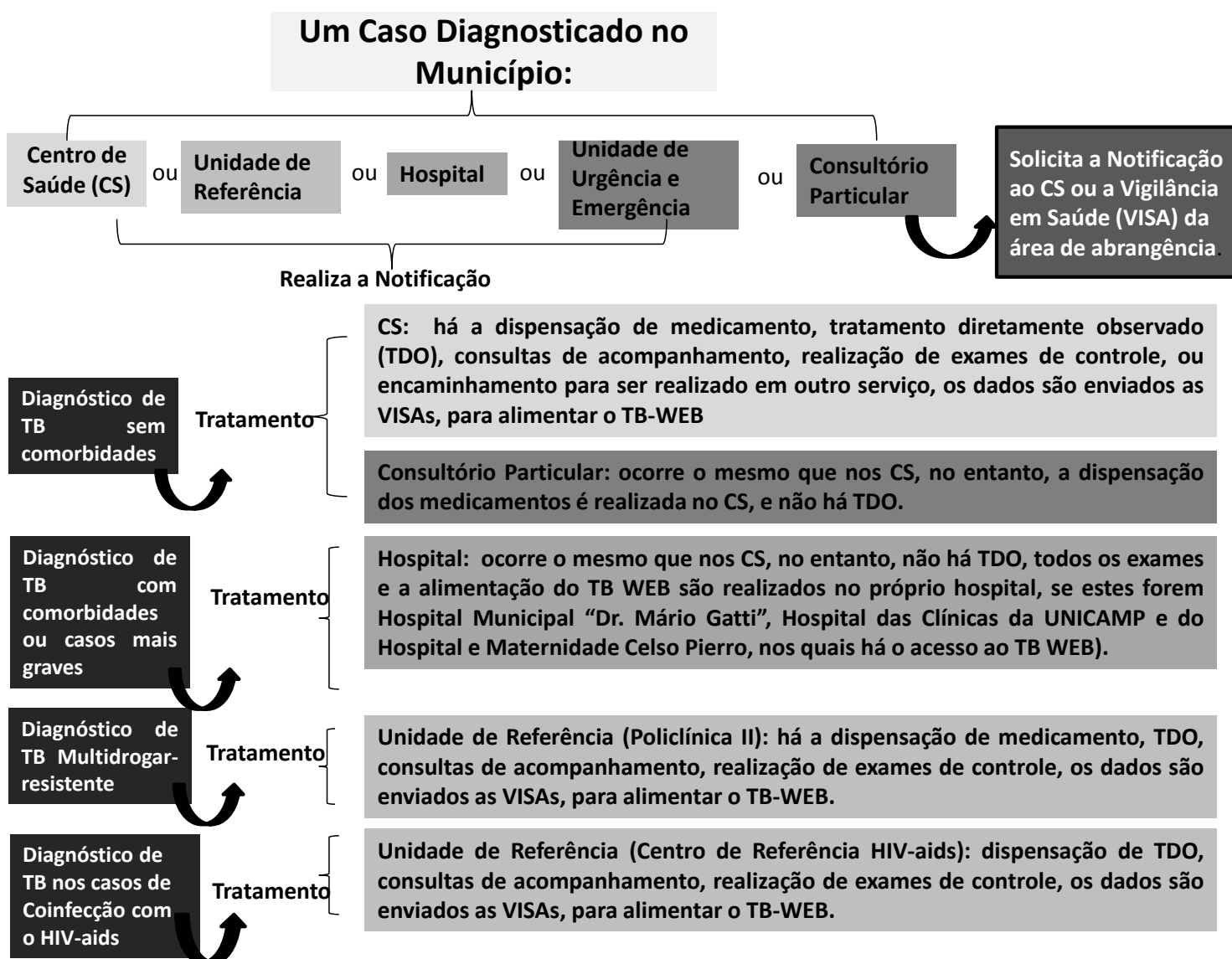

Figura 5. Fluxo do doente durante o acompanhamento dos casos com diagnóstico de tuberculose pelos tipos de serviços de saúde do Município, Campinas-SP, 2013.

Nota: O TB WEB é o Sistema de Informação do controle dos doentes de tuberculose do Estado de São Paulo, que tem acesso restrito.

\subsubsection{Disponibilidade de laboratórios para a realização de exames de diagnóstico e controle da tuberculose}

Os exames utilizados para o diagnóstico e acompanhamento dos casos de TB no município são:

- Baciloscopia de Escarro: as análises são realizadas no Laboratório Municipal de Campinas, podendo ser solicitadas por todos os CS, unidades de referência e hospitais. O pedido de realização deste exame pode ser feito por enfermeiros e médicos. Os exames são recolhidos diariamente nestes serviços, normalmente no período da manhã. No entanto a recomendação para os CS, é que 
quando a coleta é realizada em outro horário, que a amostra fique armazenada em caixas térmicas.

Os resultados saem em 24h, no entanto, em um determinado período do início do ano de 2013, demoraram até cinco dias, devidos à falta de profissionais que analisam tais amostras, devido ao rompimento de um convênio da Prefeitura Municipal com um hospital da região - solicitação do Ministério Público, visto que este achou o convênio irregular -, no qual aproximadamente 1.311 profissionais foram exonerados do cargo (sendo 629 no início de agosto de 2012; quando já foram substituídos por profissionais que haviam realizado concurso público em fevereiro do mesmo ano), e o restante a partir de março de 2013, através de outros concursos públicos que vêm sendo realizados. Esses profissionais exonerados compunham a Rede de Assistência à Saúde do município: pessoal de cargos administrativos, profissionais de saúde, e profissionais dos mais distintos cargos.

Quando o resultado da baciloscopia é positivo, a equipe do CS é informada por telefone ou através do Sistema de Informação do Laboratório, o qual pode ser acessado nos CS. Quando negativo os resultados são disponibilizados neste mesmo sistema de informação e posteriormente chegam impressos via malote.

- $\quad$ Raios-X: podem ser solicitados por todas as unidades de saúde, pelo médico, sendo os suspeitos de TB priorizados para a realização deste. Os Raios-X são realizados nos centros de referência (HIV/AIDS, ambulatórios do "Hospital Municipal Dr. Mário Gatti”; "Complexo Hospitalar Ouro Verde”; Hospital e Maternidade Dr. Celso Pierro e Hospital das Clínicas da UNICAMP), nos três serviços de pronto atendimento e pronto socorro. No entanto, quando o diagnóstico não ocorre nestes serviços, a demanda é referenciada para as regiões distritais de abrangência onde o 
usuário reside. Quando da realização do exame, o próprio doente leva os raios-X para o serviço de saúde.

- $\quad$ Teste Tuberculínico: quando disponível, é realizado em onze CS, e no Centro de Referência em HIV/AIDS, por auxiliares de enfermagem. Deve ser solicitado pelo médico e é considerado prioritário para coinfectados TB/HIV, doentes imunossuprimidos, crianças, comunicantes de doentes e suspeitos da doença. No entanto, pode não ser conclusivo, existe a necessidade de realizar outros exames complementares.

- Cultura de Escarro: a análise é realizada no Laboratório Adolf Lutz, e deve ser solicitada pelo médico e é considerado importante no diagnóstico da TB, uma vez que identifica a cepa do bacilo. Todavia, não é solicitada para todos os doentes diagnosticados, a depender do critério médico ou da própria configuração do serviço de saúde. O resultado normalmente estará disponível em até 30 dias.

\subsection{População de Referência}

A população de referência foram os Doentes de TB e Profissionais de Saúde.

\subsubsection{População de Estudo}

A população de estudo foi constituída por Doentes de $T B$ e Profissionais de Saúde ${ }^{3}$ do município de Campinas.

\subsection{Critérios de Seleção}

Para os Doentes de Tuberculose, os critérios foram realizar o tratamento para TB há três meses ou mais na atenção básica do município ou que haviam terminado o

\footnotetext{
${ }^{3}$ A seleção dos Profissionais de Saúde foi constituída por uma amostra por conveniência, visto que foram indicados pelos gestores dos Centros de Saúde, por serem os profissionais que trabalham com os doentes de tuberculose no município.
} 
tratamento em até 30 dias, com idade igual ou superior a 18 anos, fora do sistema prisional.

Para os Profissionais de Saúde, ser enfermeiros, auxiliares ou técnicos de enfermagem, trabalhar nos serviços de atenção básica do município, ter acompanhado algum caso de TB nos 12 meses anteriores à coleta de dados.

\subsection{Coleta de Dados}

Os dados foram coletados por meio de fontes primárias (entrevista com os doentes de TB e profissionais de saúde), e fontes secundárias (prontuário; ficha de acompanhamento do TDO; livro de registro do acompanhamento dos casos e o sistema de informação TBWEB (Sistema de Informação do controle dos doentes de TB do Estado de São Paulo)). A coleta foi realizada no período de agosto de 2012 a maio de 2013 com os doentes de TB e no período de agosto de 2012 a fevereiro de 2013 com os profissionais de saúde

\subsection{Instrumentos de Coleta de Dados}

Para atender os objetivos propostos, foram utilizados para a coleta de dados quatro formulários estruturados, dois para os doentes de TB (Formulários I e III), e dois para profissionais de saúde (Formulários II e IV), sendo eles:

- Formulário estruturado I: Caracterização dos doentes e do tratamento de TB (APÊNDICE II) - compreende um total de 17 questões, agrupadas em dois blocos:

Bloco A: Dados sociodemográficos, clínicos e hábitos de vida - inclui 12 questões relacionadas ao sexo; idade; escolaridade; situação empregatícia; local onde vive; com quem mora; forma clínica da TB; tipo de caso; coinfecção TB/HIV e tempo de tratamento medicamentoso; consumo de bebida alcoólica e tabaco.

Bloco B: Dados sobre o acompanhamento dos casos - inclui cinco questões: oferecimento de TDO pelo serviço de saúde; pessoa que supervisiona a ingestão do 
medicamento; quantas vezes por semana observam; incentivos que recebe do programa de TB; atendimento pelo mesmo profissional de saúde durante o TDO; distrito de saúde em que mora e realiza o tratamento.

- Formulário estruturado II: Caracterização dos profissionais de saúde que participam do tratamento de casos de TB (APÊNDICE III) - compreende um total de 14 questões, agrupadas em dois blocos:

Bloco A: Dados demográficos e profissionais - inclui 10 questões relacionadas ao sexo; idade; categoria profissional; distrito de saúde em que trabalha; tempo que trabalha com doentes de TB; procura informações sobre TB em livros e/ou internet; fez algum tipo de capacitação para atender doentes de TB; há quanto tempo realizou a última capacitação; quem realiza as capacitações.

Bloco B: Dados sobre o acompanhamento dos casos de $T B$ - inclui quatro questões relacionadas ao oferecimento de TDO; pessoa que observa a ingestão medicamentosa; quantas vezes por semana realizam a dose supervisionada; incentivos oferecidos aos doentes de TB.

- Formulário estruturado III e IV: Análise das ações desenvolvidas pelos serviços de atenção básica para adesão ao tratamento da TB (percepção dos doentes APÊNDICE IV e percepção dos profissionais de saúde - APÊNDICE V). Estes formulários foram elaborados com base no conceito multidimensional de adesão ao tratamento (WHO, 2003), não abordando somente adesão medicamentosa, considerando os aspectos relacionados ao tratamento e ao sistema de saúde, os quais sejam a gestão da doença e do tratamento em conjunto com os doentes, a flexibilidade no tratamento disponível, a educação dos doentes sobre o tratamento, bem como a supervisão e o monitoramento deste. 
Desta forma as variáveis que compõem tal formulário foram construídas a partir do "Adherence to long-term therapies: evidence for action" (OMS, 2003), do "Manual de Recomendações para o Controle da tuberculose" (BRASIL, 2010), da série de artigos "Melhores práticas para o cuidado de doentes com tuberculose" (WILLIAMS, ALARCON et al., $2008 \mathrm{a}$; b; c), estudos anteriores que abordam os aspectos de maior relevância para a adesão (JIN et al., 2008; MÁRTIN ALFONSO, BAYARRE VEA, GRAU ABALO, 2008) e para a adesão ao tratamento da TB (GONÇALVES et al., 1999; TERRA; BERTOLOZZI, 2008; RODRIGUES et al., 2010).

Estes formulários contemplam 16 questões (Quadro 1) com categorias de resposta dicotômica ( $\operatorname{sim}$ e não) com o intuito de identificar as ações desenvolvidas pelos serviços de atenção básica para a adesão ao tratamento da TB.

\subsubsection{Variáveis utilizadas no Estudo}

As variáveis utilizadas no estudo, estão descritas no Quadro 1, abaixo, as quais são correspondentes à percepção dos doentes e profissionais de saúde.

Quadro 1 - Variáveis relacionadas às ações desenvolvidas pelos serviços de atenção básica para adesão ao tratamento de tuberculose.

\begin{tabular}{l}
\hline Variáveis \\
Orientação ao doente de tuberculose sobre o que é a tuberculose; \\
Orientação aos doentes de tuberculose para buscar informações em livros e/ou internet sobre a doença \\
dele; \\
Oportunidade ao doente de tuberculose de opinar sobre o tratamento dele; \\
Agendamento de consultas mensais para o acompanhamento do tratamento do doente de tuberculose; \\
Orientação ao doente de tuberculose quanto à importância de comparecer às consultas mensais; \\
Orientação ao doente de tuberculose sobre a realização de exames de controle; \\
Orientação ao doente de tuberculose sobre como deve tomar os remédios da tuberculose; \\
Entrega aos doentes de tuberculose informações escritas sobre o tratamento dele; \\
Encorajamento ao doente de tuberculose para continuar o tratamento da tuberculose; \\
Orientação ao doente de tuberculose para procurar pelo serviço de saúde quando tem dúvidas sobre o \\
tratamento; \\
Orientação ao doente de tuberculose para observar se os sintomas dele melhoram durante o tratamento; \\
Orientação ao doente de tuberculose sobre a conduta a ser tomada se os sintomas piorar; \\
Orientação ao doente de tuberculose sobre os hábitos que deve adotar para ter uma vida mais saudável \\
(alimentação adequada, prática de exercícios físicos, evitar o uso de bebida alcoólica e cigarro); \\
Orientação ao usuário para que os familiares dele também façam exames para a tuberculose; \\
Tempo suficiente ao doente de tuberculose para ele falar sobre as dúvidas e/ou preocupações dele; \\
Convite ao doente de tuberculose para participar de algum grupo de doentes de tuberculose.
\end{tabular}




\subsubsection{Procedimentos para a coleta de dados}

Anterior à coleta de dados, houve um primeiro contato com as cinco enfermeiras responsáveis pela vigilância epidemiológica de cada distrito de saúde (VISA), juntamente com a coordenadora do PCT do município, onde foi apresentada a proposta do estudo, quais seriam as demandas necessárias para a realização do mesmo (número de doentes e profissionais envolvidos no tratamento da TB; acesso aos dados epidemiológicos, operacionais e particularidades da organização da assistência a TB no município), a forma de interação com o serviço de saúde para conseguir realizar o estudo, bem como saber quem eram os gestores e co-gestores dos serviços, que forneceriam as informações necessárias para a condução da pesquisa.

Após essa reunião, procedeu-se da seguinte forma: foram realizadas reuniões em três dos cinco distritos de saúde, em diferentes datas, com a presença dos gestores e cogestores dos CS, alguns profissionais (enfermeiros, auxiliares e técnicos de enfermagem), onde foram apresentados os objetivos do estudo; a forma como a pesquisa seria conduzida durante a coleta de dados; os critérios de seleção do estudo para os doentes e profissionais de saúde.

Foi fornecido neste dia para cada CS, um cronograma sobre as etapas da coleta, os procedimentos, e uma cópia das autorizações da secretaria da saúde para a realização da pesquisa e aprovação do comitê de ética em pesquisa, também um provável período para apresentar os resultados da pesquisa ao município.

Neste dia foi solicitado que os gestores fornecessem o nome dos profissionais de cada equipe que atendia doentes de $\mathrm{TB}$, para posterior convite a fim participar da pesquisa. Também foram solicitadas informações dos doentes que estavam em tratamento naquele determinado CS. Foi entregue pelas enfermeiras da vigilância epidemiológica do distrito o boletim de acompanhamento dos casos de TB de cada CS 
do distrito. E neste mesmo momento, por preferência de alguns gestores, foram agendadas reuniões posteriores nos CS.

Nos dois distritos em que não houve reunião com os gestores, o boletim de acompanhamento dos casos de TB, nomes, contatos telefônicos e endereço de cada gestor dos CS de cada um dos distritos foram fornecidos através de contato por email com as enfermeiras da vigilância.

Quanto ao levantamento do número de doentes, este foi realizado através da consulta ao banco de dados das VISAs (TB-WEB) e de dados secundários obtidos nas unidades de saúde (livro de Registro dos doentes em tratamento). Em seguida, foram identificados o endereço do doente e seu telefone a partir do prontuário clínico ou da ficha de acompanhamento dos casos, ou ainda da ficha de notificação.

O agendamento da entrevista com o doente deu-se por telefone ou através dos próprios profissionais do serviço. O local e o horário da entrevista foram indicados pelo doente, sendo no CS, em sala fechada, resguardando a privacidade deste, ou em domicílio. Nas situações em que o doente não foi encontrado no local combinado, foi necessário um novo contato para agendamento.

O levantamento dos profissionais realizou-se através do gestor ou co-gestor dos CS. Estes informaram quais eram os profissionais (enfermeiros, auxiliares ou técnicos de enfermagem) que acompanhavam os doentes de TB no serviço. A partir disso, sucedeu-se contato telefônico com cada profissional, convidando para participar, em um dia, horário e local oportuno para a realização da entrevista. No caso de esquecimento por parte do gestor de nomear algum profissional, essa nomeação foi feita posteriormente, através de contato telefônico no momento em que as entrevistadas eram agendadas. 
Para proceder à coleta de dados, cada entrevistado recebeu explicações quanto à natureza e objetivos do estudo, bem como foi convidado a participar do estudo mediante assinatura do termo de consentimento informado (doentes de TB - APÊNDICE VI e profissionais de saúde - APÊNDICE VII). As entrevistas foram realizadas nos CS, em locais indicados pelos próprios profissionais, no intuito de resguardar a privacidade.

\subsubsection{Aspectos observados durante a Coleta de Dados}

\section{Facilidades:}

- Parceria com o PCT do município e as VISAs, o que facilitou o contato com os CS, e por consequência, com os profissionais dos serviços de saúde e doentes de TB;

- Disponibilidade da coordenadora do PCT do município e enfermeiras da Vigilância Epidemiológica das VISAs em fornecer informações do contexto do município, forma como a assistência aos doentes e suspeitos de TB é realizada no município;

- Contatos periódicos com as enfermeiras das VISAs, para informações durante o período de coleta de dados;

- Disponibilidade do PCT do município e das VISAs em fornecer os dados epidemiológicos dos doentes de TB;

- Disponibilidade das equipes dos CS em fornecer os dados de contato dos doentes;

- Orientação por parte das equipes de saúde quanto aos locais de risco, durante a coleta de dados;

- Receptividade de muitos dos CS para colaborar com a pesquisa;

- Agendamento de entrevista com os doentes na mesma data do retorno para consulta médica (quando da escolha deste) a depender da disponibilidade no CS; 
- Agendamento durante as reuniões ocorridas nas VISAs de entrevistas com os profissionais de saúde;

- Disponibilidade de alguns auxiliares/ técnicos de enfermagem e agente comunitário de saúde em ir até o domicílio do doente, para facilitar a aproximação do entrevistador com o àquele.

\section{Obstáculos:}

- Extensão territorial do município, tornando as áreas de abrangência dos distritos extensas, e distantes umas das outras;

- Dificuldade de encontrar o doente para realizar as entrevistas;

- Difícil acesso geográfico para a aplicação dos instrumentos dos doentes, quando a entrevista não acontecia nos serviços de saúde;

- Localização dos domicílios dos doentes em áreas de vulnerabilidade social (violência; tráfico; falta de policiamento);

- Estigma que envolve a doença, tanto por alguns dos doentes, quanto por àqueles que convivem com o enfermo, e até de profissionais de saúde que não lidam com a doença;

- Dificuldade em conseguir agendar entrevistas com os profissionais de saúde, devido à grande demanda de serviço que eles têm nos CS, e também pelo fato de alguns profissionais se encontrarem no período de férias, principalmente dos meses de novembro de 2012 a fevereiro de 2013;

- Resistência de alguns profissionais em participar da pesquisa, por sentir que estavam sendo avaliados, bem como fornecer informações sobre os doentes de TB;

- Dificuldade em encontrar os gestores nos serviços de saúde para agendar as entrevistas com os profissionais, nos casos em que os gestores não estavam presentes 
nas reuniões ocorridas nos distritos (em menor número); o que gerou a necessidade de entrar em contato diversas vezes com o serviço.

\subsection{Análise dos dados}

Os dados coletados foram analisados através do programa Statistica, versão 9.0 da Statsoft. As variáveis usadas para a caracterização dos doentes de TB (APÊNDICE I), profissionais de saúde (APÊNDICE II) e da organização da assistência aos doentes de TB foram analisadas a partir de técnicas de análise exploratória, utilizando distribuição de frequência, medidas de tendência central e variabilidade.

Para analisar a associação das percepções dos doentes e profissionais de saúde quanto às ações desenvolvidas para promover a adesão ao tratamento da TB foi utilizado o teste qui-quadrado para comparação de proporções e teste exato de Fisher quando os critérios (Valores esperado, $E_{i j}>1,80 \% \operatorname{dos} E_{i j} \geq 5, N \geq$ ) não foram atendidos (SIEGEL E CASTELLAN, 1988).

\subsection{Aspectos Éticos}

A pesquisa foi autorizada pela Secretaria Municipal de Saúde de Campinas (Anexos I e II) e aprovada pelo Comitê de Ética em Pesquisa da Escola de Enfermagem de Ribeirão Preto, atendendo às recomendações contidas na resolução no 196/96 do Conselho Nacional de Saúde e das diretrizes e normas regulamentadoras de pesquisa envolvendo seres humanos, conforme protocolo 1264/2011 (Anexos III e IV).

\section{RESULTADOS}

6.1 Caracterização do perfil sociodemográfico, clínico e hábitos de vida dos doentes de tuberculose em tratamento 
Dos 349 doentes que constavam no TBWEB, no período da coleta de dados, atenderam os critérios de inclusão 165 doentes. Posto que, do total cadastrado, cinco foram transferidos para outra cidade/estado, outros cinco estavam internados no período da coleta; para três doentes solicitou-se, pela equipe dos serviços, que não entrasse em contato, justificando que eram pacientes "difíceis" (por não comparecer ao serviço, não receber profissionais no domicílio, não realizar os exames de controle, não aceitar o TDO, entre outros), e que se houvesse qualquer aproximação para a entrevista poderia causar o rompimento do vínculo com o serviço e, por consequência, o abandono. Quatro abandonaram o tratamento, cinco não foram localizados (moradores de rua) e oito foram a óbito. Ainda neste quadro, 154 não atendiam aos critérios de seleção: um era presidiário, 15 eram crianças e 134 não realizavam o tratamento nas unidades de atenção básica e quatro haviam encerrado o tratamento há mais de um mês quando houve contato com o CS.

Dos 165 doentes entrevistados, $32(19,4 \%)$ eram acompanhados no distrito de saúde Noroeste; 46 (27,9\%) no Sul; 37 (22,4\%) no Leste; 33 (20,0\%) no Sudoeste e 17 $(10,3 \%)$ no Norte.

A descrição do perfil sociodemográfico, clínico e hábitos de vida dos doentes de TB (tabela 1), mostrou que 121 (73,3\%) eram do sexo masculino; com idade média de $39[\mathrm{IQ}=29 ; 50]$ anos; $117(70,9 \%)$ estavam empregados; $128(77,6 \%)$ com 8 anos ou mais de estudo; $162(98,2 \%)$ moravam em casas; 159 (96,4\%) moravam junto com familiares; 158 (95,8\%) eram casos novos; 159 (96,4\%) com a forma clínica pulmonar; com tempo médio de tratamento de 4,6 (dp =1,6) meses ; $8(4,9 \%)$ apresentavam coinfecção TB/HIV; 39 (23,6\%) consumiam tabaco; e 37 (22,4\%) consumiam bebida alcoólica. 
Tabela 1. Distribuição de frequências da descrição do perfil sociodemográfico, clínico e hábitos de vida dos doentes de tuberculose, Campinas-SP, 2013.

\begin{tabular}{|c|c|c|c|c|c|}
\hline PERFIL & & VARIÁVEIS & & $\mathbf{n}$ & $\%$ \\
\hline \multirow{18}{*}{ 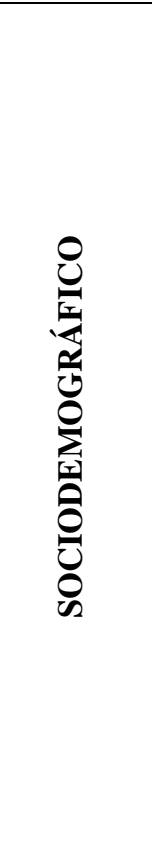 } & \multirow{2}{*}{ Sexo } & \multicolumn{2}{|l|}{ Masculino } & 121 & 73,3 \\
\hline & & \multicolumn{2}{|l|}{ Feminino } & 44 & 26,7 \\
\hline & \multirow{7}{*}{$\begin{array}{l}\text { Situação } \\
\text { Empregatícia }\end{array}$} & \multirow{4}{*}{ Empregado } & Empregado & 67 & 40,6 \\
\hline & & & Aposentado & 17 & 10,3 \\
\hline & & & Autônomo & 27 & 16,4 \\
\hline & & & Afastado & 6 & 3,6 \\
\hline & & \multirow{3}{*}{ Desempregado } & Desempregado & 36 & 21,8 \\
\hline & & & Do Lar & 8 & 4,9 \\
\hline & & & Estudante & 4 & 2,4 \\
\hline & \multirow{3}{*}{ Escolaridade } & \multicolumn{2}{|c|}{ Sem Escolaridade } & 2 & 1,2 \\
\hline & & \multicolumn{2}{|c|}{ Menos de 8 anos de Estudo } & 35 & 21,2 \\
\hline & & \multicolumn{2}{|c|}{8 anos ou mais de Estudo } & 128 & 77,6 \\
\hline & \multirow{3}{*}{ Tipo de Moradia } & \multicolumn{2}{|c|}{ Casa } & 162 & 98,2 \\
\hline & & \multicolumn{2}{|c|}{ Instituição (asilar/abrigo) } & - & - \\
\hline & & \multicolumn{2}{|c|}{ Morador de Rua } & 3 & 1,8 \\
\hline & \multirow{3}{*}{ Com que vive } & Sozinho & & 6 & 3,6 \\
\hline & & Familiares & & 159 & 96,4 \\
\hline & & Outras & & - & - \\
\hline \multirow{9}{*}{ 导 } & \multirow{4}{*}{ Tipo de Caso } & Novo & & 158 & 995,8 \\
\hline & & Recidiva & & 1 & 0,6 \\
\hline & & Abandono & & 6 & 3,6 \\
\hline & & Falência & & - & - \\
\hline & \multirow{3}{*}{ Forma Clínica } & Pulmonar & & 159 & 96,4 \\
\hline & & Pulmonar + & Pleural & 5 & 3,0 \\
\hline & & Extrapulmonar & Miliar & 1 & 0,6 \\
\hline & Coinfecção & Sim & & 8 & 4,9 \\
\hline & TB/HIV & Não & & 157 & 95,1 \\
\hline \multirow{6}{*}{ 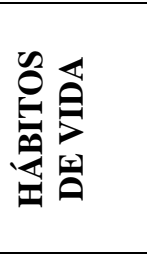 } & \multirow{3}{*}{$\begin{array}{l}\text { Consumo de } \\
\text { Bebida Alcoólica }\end{array}$} & \multirow{2}{*}{ Sim } & Esporadicamente & 25 & 15,2 \\
\hline & & & Diariamente & 12 & 7,3 \\
\hline & & Não & 128 & 77,5 & \\
\hline & \multirow{3}{*}{$\begin{array}{l}\text { Consumo de } \\
\text { Tabaco }\end{array}$} & \multirow{2}{*}{ Sim } & Esporadicamente & 4 & 2,4 \\
\hline & & & Diariamente & 35 & 21,2 \\
\hline & & Não & 126 & 76,4 & \\
\hline
\end{tabular}

\subsection{Caracterização dos profissionais de saúde da atenção básica que acompanham os casos de tuberculose, segundo variáveis demográficas e profissionais}

Foram indicados a participar da pesquisa, por atenderem casos de TB, 214 profissionais de saúde da equipe de enfermagem. Contudo, foram entrevistados 183, sendo que 16 se recusaram a participar, destes, seis informaram que estavam entrando de férias, outros três disseram que estavam muito sobrecarregados e não teriam tempo de participar e os outros 7 não revelaram o motivo para não participar da pesquisa; já os 
outros quinze profissionais não participaram, por terem informado que nunca atenderam caso de TB.

Dos 183 profissionais entrevistados, $109(59,6 \%)$ eram enfermeiros e $74(40,4 \%)$ auxiliares ou técnicos de enfermagem. Pertenciam ao Distrito de Saúde Noroeste 45 (24,6\%), ao Distrito Sul $63(34,4 \%)$, Leste $28(15,3 \%)$, Sudoeste $18(9,8 \%)$ e Norte 29 $(15,6 \%)$

Quanto à caracterização dos profissionais de saúde da atenção básica que acompanharam os casos de TB segundo o perfil demográfico e profissional (tabela 2), $158(86,3 \%)$ eram do sexo feminino, com idade média de 37,9 (dp = 9,1) anos; tempo médio de trabalho com doentes de TB de 10,7 ( $\mathrm{dp}=7,5)$ anos; sendo que destes, 136 $(74,3 \%)$ realizaram algum tipo de capacitação para atender doentes/ suspeitos de TB; 47 profissionais não lembravam há quanto tempo havia realizado a última capacitação ou não havia realizado, e para 136 profissionais o tempo médio de realização da última capacitação foi de 3,0 [IQ=1;5] anos; $136(74,3 \%)$ destas capacitações foram realizadas pelas VISAs; $161(88,0 \%)$ informaram procurar informações em livros e/ou internet sobre TB.

Tabela 2. Distribuição de frequências do perfil sociodemográfico e profissional dos profissionais de saúde que acompanharam os casos de tuberculose em tratamento, Campinas-SP, 2013.

\begin{tabular}{llcc}
\hline \multicolumn{2}{c}{ Perfil demográfico e profissional } & $\mathrm{n}$ & $\%$ \\
\hline Categoria Profissional & Enfermeiro & 109 & 59,6 \\
& Auxiliar/Técnico de & 74 & 40,4 \\
& Enfermagem & 158 & 86,3 \\
& Feminino & 25 & 13,7 \\
\hline Sexo & Masculino & 161 & 88,0 \\
\hline Procura de informações sobre & Sim & 22 & 12,0 \\
tuberculose em livros e/ou internet & Não & 136 & 74,3 \\
\hline Realização de Capacitação para & Sim & 47 & 25,7 \\
atender doentes de tuberculose & Não & 47 & 25,7 \\
\hline Quem realiza as capacitações* & Programa de Controle & 136 & 74,3 \\
& da Tuberculose & & \\
& Vigilância & &
\end{tabular}


Epidemiológica do

Distrito

Centro de Saúde

14

7,7

Outros

6

3,3

* os entrevistados poderiam responder mais de uma categoria de resposta.

\subsection{Caracterização da organização da assistência aos doentes de} tuberculose segundo a percepção dos doentes e profissionais de saúde

Quanto à caracterização da organização da assistência aos doentes de TB, (Tabela 3), segundo a percepção destes, $94(57,0 \%)$ realizava o TDO, $155(79,4 \%)$ doentes informaram que a ingesta foi observada por um profissional de saúde, com média de oferecimento de TDO 2,2 (dp = 1,6) vezes por semana, $112(67,9 \%)$ receberam um kit café da manhã e $89(54,0 \%)$ eram atendidos pelo mesmo profissional de saúde.

Segundo a percepção dos profissionais de saúde, 178 (97,3\%) profissionais ofereceram TDO para os doentes em tratamento; com média de 3,3 observações da ingesta de TDO na semana; 158 (86,3\%) oferecem o Kit Café da manhã.

Tabela 3. Distribuição de frequência da organização da assistência aos doentes de tuberculose segundo a percepção dos doentes e profissionais de saúde, Campinas-SP, 2013.

\begin{tabular}{llcccc}
\hline \multirow{2}{*}{$\begin{array}{c}\text { Itens sobre } \\
\text { organização da } \\
\text { assistência }\end{array}$} & $\begin{array}{l}\text { Categorias de } \\
\text { respostas }\end{array}$ & noentes & \% & Profissionais de \\
Saúde
\end{tabular}




\begin{tabular}{llcccc} 
TDO* & \multicolumn{5}{l}{} \\
\cline { 1 - 4 } Oferecimento de & Kit Café da Manhã & 136 & 82,4 & 158 & 86,3 \\
Incentivo** & Cesta Básica & 22 & 13,3 & 37 & 20,2 \\
& Vale transporte & 2 & 1,2 & 13 & 7,1 \\
& Não & 29 & 17,6 & 1 & 0,6 \\
\hline
\end{tabular}

*Tratamento Diretamente Observado.

** os entrevistados poderiam responder mais de uma categoria de resposta.

\subsection{Percepção dos doentes e profissionais de saúde quanto às ações desenvolvidas para promover a adesão ao tratamento da tuberculose.}

A associação das percepções dos doentes e profissionais de saúde quanto às ações desenvolvidas para promover a adesão ao tratamento da TB foram apresentadas na tabela 4. E de acordo com esta tabela, as respostas dos doentes tiveram associação com a variável: orientação para buscar informações em livros e/ou internet sobre a sua doença; e as respostas dos profissionais tiveram associação com as seguintes variáveis: oportunidade para opinar sobre o tratamento; agendamento de consultas mensais para o acompanhamento do tratamento da TB; entrega de informações escritas sobre o tratamento; orientação para que os familiares façam exames para a TB e tempo suficiente para o doente falar sobre as dúvidas e/ou preocupações.

Tabela 4. Distribuição de frequência das ações desenvolvidas pelos serviços de atenção básica para adesão ao tratamento de tuberculose na percepção dos doentes e profissionais de saúde, Campinas-SP, 2013.

\begin{tabular}{lcccc}
\hline \multicolumn{1}{c}{ Ações Desenvolvidas } & Informantes & $\begin{array}{c}\text { Sim } \\
\mathbf{n}(\%)\end{array}$ & $\begin{array}{c}\text { Não } \\
\mathbf{n}(\%)\end{array}$ & p \\
\hline 1. Orientação sobre o que é a tuberculose. & Doente & $165(100,0)$ & $0(0,0)$ & \\
& Profissional & $183(100,0)$ & $0(0,0)$ & - \\
$\begin{array}{l}\text { 2. Orientação para buscar informações em } \\
\text { livros e/ou internet sobre a sua doença. }\end{array}$ & Doente & $163(98,8)$ & $2(1,2)$ & $<0,0001^{*}$ \\
$\begin{array}{l}\text { 3. Oportunidade para opinar sobre o } \\
\text { tratamento. }\end{array}$ & Doente & $92(55,8)$ & $73(44,2)$ & $<0,0001^{*}$ \\
$\begin{array}{l}\text { 4. Agendamento de consultas mensais } \\
\text { para o acompanhamento do tratamento da } \\
\text { tuberculose. }\end{array}$ & Profissional & $172(94,0)$ & $11(6,0)$ & \\
& Profissional & $140(84,9)$ & $25(15,1)$ & $<0,0001^{*}$ \\
& & $183(100,0)$ & $0(0,0)$ & \\
\end{tabular}




\begin{tabular}{|c|c|c|c|c|}
\hline \multirow{2}{*}{$\begin{array}{l}\text { 5. Orientação quanto à importância de } \\
\text { comparecer às consultas mensais }\end{array}$} & Doente & $163(98,8)$ & $2(1,2)$ & \multirow[t]{2}{*}{0,1352} \\
\hline & Profissional & $183(100,0)$ & $0(0,0)$ & \\
\hline \multirow{2}{*}{$\begin{array}{l}\text { 6. Orientação sobre a realização de } \\
\text { exames de controle. }\end{array}$} & Doente & $163(98,8)$ & $2(1,2)$ & \multirow[t]{2}{*}{0,5023} \\
\hline & Profissional & $182(99,5)$ & $1(0,5)$ & \\
\hline \multirow{2}{*}{$\begin{array}{l}\text { 7. Orientação sobre como deve tomar os } \\
\text { remédios da tuberculose. }\end{array}$} & Doente & $164(99,4)$ & $1(0,6)$ & \multirow[t]{2}{*}{0,9414} \\
\hline & Profissional & $182(99,5)$ & $1(0,5)$ & \\
\hline \multirow{2}{*}{$\begin{array}{l}\text { 8. Entrega de informações escritas sobre o } \\
\text { tratamento. }\end{array}$} & Doente & $92(55,8)$ & $73(44,2)$ & \multirow[t]{2}{*}{$0,0006^{*}$} \\
\hline & Profissional & $134(73,2)$ & $49(26,8)$ & \\
\hline \multirow{2}{*}{$\begin{array}{l}\text { 9. Encorajamento para continuar o } \\
\text { tratamento da tuberculose. }\end{array}$} & Doente & $163(98,8)$ & $2(1,2)$ & \multirow[t]{2}{*}{0,5023} \\
\hline & Profissional & $182(99,5)$ & $1(0,5)$ & \\
\hline \multirow{2}{*}{$\begin{array}{l}\text { 10. Orientação para procurar pelo serviço } \\
\text { de saúde quando tem dúvidas sobre o } \\
\text { tratamento }\end{array}$} & Doente & $164(99,4)$ & $1(0,6)$ & \multirow[t]{2}{*}{0,6237} \\
\hline & Profissional & $181(98,9)$ & $2(1,1)$ & \\
\hline \multirow{2}{*}{$\begin{array}{l}\text { 11. Orientação para observar se os } \\
\text { sintomas melhoram durante o tratamento. }\end{array}$} & Doente & $163(98,8)$ & $2(1,2)$ & \multirow[t]{2}{*}{0,9170} \\
\hline & Profissional & $181(98,9)$ & $2(1,1)$ & \\
\hline \multirow{2}{*}{$\begin{array}{l}\text { 12. Orientação sobre a conduta a ser } \\
\text { tomada se os sintomas piorarem. }\end{array}$} & Doente & $163(98,8)$ & $2(1,2)$ & \multirow[t]{2}{*}{0,7380} \\
\hline & Profissional & $180(98,4)$ & $3(1,6)$ & \\
\hline \multirow{4}{*}{$\begin{array}{l}\text { 13. Orientação sobre os hábitos de uma } \\
\text { vida mais saudável (alimentação } \\
\text { adequada, prática de exercícios físicos, } \\
\text { evitar o uso de bebida alcoólica e cigarro). } \\
\text { 14. Orientação para que os familiares } \\
\text { façam exames para a tuberculose }\end{array}$} & Doente & $164(99,4)$ & $1(0,6)$ & \multirow[t]{2}{*}{0,9414} \\
\hline & Profissional & $182(99,5)$ & $1(0,5)$ & \\
\hline & Doente & $158(95,8)$ & $7(4,2)$ & \multirow[t]{2}{*}{$0,0216^{*}$} \\
\hline & Profissional & $182(99,5)$ & $1(0,5)$ & \\
\hline \multirow{2}{*}{$\begin{array}{l}\text { 15. Tempo suficiente para o doente falar } \\
\text { sobre as dúvidas e/ou preocupações. }\end{array}$} & Doente & $158(95,8)$ & $7(4,2)$ & \multirow[t]{2}{*}{$0,0216^{*}$} \\
\hline & Profissional & $182(99,5)$ & $1(0,5)$ & \\
\hline \multirow{2}{*}{$\begin{array}{l}\text { 16. Convite para participar de algum } \\
\text { grupo de doentes de tuberculose. }\end{array}$} & Doente & $59(35,8)$ & $106(64,2)$ & \multirow[t]{2}{*}{0,4229} \\
\hline & Profissional & $58(31,7)$ & $125(68,3)$ & \\
\hline
\end{tabular}

\section{DISCUSSÃO}

Em se tratando do perfil sociodemográfico dos doentes entrevistados, a maioria são homens em idade produtiva, são empregados; o que também está relacionado com o adoecimento por TB. (ALBUQUERQUE et al.; LIMA et al., 2001; VENDRAMINI et al., 2005; PAIXÃO; GONTIJO, 2007; SALAZAR et al., 2008; COELHO et al., 2009; BRASIL, 2009).

Um aspecto interessante observado foi o fato da maior parte dos doentes terem referido possuir oito anos ou mais de estudo, e na literatura verifica-se que a doença 
acomete um número maior de pessoas com menos ou nenhum ano de estudo (MASCARENHAS, ARAÚJO, GOMES, 2005; ALBUQUERQUE et al., 2007). Segundo a Plataforma de consulta ao Índice de Desenvolvimento Humano Municipal (IDHM) de municípios brasileiros, o percentual de pessoas com 18 anos ou mais, com ensino fundamental completo do município de Campinas, no ano de 2010, foi de 67,71; e daqueles com ensino médio completo, de 50,47\% (ATLAS DO DESENVOLVIMENTO HUMANO NO BRASIL, 2015), o que poderia justificar o maior número de doentes com mais de oito anos de estudo.

A maior parte dos doentes residia em casas, vivendo com familiares, sendo três doentes moradores de rua. Na tentativa de assegurar a realização do tratamento medicamentoso para os moradores de rua, foram identificadas situações em que as equipes dos CS e os profissionais da VISA (inclusive o motorista) utilizaram como estratégia a supervisão da ingestão do medicamento na rua.

Quanto ao perfil clínico, a maior parte dos doentes era casos novos, com a forma clínica pulmonar, o que também é observado em outros estudos (BIERRENBACH et al., 2007; COUTINHO et al., 2012; DURANS et al., 2013). No ano de 2013, o município apresentou 300 casos novos de TB, um coeficiente de incidência de todas as formas de 26,2 casos por 100.000 habitantes, sendo 213 casos com a forma clínica pulmonar (TBWEB, 2015), aspecto que tem relação com a TB, dado que a baciloscopia positiva favorece a manutenção da cadeia de transmissão (PICON et al., 1993; WHO, 1996).

A literatura apresenta relação entre a TB e a infecção pelo HIV (DEHEINZELIN et al., 1996; RIBEIRO et al., 2000; ALBUQUERQUE et al., 2001; LIBERATO et al., 2004; PICON et al., 2010). No entanto, este estudo não mostra um número elevado de coinfecção, sendo que este percentual poderia não condizer com a realidade do 
município, cuja taxa era de $11,7 \%$ em 2013. Além disso, de 349 doentes que constavam no TB-WEB, 4,6\% dos resultados estavam em andamento, e 10,6\% não havia sido realizado/oferecido (TBWEB, 2015).

Em se tratando dos hábitos de vida, destaca-se que entre os doentes que consumiam tabaco, 21,2\% utilizavam diariamente, e entre os que consumiam bebida alcoólica, 7,3\%, características que devem ser consideradas, em razão de estar diretamente ligadas ao adoecimento por TB (RIBEIRO et al., 2000; LIMA et al., 2001; ALBUQUERQUE et al., 2001; CAMPANI, MOREIRA, TIETBOHEL, 2011).

Em se tratando do perfil dos profissionais da equipe de enfermagem, observouse, neste estudo, que os enfermeiros foram o maior número de entrevistados, sendo este profissional o responsável pela coordenação das ações de controle da TB nos CS. Estudos mostram que estes profissionais realizam atividades assistenciais como o cuidado domiciliar, comunitário (SMELTZER, BARE, 2005) e educacional (QUEIROZ, NOGUEIRA, 2010; QUEIROZ et al., 2012).

Nos serviços de atenção básica de Campinas, a assistência prestada ao doente de $\mathrm{TB}$, é realizada por todos os profissionais que compõem a equipe de enfermagem, estas equipes são atuantes nas atividades de controle da doença, sendo o trabalho realizado de forma fragmentada. Os auxiliares e técnicos de enfermagem ficam responsáveis pelas ações assistenciais, de controle e observação da ingesta do medicamento, controle de comunicantes, busca de sintomáticos respiratórios (quando ocorre), e em casos específicos, acompanham os doentes para a realização de exames em outros níveis de atenção.

A depender da configuração/ organização de cada CS ou equipe, os enfermeiros realizam as ações citadas, mas na maior parte das vezes, respondem pela coordenação das ações de vigilância (não somente da TB), tendo em cada CS, pelo menos um 
enfermeiro responsável pelas ações de Vigilância Epidemiológica, fluxo de informação entre a(s) equipe(s), a(s) VISA, e o PMCT, bem como os registros, tais quais boletim de acompanhamento do tratamento dos casos de $\mathrm{TB}$, que são enviados via malote mensalmente para as VISAs; lembrando que nos CS não há acesso ao TBWEB.

Quanto aos outros registros utilizados durante o tratamento da TB, cada CS/Equipe se organiza de forma diferente, tendo aqueles que utilizam o prontuário do doente, cadernos de registro, e os outros que usam planilhas informatizadas, criadas pelo próprio profissional de saúde; apesar de todos terem o livro de registro do acompanhamento do tratamento dos casos de TB e do sintomático respiratório.

Ainda sobre o enfermeiro, este tem também função importante na liderança e capacitação da equipe, contribuindo na construção da identidade organizacional inspirada no modelo de vigilância em saúde (BRASIL, 2005), da mesma maneira que na supervisão do trabalho dos ACS, auxiliares e técnicos de enfermagem.

A participação dos ACS na assistência direta aos doentes de TB apresenta algumas limitações, uma vez que a própria equipe não permite que este profissional participe das ações, ou o próprio ACS alega que não recebe por insalubridade, recusando-se a realizar contato mais próximo ao doente.

Quanto à distribuição dos profissionais de saúde entre os distritos, o Sul foi o que apresentou maior número de profissionais $34,4 \%$, posto que é o distrito com o maior número (dezeseis) de CS no município e o que apresenta a região mais povoada e pobre (CANO e BRANDÃO, 2002; CAMPINAS, 2010).

Houve predomínio do sexo feminino entre os profissionais entrevistados, o que é observado na literatura pela característica de feminização da enfermagem (MACHADO, VIEIRA e OLIVEIRA, 2006), idade média de 37,9 anos, e tempo médio de trabalho com doentes de TB de 10,7 anos; tendo este tempo uma característica que permite um 
melhor entendimento do seu papel enquanto profissional, construído nas práticas cotidianas (VIANA, 1998).

Houve capacitação para a maior parte dos profissionais prestarem assistência aos doentes de TB, sendo eventuais com frequência a cada três anos. Tal fato mostra que é imprescindível a elaboração de estratégias de educação permanente, de tal modo que faça parte do cotidiano das equipes (SCALCO, LACERDA e CALVO, 2010) com o intuito de superar os processos tradicionais de ensino caracterizados por intervenções pontuais desvinculadas das práticas profissionais (MENDES, 2011), visto que a TB é uma condição crônica, na qual o doente realiza um longo tratamento, o que se faz indispensável à educação constante deste paciente, também a sensibilidade do profissional para conhecer as nuances que envolvem a vida desses doentes e as suas necessidades.

Sobre a procura por informações sobre TB em livros e/ou internet, a maioria dos profissionais referiu realizar, o que é importante do ponto de vista do acesso à programas educacionais e de capacitação relacionadas com a TB (WHO, 1999).

Em se tratando da organização da assistência ao doente de $T B$, o atendimento do doente nos CS ocorre de diferentes maneiras: em alguns serviços cada equipe de saúde da família (ESF) presente no CS, é responsável pelo(s) doente(s) da sua área de abrangência; em outros CS, há um grupo de profissionais de uma ou mais equipes (médico, enfermeiro, auxiliar/técnico de enfermagem, em algumas situações os ACS) responsáveis em assistir todos os doentes da área do CS, e não somente da área de abrangência da ESF.

A supervisão do TDO é realizada nos CS por um profissional que pode ser enfermeiro ou auxiliar/técnico de enfermagem. No entanto, há alguns casos, menos 
frequente, em que o auxiliar/técnico ou o ACS se desloca até o domicílio para observar a ingestão da dose.

No município de Campinas, no ano de 2013, o TDO foi indicado para 71,5\% dos doentes em tratamento (SALA DE SITUAÇÃO DA TB, 2015), e foi efetivado para cerca de 55\% dos casos novos em tratamento (TBWEB, 2015), o que está mais de acordo com o informado pelos doentes.

Quanto ao número de supervisão da dose semanal, as percepções entre doentes e profissionais foi diferente. Tal diferença reflete o contraponto entre a visão do doente sobre a assistência recebida e a visão mais normativa do profissional que considera as diretrizes do Ministério da Saúde.

No município, a realização do TDO é flexível no sentido de o doente ter opções de onde realizar a ingesta (onde for mais perto, mais acessível). Há exemplos de moradores de rua que tiveram seus tratamentos supervisionados por equipes de unidades de pronto socorro, ou seja, os CS usaram estratégias de cuidado no intuito de potencializar o TDO e, consequentemente, promover maior adesão ao tratamento.

Considerando a oferta de benefícios, os kits café da manhã estavam sendo oferecidos a praticamente todos os doentes de TB durante a época da coleta de dados. As cestas básicas eram oferecidas apenas para os que não tinham condições financeiras, e a solicitação era feita pela secretaria de assistência social. Também foi verbalizado pelos profissionais/equipes, que, em casos extremos, a(s) equipe(s) fazia(m) uma cesta ou doava(m) uma refeição para o doente.

Sobre o vale transporte, foi observado que, havia profissionais de saúde e doentes que desconheciam a lei que beneficia os doentes de TB com este incentivo, dado que poucos profissionais de saúde e doentes referiram oferecer/ receber o benefício. Portanto, a importância da equipe conhecer a rede de apoio, o que poderia 
propiciar a continuidade do tratamento. Segundo Marcolino et al. (2009), a disponibilidade de vale transporte facilita a ida do doente ao CS para o controle do tratemnto e monitoramento do TDO, no entanto, "a qualidade da atenção dispensada e o grau de satisfação do usuário devem ser considerados”.

Vendramini et al. (2002), mostram que os beneficios concedidos, aliados à assistência prestada pelo profissional que supervisiona o TDO, além de garantir a adesão ao tratamento, oferece a oportunidade de identificar outras necessidades de vida, sociais, econômicas, relacionamentos familiares, co-responsabilidade, apoio, encaminhamentos, necessidades, além do estabelecimento de vínculo com a equipe de saúde responsável pela supervisão.

Considerando as percepções de doentes e profissionais de saúde quanto às ações desenvolvidas na atenção básica para promover a adesão do doente ao tratamento da $T B$, verificou-se um alto percentual de ações realizadas dentre aquelas analisadas, sendo que as respostas foram concordantes (não apresentou associação estatística significante) entre profissionais e doentes. Desta forma, entende-se que as equipes estão oferecendo ações para o manejo dos casos, e que estas têm sido recebidas pelos doentes de TB.

Quanto à orientação sobre o que é TB, a literatura aponta que, ao iniciar o tratamento, a pessoa com TB deveria receber informação detalhada sobre o que é a doença, diagnóstico, motivo da necessidade de realizar o tratamento, reações adversas potenciais, e consequências da irregularidade do tratamento. Há a necessidade de desenvolver uma abordagem educativa sobre seus direitos (CASTILLO, 2003).

Com relação à orientação quanto à importância de comparecer às consultas mensais e realização de exames de controle, nem todos os serviços realizam consulta médica mensalmente, no entanto, o doente é acompanhado pela equipe de enfermagem, e são solicitados todos os exames de controle. 
As consultas mensais são avaliadas positivamente pelos doentes e os pacientes buscam a confirmação de sua melhora através da realização de exames (LIMA, SOUZA, FERREIRA, 2005; QUEIROZ, BERTOLOZZI 2010). A segurança do doente está associada ao reconhecimento de que a equipe é competente e lhe proporciona suporte durante o tratamento, incluindo exames e consultas, sendo que estes recursos aumentam a adesão ao tratamento (QUEIROZ, BERTOLOZZI, 2010).

Sobre a forma como deve tomar os medicamentos e o encorajamento para continuar o tratamento da TB, segundo Haynes et al. (1979), seguir o tratamento medicamentoso pode ser definido como um ponto no qual o comportamento dos doentes coincide com as orientações da equipe de saúde. Ainda assim, alguns doentes consideram os medicamentos fortes o suficiente para afetar negativamente outras partes do corpo ("conserta uma coisa e estraga outra"), podendo levá-los a não adesão (GONÇALVES et al., 1999).

A relação dos doentes com os medicamentos nem sempre é simples e restrita ao seu consumo, podendo também envolver características que levam a não adesão como o número de comprimidos, o tempo de tratamento e os efeitos colaterais (GONÇALVES et al., 1999).

Em se tratando da procura pelo serviço de saúde quando tem dúvidas sobre o tratamento, observar se os sintomas melhoram durante o tratamento e conduta a ser tomada se os sintomas piorarem, estudo realizado por Bergel e Gouveia (2005) apontou que quando o doente tem retornos frequentes nas unidades de saúde, é criada oportunidade de aproximar o paciente da equipe e do serviço de saúde iniciando um vínculo e favorecendo a adesão ao tratamento, já que, nestes momentos, são esclarecidas dúvidas sobre a doença, o tratamento e os efeitos colaterais. 
Quanto aos hábitos de uma vida mais saudável, a preocupação com a redução do consumo de tabaco e bebidas alcoólicas, bem como a instituição de uma alimentação adequada são características de indivíduos que se preocupam mais com sua melhora e, consequentemente, com a adesão ao tratamento (RIBEIRO et al., 2000).

Estudo realizado em Pelotas-RS identificou que alguns pacientes não abandonavam hábitos como consumir cigarros ou beber cervejas, mesmo atribuindo a não adesão ao tratamento às dificuldades financeiras. Isso mostra que a mudança de comportamento é algo difícil de acontecer, portanto, se faz importante o doente receber informações sobre a influência do estilo de vida no resultado do tratamento.

Sobre o recebimento de convite para participar de algum grupo de doentes de $T B$, vale destacar que, no município de Campinas, não há grupos que atende doentes de TB, apesar dos profissionais de saúde e os doentes terem referido oferecer/ receber esta ação. A questão se referia à participação do doente em algum grupo de doentes de TB, no entanto, poderia ter ocorrido o entendimento da participação do doente em outros grupos que existem nos CS.

Quanto às ações analisadas sobre receber orientação para buscar informações em livros elou internet sobre a doença, oportunidade para opinar sobre o tratamento; agendamento de consultas mensais para o acompanhamento do tratamento da TB; entrega de informações escritas sobre o tratamento; orientação para que os familiares façam exames para a TB e receber tempo suficiente para falar sobre as dúvidas elou preocupações na percepção de doentes e profissionais de saúde, foi observado que as respostas foram discordantes dentre os entrevistados (apresentou associação estatística significante). Estes dados sinalizam uma lacuna no oferecimento destas ações para a adesão ao tratamento da $\mathrm{TB}$, já que os profissionais informaram oferecer tal ação, mas 
esta não é percebida/recebida pelo doente de TB, com exceção da "orientação para buscar informações em livros elou internet sobre TB".

A literatura é consistente em relação à educação em saúde sobre TB ser considerada importante aspecto para a adesão ao tratamento (CALDAS, QUEIROZ, 2000; GRANGE, ZUMLA, 2002; DICK, LOMBARD, 1997). No entanto, estudo realizado por Paixão e Gontijo (2007) mostra que doentes consideram insuficiente a informação sobre o tratamento proporcionada pela equipe de saúde, o que justifica a importância do doente receber orientação para buscar informações em livros elou internet sobre TB. Merece destaque, que o doente percebia mais o recebimento desta orientação do que efetivamente os profissionais referiam oferecer.

Reforçando a idéia anterior, estudo mostra que, quando os doentes se tornam conhecedores de suas doenças, dos mecanismos fisiopatológicos, dos fatores desencadeantes e do risco, da lógica e dos benefícios do tratamento, entre outros aspectos, eles passam imediatamente a aderir ao tratamento (VIEIRA, FREITAS, TAVARES, 2006).

A humanização da assistência prestada pelos profissionais de saúde aos doentes de TB de forma a possibilitar a participação dos mesmos em seu tratamento, proporcionando tempo suficiente para o doente esclarecer dúvidas/preocupações e dar opiniões, não era percebida pelo doente da mesma forma que o profissional informava. Tal fato também foi observado por Gonçalves et al. (1999), ao citar que o tratamento do doente é realizado na maior parte das vezes a partir das recomendações da equipe de saúde, sendo que estas promovem pouca ou nenhuma autonomia do doente. Da mesma forma, estudo realizado por Reigota e Carandina (2002) sobre o TDO mostrou que apenas $18,1 \%$ dos doentes referiram-se à "participação no próprio tratamento". 
Sobre o agendamento de consultas mensais para o acompanhamento do tratamento dos doentes, o profissional respondeu o que era preconizado nas diretrizes do Ministério da Saúde, o que nem sempre ocorria na realidade vivenciada pelos doentes de TB, de modo que esta condizia com a ausência de profissionais médicos em alguns CS do município. Estudo de Reiners et al. (2006) aponta que há falhas na orientação, e no agendamento dos retornos, e que essas características poderiam revelar o pouco interesse do profissional na adesão do paciente ao tratamento. Importante destacar, ainda, que estes agendamentos deveriam ser em horários adequados para o doente no intuito de possibilitar maior adesão ao tratamento (LIMA et al, 2001; CULQUI, et al., 2005).

O recebimento de informações escritas sobre o tratamento ocorreu para 55,8\% dos doentes, apesar de 73,2\% dos profissionais referirem oferecer. O oferecimento de tais informações auxilia na adesão ao tratamento e deve ocorrer de maneira simples e clara (CROFTON, 1980), uma vez que os doentes só assimilam metade das orientações faladas pelo profissional de saúde (SBARBARO, 1991).

Apesar de discordantes na opinião dos doentes e profissionais de saúde, a orientação para que os familiares façam exames para a $T B$ teve um resultado acima de 90\%, dado que a investigação dos contatos possibilita a aproximação da família com a equipe, incluindo-a no tratamento do doente de TB (GONÇALVES et al., 1999; GAZETTA et al., 2006; QUEIROZ, BERTOLOZZI, 2010). Tal aproximação colabora no enfrentamento da doença, influenciando hábitos, e condutas para a continuidade e adesão ao tratamento (NOGUEIRA et al., 2011).

Portanto, para assegurar a adesão do doente de TB ao tratamento, os profissionais devem estar sensibilizados para conhecer as necessidades do usuário e para desenvolver a corresponsabilização na assistência (SÁ et al., 2007). É de grande 
importância escutar as queixas do doente, ajustar a assistência e propor soluções em conjunto (equipe de saúde e usuário), estabelecendo uma relação com base no acolhimento, no vínculo e na parceria com a comunidade (SÁ et al., 2007).

A motivação para aderir ao tratamento recomendado pela equipe de saúde é influenciada pelo valor atribuído ao fato do paciente querer segui-lo, pela confiança que tem em si mesmo para dar continuidade. No entanto, constantemente é necessário reforçar a motivação intrínseca do paciente, aumentando a importância percebida da adesão (MILLER, 1999).

\section{LIMITAÇÕES DO ESTUDO}

Enquanto limitações do estudo foram identificadas:

- Viés de memória para aqueles doentes que terminaram o tratamento em até 30 dias antes da coleta de dados por talvez não lembrar sobre o seu tratamento; e pelos profissionais de saúde que não estavam acompanhando caso de TB no período da coleta de dados.

- Viés de seleção, pois entre os doentes, alguns eram moradores de rua e não foram encontrados. Em outros casos, a equipe solicitou que não houvesse o contato para a participação da pesquisa, dado que eram considerados pacientes "difíceis". Não foram entrevistados doentes que abandonaram o tratamento, pois nem as próprias equipes conseguem encontrar esses pacientes. No caso dos profissionais de saúde, por terem sido indicados pelos gestores dos serviços, como sendo os responsáveis pelo tratamento da TB no CS.

- Viés de compreensão, pelo fato de doentes e profissionais responderem as questões através de um entendimento pessoal, pelo conhecimento/visão/vivência que eles apresentam, através da percepção e satisfação da assistência que é 
prestada/oferecida, e recebida, bem como a maneira como os mesmos compreendem a doença.

\section{CONSIDERAÇÕES FINAIS}

A caracterização do perfil sociodemográfico, clínico e hábitos de vida dos doentes de TB que estavam em tratamento nos serviços de atenção básica do município mostrou que eram homens; em idade produtiva; se encontravam empregados; apresentando oito anos ou mais de estudo; parte deles consumidores de tabaco e álcool; residentes em casas; com familiares; eram casos novos; com a forma pulmonar; tempo médio de tratamento da TB de 4,6 meses, e aproximadamente 5\% de coinfecção TB/HIV.

Quanto à caracterização dos profissionais de saúde da atenção básica que acompanham os casos de TB, segundo variáveis demográficas e profissionais as características observadas foram que, a maior parte era do sexo feminino; idade média de 37,9 anos; enfermeiros; tempo médio de trabalho com doentes de TB de 10,7 anos; receberam algum tipo de capacitação para atender doentes/ suspeitos de TB; e referiram procurar informações em livros e/ou internet sobre TB.

Em se tratando da organização da assistência aos doentes de TB, segundo a percepção dos doentes e profissionais de saúde, observou-se que a maior parte dos profissionais referiu oferecer o TDO para os doentes em tratamento, no entanto, menor parte destes alegou recebê-lo. Houve divergência entre a média de observações semanais entre doentes e profissionais. Maior quantidade de profissionais citou oferecer o kit café da manhã em relação aos doentes. Tal fato também ocorre quanto ao vale transporte, e cestas básicas. 
Foi observado que o TDO não é realizado por todos os doentes em tratamento, e para aqueles que recebem a observação não é diária. Quanto aos benefícios, seria interessante que o PCT pudesse assegurar a cesta básica durante os seis meses de tratamento, pelo menos para aqueles doentes que não possuem recursos financeiros. Vale destacar que a lei que o município apresenta quanto ao vale transporte é uma conquista, todavia, a população e os profissionais de saúde precisam conhecer a disponibilidade do benefício para os doentes de TB, da mesma maneira que os profissionais precisam assegurar através da disponibilização da documentação pelos CS para que os doentes consigam o benefício, que é um direito assegurado por Lei.

Considerando a adesão como um fenômeno multidimensional, compreende-se que a Atenção Básica do município de Campinas vem oferecendo aos doentes de TB ações como a orientação sobre como deve tomar os remédios da $T B$, e outras que vão além de estratégias voltadas à adesão da terapia medicamentosa, como a orientação sobre doença; importância de comparecer às consultas mensais e realização de exames de controle; encorajamento para continuar o tratamento da TB; procurar pelo serviço de saúde quando tem dúvidas sobre o tratamento; observar se os sintomas melhoram durante o tratamento; a conduta a ser tomada se os sintomas piorarem; orientação sobre os hábitos de uma vida mais saudável (alimentação adequada, prática de exercícios físicos, evitar o uso de bebida alcoólica e cigarro) e convite para participar de algum grupo de doentes de TB.

Entende-se isso como um avanço, no entanto, ainda há deficiências na promoção de autonomia dos doentes pelos serviços de saúde, participação do doente nas decisões do tratamento, investigação dos contatos, assim como na oferta de ações extramuros e voltadas a uma assistência familiar e comunitária que poderiam ajudar ainda mais na adesão ao tratamento, porquanto as ações como, a orientação para buscar 
informações em livros elou internet sobre a sua doença; doente opinar sobre o tratamento; agendamento de consultas mensais para o acompanhamento do tratamento da TB; entrega de informações escritas sobre o tratamento; orientação para que os familiares façam exames para a TB; tempo suficiente para o doente falar sobre as dúvidas elou preocupações, tiveram associação na percepção de doentes e profissionais, ou seja, a forma como estas ações estão sendo oferecidas/ recebidas são percebidas de forma diferente, tendo a necessidade de uma maior participação dos profissionais na vida dos doentes e familiares, a fim de entender suas particularidades, no intuito de melhorar a adesão ao tratamento, posto que envolve diversos aspectos.

\section{REFERÊNCIAS BIBLIOGRÁFICAS}

ABUAKU, B.; TAN, H.; LI, X.; CHEN, M.; HUANG, X. Treatment default and death among tuberculosis patients in Hunan, China. Scand J Infect Dis, London, v. 42, n.4, p.281-287, 2010.

ALBUQUERQUE, M.F.M.; LEITÃO, C.C.S.; CAMPELO, A.R.L.; SOUZA, W.V.; SALUSTIANO, A. Fatores prognósticos para o desfecho do tratamento da tuberculose pulmonar em Recife, Pernambuco, Brasil. Rev Panam Salud Publica, Washington, DC, v. 9, n.6, p. 368-374, 2001.

ALBUQUERQUE, M.F.P.M.; XIMENES, R.A.A.; SILVA, N.L.; SOUZA, W.V.; DANTAS, A.T.; DANTAS, O.M.S. Fatores associados à falha do tratamento, abandono e morte em uma coorte de pacientes de tuberculose e Recife Brasil. Cad Saúde Publica, Rio de Janeiro, v. 23, n.7, p. 1573-1582, 2007.

AMUHA, M.G.; KUTYABAMI, P.; KITUTU, F.E.; ODOI-ADOME, R.; KALYANGO, J.N. Non-adherence to anti-TB drugs among TB/HIV co-infected patients in Mbarara Hospital Uganda: Prevalence and associated factors. Afr Health Sci, Kampala, v. 9, n.2, p. 1573-1582, 2007. Disponível em: <http://www.ajol.info/index.php/ahs/article/view/47806>.

ATLAS DO DESENVOLVIMENTO HUMANO NO BRASIL. Acesso em: Disponível em: <http://www.atlasbrasil.org.br/2013/pt/consulta/> Acesso em 05 jun. 2015.

AYISI, J.G.; VAN'T HOOG, A.H.; AGAYA, J.A.; MCHEMBERE, W.; NYAMTHIMBA, P.O.; MUHENJE, O.; MARSTON, B.J. Care seeking and attitudes towards treatment compliance by newly enrolled tuberculosis patients in the district treatment programme in rural western Kenya: a qualitative study. BMC public health, London, v. 11, n.1, p. 515, 2011. 
BAGCHI, S.; AMBE, G.; SATHIAKUMAR, Nc. Determinants of poor adherence to anti-tuberculosis treatment in Mumbai, India. Int J Prev Med, v. 1, n.4, p. 223, 2010.

BERGEL, F.S.; GOUVEIA, N. Retornos freqüentes como nova estratégia para adesão ao tratamento de tuberculose. Rev. Saúde Publica, São Paulo, v. 39, n. 6, p. 898905, Dec. $2005 \quad$ Disponível em: http://www.scielo.br/scielo.php?script=sci_arttext\&pid=S0034-

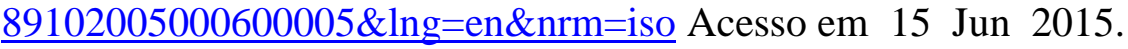

BIERRENBACH, A.L.; GOMES, A.B.F.; NORONHA, E.F.; SOUZA, M.F.M. Incidência de tuberculose e taxa de cura, Brasil, 2000 a 2004. Rev. Saúde Publica [online]. $\quad$ v. 41, suppl.1, pp. 24-33, 2007. Disponível em: <http://dx.doi.org/10.1590/S0034-89102007000800005>.

BRASIL. Ministério da Saúde. Secretaria de Vigilância em Saúde. Nota Técnica $\mathbf{n}^{\mathbf{0}} \mathbf{1 5}$ de 2011. Brasília, DF, 2011.

Ministério da Saúde. Secretaria de Vigilância em Saúde. Departamento de Vigilância Epidemiológica. Tratamento Diretamente Observado da Tuberculose na Atenção Básica: Protocolo de Enfermagem. Brasília, DF, 2010.

- Ministério da Saúde. Secretaria de Atenção Básica. Guia prático para o PSF. Brasília, DF, 2005.

Ministério da Saúde. Fundação Nacional de Saúde. Plano Nacional de Controle da Tuberculose. Brasília, DF, 2004.

Ministério da Saúde. Portaria MS/GM n. 95, de 26 de janeiro divulga a Norma Operacional de Assistência á Saúde - NOAS-SUS 01/2001. Diário Oficial da União, Brasilia, DF, 29 jan. 2001. Seção 1, p. 23E-31E.

CADASTRO NACIONAL DE ESTABELECIMENTOS DE SAÚDE (CNES). Consultas aos estabelecimentos de Saúde. Disponível em: <http://cnes.datasus.gov.br/Lista_Tot_Es_Estado.asp〉.

CALDAS, A.J.M.; QUEIROZ, L.S. Causas do abandono ao tratamento de tuberculose em São Luis - MA. Nursing (Säo Paulo), São Paulo, v. 3, n.21, p. 13-15, 2000.

CAMPANI, S.T.A.; MOREIRA, J.S.; TIETBOHEL, C.N. Fatores preditores para o abandono do tratamento da tuberculose pulmonar preconizado pelo Ministério da Saúde do Brasil na cidade de Porto Alegre (RS). J. bras. pneumol. [online], v. 37, n.6, p. 776782 2011. Disponível em: <http://www.scielo.br/scielo.php?script=sci_arttext\&pid=S1806$37132011000600011 \& \operatorname{lng}=\mathrm{en} \& \mathrm{nrm}=\mathrm{iso}>$.

CAMPINAS. Secretaria Municipal de Saúde. Informe da Vigilância em Saúde de Campinas. Boletim Epidemiológico de Campinas. Ano XIV, 14, 2011. http://2009.campinas.sp.gov.br/saude/. Acesso em: 25 nov de 2011. 
CAMPINAS. Secretaria Municipal de Saúde. Plano Municipal de Assistência Social 2010-2013. Disponível em: 〈http://www.campinas.sp.gov.br/arquivos/cidadania/ATT00085.pdf $>$. Acesso em 03 de março de 2015.

CANO, W.; BRANDÃO, C.A. (coords.) A Região Metropolitana de Campinas: urbanização, economia, finanças e meio ambiente. Campinas: Editora da Unicamp, v. 2, p. 415, 2002.

CASTILLO, O.J. La tuberculosis multirresistente en el Perú. Cuaderno de trabajo 1 [online]. Lima, PE: Foro Salud y Observatorio del derecho a la Salud CIES, 2003. Disponível em: <http://www.consorcio.org/Observatorio/ publicaciones/jave.pdf>. Acesso em 08 de março de 2015.

CAVALCANTI, Z.R.; ALBUQUERQUE, M.F.P.M.; CAMPELO, A.R.L.; XIMENES, R.; MONTARROYOS, U.; VERÇOSA, M.K.A. Características da tuberculose em idosos no Recife (PE): contribuição para o programa de controle. J Bras Pneumol. [Online], Brasília, DF, v. 32, n.6, p. 535-543, 2006.

CEGOLON, L.; MAGUIRE, H.; MASTRANGELO, G.; CARLESS, J.; KRUIJSHAAR, M.E.; VERLANDER, N.Q. Predictors of failure to complete tuberculosis treatment in London, 2003-2006. Int J Tuberc Lung Dis, Paris, v. 14, n.11, p. 1411-1417, 2010.

CENTRO DE VIGILÂNCIA EPIDEMIOLÓGICA ALEXANDRE FLEMING. Divisão de Controle da Tuberculose. Sala de Situação de Tuberculose do Estado de São Paulo. Disponível em: 〈http://www.cve.saude.sp.gov.br/tuberculose/>. Acesso em 17 de Abril de 2014.

COELHO, A.G.V.; ZAMARIOLI, L.A.; PERANDONES, C.A.; CUNTIERRI, I.; WALDMAN, E.A. Características da tuberculose pulmonar em área hiperendêmica municipio de Santos. J Bras Pneum, Brasília, DF, v. 35, n. 10, p. 998-1007, 2009.

COSTA, J.S.D.; GONÇALVES, H.; MENEZES, A.M.B.; DEVENS, E.; PIVA, M.; GOMES, M.; VAZ, M. Controle epidemiológico da tuberculose na cidade de Pelotas, Rio Grande do Sul, Brasil: adesão ao tratamento. Cad. Saúde Publica [online], v. 14, n.2, p. 409-415, $1998 . \quad$ Disponível em: <http://www.scielo.br/scielo.php?script=sci_arttext\&pid=S0102-

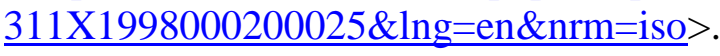

COUTINHO, L.A.S.A.; OLIVEIRA, D.S.; SOUZA, G.F.; FERNANDES FILHO, G.M.C.; SARAIVA, M.G. Perfil Epidemiológico da Tuberculose no Município de João Pessoa- PB, entre 2007-2010. Revista Brsileira de Ciências da Saúde, João Pessoa, v.16, n.1, p. 35-42, 2012.

CROFTON J. Les causes possibles de l'echec des trautment de la tuberculosis pulmonaire comment les eviter. Bol Union Int Tuberc, Paris, v.55, n. 3-4, p. 93-101, 1980. 
CULQUI DR, GRIJALVA CG, TEATEGUI SR, CAJO JM, SUAREZ LA. Factores prognósticos del abandonp del tratamento antituberculoso em uma región endêmica del Peru. Rev Panam Salud Publica, Washington, DC, v.18, n. 1, p. 14-20, 2005.

DEHEINZELIN, D.; TAKAGAKI, T.Y.; SARTORI, A.M.C.; LEITE, O.H.M.; AMATO NETO, V.; CARVALHO, C.R.R. Fatores preditivos de abandono de tratamento por pacientes com tuberculose. Rev. Hosp. Clin. Fac. Med. Univ. São Paulo, São Paulo, v.51, n. 4, p. 131-135, 1996.

DICK, J.; LOMBARD, C. Shared vision: a health education project designed to enhance adherence to anti-tuberculosis treatment. Int J Tuberc Lung Dis. Paris, v.1, n. 2, p. 181-186, 1997.

DURANS, J.J.F.; SÁ, E.M.; PEREIRA, F.B.; SOARES, D.L.; OLIVEIRA, O.S.; AQUINO, D.M.C.; CALDAS, A.J.M. Perfil clínico e sociodemográfico de pacientes que abandonaram o tratamento de tuberculose no município de São Luís - MA. Rev Pesq Saúde, [Online], v.14, n. 3, p. 175-178, 2013. Disponível em: <http://www.periodicoseletronicos.ufma.br/index.php/revistahuufma/article/view/2794/ $\underline{861>}$.

DYE, C.; WATT, C.J.; BLEED, D.M.; HOSSEINI, S.M.; RAVIGLIONE, M.C. Evolution of tuberculosis control and prospects for reducing tuberculosis incidence, prevalence, and deaths globally. JAMA, Chicago, v.293, n. 22, p. 2767-2775, 2005.

FERREIRA, S.M.B.; SILVA, A.M.C.; BOTELHO, C. Abandono de tratamento da tuberculose pulmonar em Cuiabá (MT) Brasil. J Bras Pneum, Brasília, DF, v. 3, n. 5, p. 427-435, 2005.

FLOREZ-ALARCON, L.; MERCEDES BOTERO, M.; MORENO JIMENEZ, B. Psicología de la salud. Temas actuales de investigación en Latinoamérica, Bogotá. Editora ALAPSA, p59-76, 2005.

GAZETTA, C.E.; RUFFINO-NETTO, A, PINTO NETO, J.M.; SANTOS, M.L.S.G.; CURY, M.R.C.O.; VENDRAMINI, S.H.F.; VILLA, T.C.S. O controle de comunicantes de tuberculose no programa de controle da tuberculose em um município de médio porte da Região Sudeste do Brasil, em 2002. J. Bras. Pneumol, Brasília, v. 32, n. 6, p. 559-565, 2006.

GOLUB, J.E.; MOHAN, C.I.; COMSTOCK, G.W.; CHAISSON, R.E. Active case finding of tuberculosis: historical perspective and future prospects. Int J Tuberc Lung Dis. Paris, v. 9, n. 11, p. 1183-1203, 2005.

GONÇALVES, H.; COSTA, J.S.D.; MENEZES, A.M.B.; KNAUTH, D.; LEAL, O.F. Adesão à terapêutica da tuberculose em Pelotas, Rio Grande do Sul: na perspectiva do paciente. Cad. Saúde Publica. v. 15, n. 4, p. 777-787, 1999.

GRANGE, J.M.; ZUMLA, A. The global emergency of tuberculosis: what is the cause? J R Soc Health, London, v. 122, n. 2, p. 78-81, 2002. 
HASKER, E.; KHODJIKHANOV, M.; USAROVA, S.; ASAMIDINOV, U.; YULDASHOVA, U.; WERF, M.J.; VEEN, J. Default from tuberculosis treatment in Tashkent, Uzbekistan; Who are these defaulters and why do they default?. BMC infectious diseases, London, v. 8, n. 1, p. 97, 2008.

HAYNES, R.; B. Determinants of compliance: The disease and the mechanics of treatment., Johns Hopkins University Press, Baltimore, 1979.

HECK, M.A.; COSTA, J.S.D.D.; NUNES, M.F. Tuberculosis treatment drop out prevalence and associated factors in Sapucaia do Sul County (RS), Brazil, 20002008. Rev Bras Epidemiol, São Paulo, v. 14, n. 3, p. 478-485, 2011.

HIJJAR, M.A. Tuberculose: desafio permanente. Cad Saúde Publica, Rio de Janeiro, v. 11, n. 2, p. 348-349, 2005.

INSTITUTO BRASILEIRO DE GEOGRAFIA E ESTATÍSTICA (IBGE). Estimativas das populações residentes, segundo município. Disponível em: <http://www.ibge.gov.br/cidadesat/topwindow.htm?1> Acesso em: 22 mai. 2014.

JAKUBOWIAK, W.; BOGORODSKAYA, E.M.; BORISOV, S.E.; DANILOVA, I.D.; LOMAKINA, O.B.; KOURBATOVA, E.V. Impact of socio-psychological factors on treatment adherence of TB patients in Russia. Tuberculosis, Montevideo, v. 88, n. 5, p. 495-502, 2008.

JANAKAN, N.; SENEVIRATNE, R. Factors contributing to medication noncompliance of newly diagnosed smear-positive pulmonary tuberculosis patients in the district of Colombo, Sri Lanka. Asia Pac J Public Health, Hong Kong, v. 20, n. 3, p. 214-223, 2008.

JIN, J.; SKLAR, G.E.; SEN, O.H.V.M.; LI, S.C. Factors affecting therapeutic compliance: A review from the patient's perspective. Ther Clin Risk Manag, Albany, v. 4, n. 1, p. 269-286, 2008.

KEBEDE, A.; WABE, N.T. Medication adherence and its determinants among patients on concomitant tuberculosis and antiretroviral therapy in South West Ethiopia. N Am J Med Sci, Hamilton, v. 4, n. 2, p. 67, 2012.

KLIIMAN, K.; ALTRAJA, A. Predictors and mortality associated with treatment default in pulmonary tuberculosis. Int J Tuberc Lung Dis. Paris, v. 14, n. 4, p. 454463, 2010.

LIBERATO, I.R.; ALBUQUERQUE, M. F.; CAMPELO, A.R.; MELO, H.R. Characteristics of pulmonary tuberculosis in HIV seropositive and seronegative patients in a Northeastern region of Brazil. Rev Soc Bras Med Trop, Rio de Janeiro, v. 37, n. 1, p. 46-50, 2004.

LIMA, A.L.; SOUZA, F.B.A.; FERREIRA, G.L. Tuberculose: atitudes frente à doença. Bol Pneumol Sanit. Brasília, v. 13, n. 2, p. 83-90, 2005. 
LIMA, M.B.; MELLO, D.A.; MORAIS, A.P.; SILVA, W.C. Estudo de casos sobre abandono do tratamento da tuberculose: avaliação do atendimento, percepção e conhecimentos sobre a doença na perspectiva dos clientes (Fortaleza, Ceará, Brasil). Cad Saúde Publica. Rio de Janeiro, v. 17, n. 4, p. 877-885, 2001.

LIMA, M.M. HIV/tuberculosis co-infection: a request for a better surveillance. Rev Saúde Publica, São Paulo, [online]. v. 31, n. 3, p. 217-220, 1997.

MACHADO, M.HE.; VIEIRA, A.L.S.; OLIVEIRA, E. "Construindo o perfil da enfermagem*." Enfermagem em foco, Brasília, v. 3, n. 3, p. 119-122, 2012.

MARCOLINO, A.B.L.; NOGUEIRA, J.A.; RUFFINO-NETTO, A.; MORAES, R. M.; SÁ, L.D.; VILLA, T.C.S.; ROLIM, F.J. Avaliação do acesso às ações de controle da tuberculose no contexto das equipes de saúde da família de Bayeux - PB. Rev. bras. epidemiol, São Paulo, v.12, n. 2, p. 144-157, 2009. Disponível em:

<http://www.scielo.br/scielo.php?script=sci_arttext\&pid=S1415-

90X2009000200005\&lng=en\&nrm=iso>.

MÁRTIN ALFONSO, L.; BAYARRE VEA, H.D.; GRAU ABALO, J. A. Validácion del cuestionario MBG (Mártin-Bayarre_Grau) para evaluar la adherencia terapéutica em hipertensión arterial. Rev Cuhana Adm Salud [online], La Habana, v.34, n. 1, p. 144157, 2008.

em: <http://www.bvs.sld.cu/revistas/spu/vol34_1_08/spu12108.htm>.

MARTINS, N.; GRACE, J.; KELLY, P.M. An ethnographic study of barriers to and enabling factors for tuberculosis treatment adherence in Timor Leste. Int J Tuberc Lung Dis. Paris, v. 12, n. 5, p. 532-537, 2008.

MARX, F.M.; DUNBAR, R.; HESSELING, A.C.; ENARSON, D.A.; FIELDING, K.; BEYERS, N. Increased risk of default among previously treated tuberculosis cases in the Western Cape Province, South Africa. Int J Tuberc Lung Dis. Paris, v. 16, n. 8, p. 1059-1065, 2012.

MASCARENHAS, M.D.M.; ARAUJO, L.M.; GOMES, K.R.O. Perfil epidemiológico da tuberculose entre casos notificados no Município de Piripiri, Estado do Piauí, Brasil. Epidemiol. Serv. Saúde, Brasília, v. 14, n. 1, 2005. Disponível em: $<$ http://scielo.iec.pa.gov.br/scielo.php?script=sci_arttext\&pid=S1679$49742005000100002 \& \operatorname{lng}=$ pt\&nrm=iso>.

MATEUS-SOLARTE, J.C.; CARVAJAL-BARONA, R. Factors predictive of adherence to tuberculosis treatment, Valle del Cauca, Colombia. Int J Tuberc Lung Dis. Paris, v. 12, n. 5, p. 520-526, 2008.

MENDES, E.V. As redes de atenção à saúde. 2.ed. Brasília (DF): Organização PanAmericana da Saúde; 2011.

MESFIN, M.M.; NEWELL, J.N.; WALLEY, J.D.; GESSESSEW, A.; TESFAYE, T.; LEMMA, F.; MADELEY, R.J. Quality of tuberculosis care and its association with patient adherence to treatment in eight Ethiopian districts. Health policy plan, London, v. 24, n. 6, p. 457-466, 2009. 
MILlER, W.; ROLLNICK, S. Motivational interviewing. Nueva York, Guilford Press, 1999.

MKOPI, A.; RANGE, N.; LWILLA, F.; EGWAGA, S.; SCHULZE, A, GEUBBELS, E.; VAN LETH, F. Adherence to tuberculosis therapy among patients receiving homebased directly observed treatment: evidence from the United Republic of Tanzania. PloS one [Online], San Francisco, v. 7, n. 12, 2012. Disponível em: http://journals.plos.org/plosone/article?id=10.1371/journal.pone.0051828>.

MOLINA, R.M.; FERNÁNDEZ, A.A.; RODRÍGUEZ, D.Á.M.; LÓPEZ, H.B. Factors associated to dropout of tuberculostatic treatment in the province of Granada. Rev Clin Esp, Barcelona, v. 212, n. 8, p. 383-388, 2012.

MUNIZ, J.A.N.; PALHA, P.F.; MONROE, A.A.; GONZALES, R.C.; RUFFINONETO, A.; VILLA, T.C.S. A incorporação da busca ativa de sintomáticos respiratórios para o controle da tuberculose na prática do agente comunitário de saúde. Ciênc Saúde Colet, Rio de Janeiro, v. 10, n. 2, p. 315-21, 2005.

MUTURE, B.N.; KERAKA, M.N.; KIMUU, P.K.; KABIRU, E.W.; OMBEKA, V.O.; OGUYA, F. Factors associated with default from treatment among tuberculosis patients in Nairobi province, Kenya: a case control study. BMC public health, London, v. 11, n. 1, p. 696, 2011.

NAIDOO, P.; DICK, J.; COOPER, D. Exploring tuberculosis patients' adherence to treatment regimens and prevention programs at a public health site. Qual. health res, Newbury Park, v. 19, n. 1, p. 55-70, 2009.

NGAMVITHAYAPONG-YANAI, J.; PUANGRASSAMI, P.; YANAI, H. Compliance to tuberculosis treatment: a gender perspective. In: DIWAN, V.; THORSON, A.; WINKIVIST, A. (eds). Gender and tuberculosis. Goteborg, Nordic School of Public Health, p 127-48, 1998.

NOGUEIRA, J.A.;TRIGUEIRO, D.R.S.G.; SÁ, L.D.; SILVA, C.A.; OLIVEIRA, L.C.S.; VILLA, T.C.S.; SCATENA, L.M. . Enfoque familiar e orientação para a comunidade no controle da tuberculose. Rev. bras. Epidemiol, São Paulo, v. 14, n. 2, p. 2017-216, 2011. Disponível em: $<$ http://www.scielosp.org/scielo.php?script=sci_arttext\&pid=S1415$790 X 2011000200003 \& \operatorname{lng}=e n \& n r m=i s o>$. access

PAIXÃO, L.M.M.; GONTIJO, E.D. Perfil de casos de tuberculose notificados e fatores associados ao abandon, Belo Horizonte (MG). Rev Saúde Publica, São Paulo, v. 41, n. 2, p. $205-213,2007$.

PICON, P.D.; RIZZON, C.F.; JARCZEWSKI, C.A. Fármacos Utilizados no Tratamento da Tuberculose. In: Barros, E.; Barros, M.M., (eds). Medicamentos na Prática Clínica. São Paulo: ArtMed; p. 550-572, 2010.

PICON, P.; RIZZON, C.F.; OTT, W. P. Tuberculose: Epidemiologia, Diagnóstico e Tratamento em Clínica e Saúde Pública. Rio de Janeiro: Medsi, p. 690, 1993. 
QUEIROZ, E.M.; DE LA TORRE UGARTE GUANILO, M.C.; FERREIRA, K.R.; BERTOLOZZI, M.R. Tuberculosis: limitations and strengths of Directly Observed Treatment Short-Course. Rev Latino Am Enfermagem, Ribeirão Preto, v. 20, n. 2, p. 369-377, 2012.

QUEIROZ, E.M.; BERTOLOZZI, M.R. Tuberculosis: supervised treatment in North, West and East Health Departments of São Paulo. Rev Esc Enferm USP [Internet], São Paulo, v. 44, n. 2, p453-461, 2010. Disponível em: <http://www.scielo.br/pdf/ reeusp/v44n2/en_30.pdf $>$.

QUEIROZ, R.; NOGUEIRA, P.A. Diferenças na Adesão ao Tratamento da Tuberculose em Relação ao Sexo no Distrito de Saúde da Freguesia do Ó/Brasilândia--São, Paulo. Saúde e Soc, [Online] São Paulo, v. 19, n. 3, p. 627-637, 2010.

RAND, C.S. Measuring adherence with therapy for chronic diseases: implications for the treatment of heterozygous familial hypercholesterolemia. Am. j. cardiol, New York, v. 72, p. 72:68D-74D, 1993.

REIGOTA, R. M. S.; CARANDINA, L. Implantação do tratamento supervisionado no município de Bauru/SP - Avaliação da tuberculose pulmonar,1999/2000. Bol Pneumol Sanit. Brasília, v. 10, n. 1, 2002. Disponível em $<$ http://scielo.iec.pa.gov.br/scielo.php?script=sci_arttext\&pid=S0103460X2002000100004\&lng=pt\&nrm=iso>.

REINERS A.A.O.; AZEVEDO, C.R.; VIEIRA, M.A.; GAWLINSKI, A.L. Produção bibliográfica sobre adesão/não adesão de pessoas ao tratamento de saúde. Ciên Saúde Coletiva, Rio de Janeiro, v. 13, n. 2, p. 2294-2305, 2006.

REYES-GUILLÉN， I.; SÁNCHEZ-PÉREZ， H.J.; CRUZ-BURGUETE， J.; IZAURIETA-DE JUAN, M. Anti-tuberculosis treatment defaulting: an analysis of perceptions and interactions in Chiapas, Mexico. Salud pública Méx, México, v. 50, n. 3, p. 251-257, 2008.

RIBEIRO, S.A.; AMADO, V.M.; CAMELIER, A.A.; FERNANDES, M.M.A.; SCHENKMAN, S. Estudo caso-controle de indicadores de abandono em doentes com tuberculose. J. Bras. Pneumol, Brasília, v. 26, n. 6, p. 291-296, 2000.

Disponível em: <http://www.scielo.br/scielo.php?script=sci_arttext\&pid=S0102$35862000000600004 \& \operatorname{lng}=$ en\&nrm=iso>.

RODRIGUES, I.L.A.; MONTEIRO, L.L.; PACHECO, R.H.B.; SILVA, S.E.D. Abandono do tratamento de tuberculose em co-infectados TB/HIV. Rev Esc Enferm USP, São Paulo, v. 44, n. 2, p. 380-384, 2010.

RUFFINO-NETTO, A. Tuberculose: a calamidade negligenciada. Rev Soc Bras Med Trop, Rio de Janeito, v. 35, n. 1, p. 51-58, 2002.

SÁ, L.D.; SOUZA, K.M.J.; NUNES, M.G.; PALHA, P.F.; NOGUEIRA, J.A.; VILLA, T.C.S. Tratamento da tuberculose em unidades de saúde da família: histórias de abandono. Texto \& Contexto Enferm, Florianópolis, v. 16, n. 4, p. 712-718, 2007. 
SAGBAKKEN, M.; FRICH, J.C.; BJUNE, G. Barriers and enablers in the management of tuberculosis treatment in Addis Ababa, Ethiopia: a qualitative study. BMC Public Health, London, v. 8, n. 1, p. 11, 2008.

SALA DE SITUAÇÃO DO ESTADO DE SÃO PAULO. Disponível em: http://tuberculosesp.cealag.com.br/ Acesso em: 22 mai. 2014; 07 de março de 2015.

SALAZAR, J.L.; ASOREY, C.P.; ARIAS, D.R.; DÍAZ, R.C.; MACHADO, L.O. Social and economic risk factors of the lung tuberculosis in Santiago de Cuba municipality. Medisan [Online], Santiago de Cuba, v. 13, n. 4, p. 11, 2008. Disponível em: <http://scielo.sld.cu/pdf/san/v13n4/san07109.pdf >. Acesso em: 20 out de 2012.

SANTOS J. Resposta brasileira ao controle da tuberculose. Rev Saude Publica, São Paulo, v. 41, (Supl 1), p. 4189- 4194, 2007.

SBARBARO J. Cumplimiento del paciente con el tratamiento preventivo. Consideraciones operacionales. Bol Unión Int Tuberc Enf Resp. 66 (Supl 1), p. 39-41, 1990-1991.

SCALCO, S.V.; LACERDA, J.T.; CALVO, M.C.M. Modelo para avaliação da gestão de recursos humanos em saúde .Cad Saude Publica, Rio de Janeiro, v. 26, n. 3, p. 603 $614,2010$.

SECRETARIA DA SAÚDE DO ESTADO DE SÃO PAULO SES SP/COSEMS SP. Mapa da Rede Regional de Atenção à Saúde (RRAS). Disponível em: http://www.saude.sp.gov.br/resources/ces/homepage/rras/estado_rras_drs_rs_2012_dpi_ 300.jpg Acesso em 05 jun. 2013.

SECRETARIA MUNICIPAL DE SAÚDE. Mapa da Saúde da Região de Saúde de Campinas, 2012. Disponível em: http://2009.campinas.sp.gov.br/saude/ Acesso em 06 jun. 2013.

SIEGEL, S.; CASTELLAN, N. John, Jr (1988). Nonparametric statistics for the behavioral sciences ( $2^{\text {nd }}$ edition). New York: McGraw-Hill, 1988.

SILVEIRA, L.M.; RIBEIRO, V.M.B. Grupo de adesão ao tratamento: espaço de "ensinagem" para profissionais de saúde e pacientes. Interface (Botucatu), Botucatu, v. 9, n. 16, p. 91-104, 2005.

SMELTZER, S.C.; BARE, B.G. Brunner \& Suddarth (coords): Tratado de Enfermagem Médico Cirúrgica. 10ed. Rio de Janeiro: Guanabara Koogan, 2005.

SOUSA, F.M.; LUNA, I.T.; SILVA, K.L.; PINHEIRO, D.P.N. Patients living with HIV/AIDS and co-infection by tuberculosis: difficulties associated with treatment compliance or dropout. Rev. gaúcha enferm, [Online], Porto Alegre, v. 33, n. 2, p. 139-145, 2012.

SOUZA, K.M.J.D.; SÁ, L.D.D.; PALHA, P.F.; NOGUEIRA, J.A.; VILLA, T.C.S.; FIGUEIREDO, D.A. Abandono do tratamento de tuberculose e relações de vínculo com 
a equipe de saúde da família. Rev Esc Enferm USP, São Paulo, v. 44, n. 4, p. 904-910, 2010.

SOUZA, M.S.P.L.; PEREIRA, S.M.; MARINHO, J.M.; BARRETO, M.L. Características dos serviços de saúde associadas à adesão ao tratamento da tuberculose. Rev Saúde Publica, Rio de Janeiro, v. 43, n. 6, p. 998-1005, 2009. Disponível em: http://www.scielo.br/pdf/rsp/v43n6/11

SUMARTOJO, E. When tuberculosis treatment fails: A social behavioral account of patient adherence. Am. rev. respir. dis, New York, v. 147, p. 1311-1320, 1993.

TACHFOUTI, N.; SLAMA, K.; BERRAHO, M.; NEJJARI, C. The impact of knowledge and attitudes on adherence to tuberculosis treatment: a case-control study in a Moroccan region. Pan Afr Med J, Uganda, v. 11, n. 1, 2012.

TB-WEB. Sistema de Notificação e Acompanhamento dos Casos de Tuberculose. Disponível em: HTTP://www.cvetb.saude.sp.gov.br/tbweb/index.jsp (acesso restrito). Acesso em 05 de março de 2015.

TERRA, M.F.; BERTOLOZZI, M.R. Tratamento diretamente supervisionado (DOTS) contribui para a adesão ao tratamento da Tuberculose? Rev Latino Am Enfermagem [online], Ribeirão Preto, v. 16, n. 4, p. 659-664, 2008.

BOOGAARD, J.; MSOKA, E.; HOMFRAY, M.; KIBIKI, G.S.; HELDENS, J.J.; FELLING, A.J.; AARNOUTSE, R.E. An exploration of patient perceptions of adherence to tuberculosis treatment in Tanzania. Qual. health res, Newbury Park, v. 22, n. 6, p. 835-845, 2012.

VENDRAMINI, S. H.; GAZETTA, C. E.; NETTO, F. C.; CURY, M. R.; MEIRELLES, E. B.; KUYUMJIAN, F. G.; VILLA, T. C.S. Tuberculose em município de porte médio do sudeste do Brasil: indicadores de morbidade e mortalidade, de 1985 a 2003. J Bras Pneumol, Brasília, v.31, n.3, p. 237-43, 2005.

VENDRAMINI, S.H.F.; VILLA, T.C.S.; PALHA, P.F.; MONROE, A.A. Tratamento supervisionado no controle da tuberculose em uma unidade de saúde de Ribeirão Preto: a percepção do doente. Bol. Pneumol. Sanit, [online], Brasília, v. 10, n. 1, 2002.

Disponível em: <http://scielo.iec.pa.gov.br/scielo.php?script=sci_arttext\&pid=S0103460X2002000100002\&lng=pt\&nrm=iso >. ISSN 0103-460X. Acesso em 03 de mar de 2015.

VIANA, A.L.; POZ, M.R. A reforma do sistema de saúde no Brasil e o Programa de Saúde da Família. Physis, Online]. Rio de Janeiro1998;8(2):11-48.

VIEIRA, V.; FREITAS, J.B.; TAVARES, A. Adesão ao tratamento clínico. In: Diniz, D.P.; Schor, N. (organizs). Qualidade de vida. São Paulo: Manole; 2006. p.157-64.

WENDLING APB, MODENA CM, SCHALL VT. Abandonment of tuberculosis treatment in the perspective of health centers managers in Belo Horizonte-MG, Brazil. Texto \& Contexto-Enfermag, Florianópolis, v. 21, n. 1, p. 77-85, 2012. 
WILLIAMS, G.; ALARCON, E.; JITTIMANEE, S.; WALUSIMBI, M.; SEBEK, M.; BERGA, E. et al. Care during the continuation phase. Int J Tuberc Lung Dis, Paris, v. 12, n.7, p. 731-5, 2008a. Disponível em: < http://www.ncbi.nlm.nih.gov/pubmed/18544196

Care during the intensive phase: promotion of adherence. Int $\mathbf{J}$ Tuberc Lung Dis, Paris, v. 12, n. 6, p. 601-5, 2008b. Disponível em: < http://www.ncbi.nlm.nih.gov/pubmed/18492324

- Starting treatment: caring for patients and their families. Int J Tuberc Lung Dis, Paris, v. 12, n. 5, p. 493-7, 2008c. Disponível em: 〈http://www.ncbi.nlm.nih.gov/pubmed/18419883 >.

WORLD HEALTH ORGANIZATION (WHO). Implementing the WHO Stop TB Strategy: a handbook for national tuberculosis control programmes. Geneva, (WHO/HTM/ TB/2008.401), 2008.

Geneva, 2006.

Tuberculosis control: surveillance, planning, financing: WHO Report 2006.

Adherence to long-term therapies. Evidence for action. Geneva, 2003.

Guidelines for the prevention of tuberculosis in health care facilities in resource-limited settings. Geneva, p.1-51,1999.

WHO report on the tuberculosis epidemic, 1997: use dots more widely. Geneva, (WHO, TB/97.224), 1997.

Group at risk: annual report, 1996. Geneva, 1996.

XU, W.; LU, W.; ZHOU, Y.; ZHU, L.; SHEN, H.; WANG, J. Adherence to antituberculosis treatment among pulmonary tuberculosis patients: a qualitative and quantitative study. BMC Health Services Research, London, v.9, n. 1, p. 169, 2009.

YAO, S.; HUANG, W. H.; VAN DEN HOF, S.; YANG, S. M.; WANG, X. L.; CHEN, W.; PAN, H.F. Treatment adherence among sputum smear-positive pulmonary tuberculosis patients in mountainous areas in China. BMC health services research, 11(1), 341, 2009. 


\section{APÊNDICE I - REVISÃO DA LITERATURA}

Quadro 1. Artigos, segundo o ano de publicação, periódico, autores, país, tipo e população de estudo, enfoque (adesão, não adesão ou adesão + não adesão), através das características relacionadas às dimensões da Organização Mundial da Saúde (OMS, 2003$), 2014$.

\begin{tabular}{|c|c|c|c|c|c|c|c|c|c|c|c|c|}
\hline \multirow[b]{2}{*}{$\begin{array}{c}\mathbf{N} \\
\mathbf{0}\end{array}$} & \multirow[b]{2}{*}{ Ano } & \multirow[b]{2}{*}{ Periódico } & \multirow[b]{2}{*}{ Autores } & \multirow[b]{2}{*}{$\begin{array}{l}\text { País de } \\
\text { Estudo }\end{array}$} & \multirow[b]{2}{*}{$\begin{array}{l}\text { Tipo de } \\
\text { Estudo }\end{array}$} & \multirow[b]{2}{*}{ Enfoque } & \multirow[b]{2}{*}{$\begin{array}{l}\text { População } \\
\text { de Estudo }\end{array}$} & \multicolumn{5}{|c|}{ Dimensões Relacionadas: } \\
\hline & & & & & & & & Paciente & $\begin{array}{c}\text { Sócio- } \\
\text { demografic } \\
\text { a } \\
\end{array}$ & Doença & Tratamento & $\begin{array}{c}\text { Sistemas e } \\
\text { Equipes de } \\
\text { Saúde } \\
\end{array}$ \\
\hline 1 & $\begin{array}{c}200 \\
8\end{array}$ & Tuberculosis & $\begin{array}{c}\text { Jakubowia } \\
\text { k et al. }\end{array}$ & Rússia & $\begin{array}{c}\text { Transvers } \\
\text { al }\end{array}$ & Não Adesão & $\begin{array}{c}\text { Doentes de } \\
\text { TB }\end{array}$ & $\begin{array}{l}\text { - Sentimentos } \\
\text { negativos } \\
\text { pela equipe } \\
\text { médica } \\
\text { - Achar que } \\
\text { pode confiar } \\
\text { apenas em si } \\
\text { mesmo } \\
\text { - Não } \\
\text { acreditar na } \\
\text { recuperação } \\
\text { total (cura) } \\
\text { - Não querer } \\
\text { finalizar o } \\
\text { tratamento; } \\
\text { - Apresentar } \\
\text { história } \\
\text { prisional } \\
\text { - Não se } \\
\text { preocupar } \\
\text { com a família } \\
\text { - Apresentar } \\
\text { humor } \\
\text { instável } \\
\text { - Não sentir } \\
\text { vontade de } \\
\text { ajudar outros } \\
\text { pacientes } \\
\text { com } \\
\text { tuberculose } \\
\text { - Falta de } \\
\text { Falta }\end{array}$ & $\begin{array}{l}\text { - Ser do sexo } \\
\text { masculino } \\
\text { - Estar } \\
\text { desempregad } \\
\text { o }\end{array}$ & $\begin{array}{l}\text { - Se } \\
\text { Considerar } \\
\text { saudável }\end{array}$ & & $\begin{array}{l}\text { - Médicos e } \\
\text { enfermeiros } \\
\text { hostis }\end{array}$ \\
\hline
\end{tabular}




\begin{tabular}{|c|c|c|c|c|c|c|c|c|c|c|c|c|}
\hline \multirow[b]{2}{*}{$\underset{\mathbf{0}}{\mathbf{N}}$} & \multirow[b]{2}{*}{ Ano } & \multirow[b]{2}{*}{ Periódico } & \multirow[b]{2}{*}{ Autores } & \multirow[b]{2}{*}{$\begin{array}{l}\text { País de } \\
\text { Estudo }\end{array}$} & \multirow[b]{2}{*}{$\begin{array}{l}\text { Tipo de } \\
\text { Estudo }\end{array}$} & \multirow[b]{2}{*}{ Enfoque } & \multirow[b]{2}{*}{$\begin{array}{l}\text { População } \\
\text { de Estudo }\end{array}$} & \multicolumn{5}{|c|}{ Dimensões Relacionadas: } \\
\hline & & & & & & & & Paciente & $\begin{array}{c}\text { Sócio- } \\
\text { demografic } \\
\text { a }\end{array}$ & Doença & Tratamento & $\begin{array}{l}\text { Sistemas e } \\
\text { Equipes de } \\
\text { Saúde }\end{array}$ \\
\hline & & & & & & & & $\begin{array}{l}\text { informação } \\
\text { quanto ao } \\
\text { tempo de } \\
\text { tratamento da } \\
\text { tuberculose }\end{array}$ & & & & \\
\hline 2 & $\begin{array}{c}200 \\
8\end{array}$ & $\begin{array}{l}\text { The } \\
\text { International } \\
\text { Journal of } \\
\text { Tuberculosis } \\
\text { and Lung } \\
\text { Disease }\end{array}$ & $\begin{array}{l}\text { Mateus- } \\
\text { Solarte, } \\
\text { Carvajal- } \\
\text { Barona }\end{array}$ & Colômbia & Coorte & Não Adesão & $\begin{array}{c}\text { Doentes de } \\
\text { TB }\end{array}$ & $\begin{array}{l}\text { - Falta de } \\
\text { apoio familiar } \\
\text { - Difícil } \\
\text { relacionament } \\
\text { o familiar } \\
\text { - Não residir } \\
\text { com a família }\end{array}$ & $\begin{array}{l}\text { - Estar } \\
\text { empregado } \\
\text { ou estudando } \\
\text { - Distância } \\
\text { até o serviço } \\
\text { de saúde }\end{array}$ & $\begin{array}{l}\text { - Consumo de } \\
\text { bebida } \\
\text { alcoólica } \\
\text { - Consumo de } \\
\text { drogas }\end{array}$ & & $\begin{array}{l}\text { - Tipo de } \\
\text { cobertura do } \\
\text { serviço de } \\
\text { saúde }\end{array}$ \\
\hline 3 & $\begin{array}{c}200 \\
8\end{array}$ & $\begin{array}{l}\text { Asia-Pacific } \\
\text { Journal of } \\
\text { Public } \\
\text { Health }\end{array}$ & $\begin{array}{c}\text { Janakan, } \\
\text { Seneviratn } \\
\text { e }\end{array}$ & Sri Lanka & Coorte & Não Adesão & $\begin{array}{c}\text { Doentes de } \\
\text { TB }\end{array}$ & $\begin{array}{l}\text { - Viver } \\
\text { sozinho, ou } \\
\text { com família } \\
\text { grande }\end{array}$ & $\begin{array}{l}\text { - Sexo } \\
\text { masculino } \\
\text { - Menor } \\
\text { nível escolar } \\
\text { - Morar em } \\
\text { favelas } \\
\text { - Idosos }\end{array}$ & $\begin{array}{l}\text { - Consumo de } \\
\text { tabaco } \\
\text { - Consumo de } \\
\text { drogas }\end{array}$ & $\begin{array}{l}\text { - Efeito } \\
\text { colateral do } \\
\text { medicament } \\
\text { o }\end{array}$ & \\
\hline \multirow[t]{2}{*}{4} & \multirow[t]{2}{*}{$\begin{array}{c}200 \\
8\end{array}$} & \multirow[t]{2}{*}{$\begin{array}{l}\text { Salud } \\
\text { Pública de } \\
\text { México }\end{array}$} & \multirow[t]{2}{*}{$\begin{array}{l}\text { Reyes- } \\
\text { Guillén et } \\
\text { al. }\end{array}$} & \multirow[t]{2}{*}{ México } & \multirow[t]{2}{*}{$\begin{array}{c}\text { Pesquisa } \\
\text { Qualitativ } \\
\text { a }\end{array}$} & \multirow[t]{2}{*}{ Não Adesão } & $\begin{array}{l}\text { Profissiona } \\
1 \text { de saúde } \\
\text { (médicos e } \\
\text { gestores), } \\
\text { familiares. }\end{array}$ & $\begin{array}{l}\text { - Falta de } \\
\text { compromisso } \\
\text { do doente } \\
\text { com o } \\
\text { tratamento } \\
\text { - Influência } \\
\text { familiar } \\
\text { negativa }\end{array}$ & & & $\begin{array}{l}\text { - Efeito } \\
\text { colateral do } \\
\text { medicament } \\
\text { o }\end{array}$ & $\begin{array}{l}\text { - Relação } \\
\text { médico e } \\
\text { doente } \\
\text { negativa } \\
\text { - Rivalidade } \\
\quad \text { dos } \\
\text { curandeiros } \\
\quad \text { com a } \\
\text { medicina } \\
\text { tradicional }\end{array}$ \\
\hline & & & & & & & $\begin{array}{c}\text { Doentes de } \\
\text { TB }\end{array}$ & $\begin{array}{l}\text { - Não } \\
\text { acreditar na } \\
\text { cura }\end{array}$ & & & $\begin{array}{l}\text { - Tratamento } \\
\text { com longa } \\
\text { duração; } \\
\text { - Efeito } \\
\text { colateral do } \\
\text { medicament } \\
\text { o }\end{array}$ & $\begin{array}{l}\text { - Falta de } \\
\text { informação } \\
\text { por parte da } \\
\text { equipe de } \\
\text { saúde }\end{array}$ \\
\hline 5 & 200 & BMC Public & Sagbakken & Etiópia & Pesquisa & Não Adesão & Doentes de & & - Distância & & & - Falta de \\
\hline
\end{tabular}




\begin{tabular}{|c|c|c|c|c|c|c|c|c|c|c|c|c|}
\hline \multirow[b]{2}{*}{$\underset{\mathbf{o}}{\mathbf{N}}$} & \multirow[b]{2}{*}{ Ano } & \multirow[b]{2}{*}{ Periódico } & \multirow[b]{2}{*}{ Autores } & \multirow[b]{2}{*}{$\begin{array}{l}\text { País de } \\
\text { Estudo }\end{array}$} & \multirow[b]{2}{*}{$\begin{array}{l}\text { Tipo de } \\
\text { Estudo }\end{array}$} & \multirow[b]{2}{*}{ Enfoque } & \multirow[b]{2}{*}{$\begin{array}{l}\text { População } \\
\text { de Estudo }\end{array}$} & \multicolumn{5}{|c|}{ Dimensões Relacionadas: } \\
\hline & & & & & & & & Paciente & $\begin{array}{c}\text { Sócio- } \\
\text { demografic } \\
\text { a }\end{array}$ & Doença & Tratamento & $\begin{array}{l}\text { Sistemas e } \\
\text { Equipes de } \\
\text { Saúde }\end{array}$ \\
\hline & 8 & Health & $\begin{array}{l}\text {, Frich, } \\
\text { Bjune. }\end{array}$ & & $\begin{array}{c}\text { Qualitativ } \\
\text { a }\end{array}$ & & TB & & $\begin{array}{l}\text { até o serviço } \\
\text { de saúde } \\
\text { - Perda do } \\
\text { emprego } \\
\text { - Falta de } \\
\text { dinheiro para } \\
\text { se alimentar }\end{array}$ & & & $\begin{array}{l}\text { flexibilidade } \\
\text { no horário do } \\
\text { tratamento } \\
\text { diretamente } \\
\text { observado } \\
\text { - Descaso } \\
\text { por parte dos } \\
\text { profissionais } \\
\text { de saúde }\end{array}$ \\
\hline \multirow{3}{*}{6} & \multirow{3}{*}{$\begin{array}{c}200 \\
8\end{array}$} & \multirow{3}{*}{$\begin{array}{l}\text { The } \\
\text { International } \\
\text { Journal of } \\
\text { Tuberculosis } \\
\text { and Lung } \\
\text { Disease }\end{array}$} & \multirow{3}{*}{$\begin{array}{l}\text { Martins, } \\
\text { Grace, } \\
\text { Kelly }\end{array}$} & \multirow{3}{*}{$\begin{array}{l}\text { Timor } \\
\text { Leste }\end{array}$} & \multirow{3}{*}{$\begin{array}{c}\text { Pesquisa } \\
\text { Qualitativ } \\
\text { a }\end{array}$} & $\begin{array}{l}\text { Adesão } \\
+\end{array}$ & $\begin{array}{l}\text { Perspectiva } \\
\text { Profissiona } \\
\text { is }\end{array}$ & $\begin{array}{l}\text { - Bom } \\
\text { vínculo com } \\
\text { os } \\
\text { enfermeiros }\end{array}$ & $\begin{array}{l}\text { - Reembolso } \\
\text { do transporte } \\
\text { - } \\
\text { Recebimento } \\
\text { de alimento }\end{array}$ & & $\begin{array}{l}\text { - Melhora } \\
\text { dos sintomas }\end{array}$ & \\
\hline & & & & & & \multirow[t]{2}{*}{ Não Adesão } & $\begin{array}{l}\text { Doentes de } \\
\text { TB }\end{array}$ & & $\begin{array}{l}\text { - Falta de } \\
\text { recurso } \\
\text { financeiro } \\
\text { para ir ao } \\
\text { serviço de } \\
\text { saúde } \\
\text { - Estar } \\
\text { empregado } \\
\text { ou estudando } \\
\text { - Perda de } \\
\text { rendimento; } \\
\text { - Custos com } \\
\text { transporte } \\
\end{array}$ & $\begin{array}{l}\text { - Dificuldade } \\
\text { de andar }\end{array}$ & $\begin{array}{l}\text { - Melhora } \\
\text { dos sintomas }\end{array}$ & $\begin{array}{l}\text { - Longa } \\
\text { espera para } \\
\text { receber } \\
\text { medicamento }\end{array}$ \\
\hline & & & & & & & $\begin{array}{l}\text { Profissiona } \\
\text { is e } \\
\text { membros } \\
\text { da } \\
\text { comunidad } \\
\text { e } \\
\end{array}$ & $\begin{array}{c}\text { - Pouco } \\
\text { conhecimento } \\
\text { sobre a } \\
\text { doença e o } \\
\text { tratamento }\end{array}$ & & & $\begin{array}{l}\text { - Melhora } \\
\text { dos sintomas }\end{array}$ & \\
\hline \multirow[b]{2}{*}{7} & \multirow{2}{*}{$\begin{array}{c}200 \\
8\end{array}$} & \multirow{2}{*}{$\begin{array}{c}\text { BMC } \\
\text { Infectious } \\
\text { Diseases }\end{array}$} & \multirow{2}{*}{$\begin{array}{l}\text { Hasker et } \\
\text { al. }\end{array}$} & \multirow{2}{*}{$\begin{array}{c}\text { Uzbequistã } \\
\text { o }\end{array}$} & \multirow{2}{*}{$\begin{array}{c}\text { Caso } \\
\text { Controle }\end{array}$} & Adesão + & \multirow{2}{*}{$\begin{array}{l}\text { Doentes de } \\
\text { TB } \\
\text { aderentes e } \\
\text { não } \\
\text { aderentes }\end{array}$} & & $\begin{array}{c}\text { - Estar } \\
\text { empregado }\end{array}$ & & & \\
\hline & & & & & & Não Adesão & & & $\begin{array}{l}\text { - } \\
\text { Aposentado } \\
\text { ou }\end{array}$ & $\begin{array}{l}\text { - Consumo de } \\
\text { bebida } \\
\text { alcoólica }\end{array}$ & $\begin{array}{l}\text { - Efeito } \\
\text { colateral do } \\
\text { medicament }\end{array}$ & \\
\hline
\end{tabular}




\begin{tabular}{|c|c|c|c|c|c|c|c|c|c|c|c|c|}
\hline \multirow[b]{2}{*}{$\begin{array}{c}\mathbf{N} \\
\mathbf{0}\end{array}$} & \multirow[b]{2}{*}{ Ano } & \multirow[b]{2}{*}{ Periódico } & \multirow[b]{2}{*}{ Autores } & \multirow[b]{2}{*}{$\begin{array}{l}\text { País de } \\
\text { Estudo }\end{array}$} & \multirow[b]{2}{*}{$\begin{array}{l}\text { Tipo de } \\
\text { Estudo }\end{array}$} & \multirow[b]{2}{*}{ Enfoque } & \multirow[b]{2}{*}{$\begin{array}{l}\text { População } \\
\text { de Estudo }\end{array}$} & \multicolumn{5}{|c|}{ Dimensões Relacionadas: } \\
\hline & & & & & & & & Paciente & $\begin{array}{c}\text { Sócio- } \\
\text { demografic } \\
a\end{array}$ & Doença & Tratamento & $\begin{array}{l}\text { Sistemas e } \\
\text { Equipes de } \\
\text { Saúde }\end{array}$ \\
\hline & & & & & & & & & $\begin{array}{l}\text { desempregad } \\
\text { o } \\
\text { - Sem } \\
\text { moradia }\end{array}$ & & $\begin{array}{l}\text { o } \\
\text { - Doente não } \\
\text { aceitar } \\
\text { tratamento } \\
\text { nas } \\
\text { condições } \\
\text { oferecidas }\end{array}$ & \\
\hline & & & & & & & $\begin{array}{l}\text { Profissiona } \\
1 \text { de Saúde }\end{array}$ & $\begin{array}{l}\text { - Estigma } \\
\text { (medo de } \\
\text { perder o } \\
\text { emprego). }\end{array}$ & & & $\begin{array}{l}\text { - Efeito } \\
\text { colateral do } \\
\text { medicament } \\
\text { o } \\
\text { - Longa } \\
\text { duração do } \\
\text { tratamento }\end{array}$ & \\
\hline 8 & $\begin{array}{c}200 \\
9\end{array}$ & $\begin{array}{l}\text { BMC Health } \\
\text { Services } \\
\text { Research }\end{array}$ & Xu et al. & China & $\begin{array}{c}\text { Transvers } \\
\text { al }\end{array}$ & Não Adesão & $\begin{array}{c}\text { Doentes de } \\
\text { TB }\end{array}$ & & $\begin{array}{c}\text { - Custos com } \\
\text { medicament } \\
\text { o (gratuito } \\
\text { tem efeito } \\
\text { colateral) } \\
\text { - Falta de } \\
\text { recurso } \\
\text { financeiro } \\
\text { para manter } \\
\text { o tratamento } \\
\text { - Ser } \\
\text { analfabeto } \\
\text { - Divorciado } \\
\text { ou viúvo; } \\
\text { - Não ter } \\
\text { seguro } \\
\text { saúde; } \\
\text { - Migrante; } \\
\text { - Despesas } \\
\text { médicas }\end{array}$ & $\begin{array}{c}\text { - Consumo de } \\
\text { drogas; } \\
\text { - Apresentar } \\
\text { outros } \\
\text { distúrbios; }\end{array}$ & $\begin{array}{c}\text { - Efeito } \\
\text { colateral do } \\
\text { medicament } \\
\text { o } \\
\text { - Melhora } \\
\text { dos } \\
\text { sintomas; } \\
\text { - Longa } \\
\text { duração do } \\
\text { tratamento } \\
\text { - Muitos } \\
\text { medicament } \\
\text { os }\end{array}$ & \\
\hline 9 & $\begin{array}{c}200 \\
9\end{array}$ & $\begin{array}{l}\text { African } \\
\text { Health } \\
\text { Sciences }\end{array}$ & $\begin{array}{c}\text { Amuha et } \\
\text { al. }\end{array}$ & Uganda & $\begin{array}{c}\text { Transvers } \\
\text { al }\end{array}$ & Não Adesão & $\begin{array}{l}\text { Doentes de } \\
\text { TB/HIV }\end{array}$ & $\begin{array}{c}\text { - Falta de } \\
\text { conhecimento } \\
\text { de como a } \\
\text { tuberculose é }\end{array}$ & & $\begin{array}{c}\text { - Consumo de } \\
\text { bebida } \\
\text { alcoólica; }\end{array}$ & $\begin{array}{c}\text { - Fase de } \\
\text { manutenção } \\
\text { do } \\
\text { tratamento } \\
\end{array}$ & \\
\hline
\end{tabular}




\begin{tabular}{|c|c|c|c|c|c|c|c|c|c|c|c|c|}
\hline \multirow[b]{2}{*}{$\begin{array}{c}\mathbf{N} \\
\mathbf{0}\end{array}$} & \multirow[b]{2}{*}{ Ano } & \multirow[b]{2}{*}{ Periódico } & \multirow[b]{2}{*}{ Autores } & \multirow[b]{2}{*}{$\begin{array}{l}\text { País de } \\
\text { Estudo }\end{array}$} & \multirow[b]{2}{*}{$\begin{array}{l}\text { Tipo de } \\
\text { Estudo }\end{array}$} & \multirow[b]{2}{*}{ Enfoque } & \multirow[b]{2}{*}{$\begin{array}{l}\text { População } \\
\text { de Estudo }\end{array}$} & \multicolumn{5}{|c|}{ Dimensões Relacionadas: } \\
\hline & & & & & & & & Paciente & $\begin{array}{c}\text { Sócio- } \\
\text { demografic } \\
\text { a }\end{array}$ & Doença & Tratamento & $\begin{array}{l}\text { Sistemas e } \\
\text { Equipes de } \\
\text { Saúde }\end{array}$ \\
\hline & & & & & & & & transmitida & & & $\begin{array}{c}\mathrm{da} \\
\text { tuberculose } \\
\text { - Melhora } \\
\text { dos sintomas } \\
\text { - Quantidade } \\
\text { de } \\
\text { medicament } \\
\text { o } \\
\text { - Efeito } \\
\text { colateral do } \\
\text { medicament } \\
\text { o } \\
\end{array}$ & \\
\hline \multirow[t]{2}{*}{10} & \multirow[t]{2}{*}{$\begin{array}{c}200 \\
9\end{array}$} & \multirow[t]{2}{*}{$\begin{array}{c}\text { Health } \\
\text { Policy and } \\
\text { Planning }\end{array}$} & \multirow[t]{2}{*}{$\begin{array}{l}\text { Mesfin et } \\
\text { al. }\end{array}$} & \multirow[t]{2}{*}{ Etiópia } & \multirow[t]{2}{*}{$\begin{array}{c}\text { Transvers } \\
\text { al }\end{array}$} & Adesão + & \multirow[t]{2}{*}{$\begin{array}{c}\text { Doentes de } \\
\text { TB }\end{array}$} & & & & & $\begin{array}{l}\text { - Presença de } \\
\text { profissionais } \\
\text { de saúde } \\
\text { treinados } \\
\text { - Realização } \\
\quad \text { do } \\
\text { tratamento } \\
\text { em clínicas } \\
\text { próprias para } \\
\text { o tratamento } \\
\text { da } \\
\text { tuberculose } \\
\text { - Não } \\
\text { receber } \\
\text { tratamento } \\
\text { diretamente } \\
\text { observado }\end{array}$ \\
\hline & & & & & & Não Adesão & & & & $\begin{array}{l}\text { - Apresentar } \\
\text { vômito } \\
\text { durante o } \\
\text { tratamento }\end{array}$ & & $\begin{array}{c}\text { - Não ter a } \\
\text { presença de } \\
\text { um } \\
\text { profissional } \\
\text { treinado para } \\
\text { alertar sobre } \\
\text { o efeito } \\
\text { colateral dos } \\
\text { medicamento }\end{array}$ \\
\hline
\end{tabular}




\begin{tabular}{|c|c|c|c|c|c|c|c|c|c|c|c|c|}
\hline \multirow[b]{2}{*}{$\underset{\mathbf{0}}{\mathbf{N}}$} & \multirow[b]{2}{*}{ Ano } & \multirow[b]{2}{*}{ Periódico } & \multirow[b]{2}{*}{ Autores } & \multirow[b]{2}{*}{$\begin{array}{l}\text { País de } \\
\text { Estudo }\end{array}$} & \multirow[b]{2}{*}{$\begin{array}{l}\text { Tipo de } \\
\text { Estudo }\end{array}$} & \multirow[b]{2}{*}{ Enfoque } & \multirow[b]{2}{*}{$\begin{array}{l}\text { População } \\
\text { de Estudo }\end{array}$} & \multicolumn{5}{|c|}{ Dimensões Relacionadas: } \\
\hline & & & & & & & & Paciente & $\begin{array}{c}\text { Sócio- } \\
\text { demografic } \\
\text { a }\end{array}$ & Doença & Tratamento & $\begin{array}{c}\text { Sistemas e } \\
\text { Equipes de } \\
\text { Saúde }\end{array}$ \\
\hline & & & & & & & & & & & & $\mathrm{s}$ \\
\hline \multirow[b]{2}{*}{11} & \multirow[b]{2}{*}{$\begin{array}{c}200 \\
9\end{array}$} & \multirow[b]{2}{*}{$\begin{array}{l}\text { Qualitative } \\
\text { Health } \\
\text { Research }\end{array}$} & \multirow[b]{2}{*}{$\begin{array}{l}\text { Naidoo, } \\
\text { Dick, } \\
\text { Cooper }\end{array}$} & \multirow[b]{2}{*}{$\begin{array}{c}\text { África do } \\
\text { Sul }\end{array}$} & \multirow[b]{2}{*}{$\begin{array}{c}\text { Pesquisa } \\
\text { Qualitativ } \\
\text { a }\end{array}$} & Adesão + & \multirow[b]{2}{*}{$\begin{array}{c}\text { Doentes de } \\
\text { TB }\end{array}$} & $\begin{array}{l}\text { - Conhecer } \\
\text { alguém que } \\
\text { se recuperou } \\
\text { da doença. }\end{array}$ & $\begin{array}{c}\text { - Falta de } \\
\text { recursos } \\
\text { financeiros } \\
\text { para } \\
\text { alimentação }\end{array}$ & $\begin{array}{l}\text {-Reinfecção } \\
\text { por } \\
\text { tuberculose }\end{array}$ & $\begin{array}{l}\text { - Melhora } \\
\text { dos sintomas }\end{array}$ & \\
\hline & & & & & & Não Adesão & & $\begin{array}{l}\text { - Estigma; } \\
\text { - Sentimento } \\
\text { de impotência } \\
\text { diante do } \\
\text { preconceito; } \\
\text { - } \\
\text { Possibilidade } \\
\text { de descobrir } \\
\text { que tem HIV } \\
\text { ("pois muitos } \\
\text { doentes com } \\
\text { tuberculose } \\
\text { têm HIV") }\end{array}$ & $\begin{array}{l}\text { - Estar } \\
\text { empregado } \\
\text { ou } \\
\text { estudando. }\end{array}$ & & $\begin{array}{l}\text { - Uso de } \\
\text { medicament } \\
\text { os a base de } \\
\text { plantas; } \\
\text { - Melhora } \\
\text { dos sintomas }\end{array}$ & $\begin{array}{l}\text { - Tratamento } \\
\text { com } \\
\text { curandeiros }\end{array}$ \\
\hline \multirow[t]{2}{*}{$\begin{array}{l}1 \\
2\end{array}$} & \multirow[t]{2}{*}{$\begin{array}{c}200 \\
9\end{array}$} & \multirow[t]{2}{*}{$\begin{array}{l}\text { BMC Health } \\
\text { Services } \\
\text { Research }\end{array}$} & \multirow[t]{2}{*}{ Yao et al. } & \multirow[t]{2}{*}{ China } & \multirow[t]{2}{*}{$\begin{array}{c}\text { Transvers } \\
\text { al }\end{array}$} & \multirow[t]{2}{*}{ Não Adesão } & $\begin{array}{l}\text { Profissiona } \\
\text { l de saúde } \\
\text { (médicos) e } \\
\text { gestores. }\end{array}$ & $\begin{array}{l}\text { - Atenção } \\
\text { insuficiente } \\
\text { aos sintomas } \\
\text { de } \\
\text { tuberculose }\end{array}$ & $\begin{array}{l}\text { - Dificuldade } \\
\text { com trafego } \\
\text { - Distância } \\
\text { até o serviço } \\
\text { de saúde } \\
\text { - Trabalho } \\
\text { migrante } \\
\text { - } \\
\text { Dificuldades } \\
\text { financeiras } \\
\text { relacionadas } \\
\text { ao } \\
\text { tratamento } \\
\text { da } \\
\text { tuberculose }\end{array}$ & & $\begin{array}{l}\text { - Efeito } \\
\text { colateral do } \\
\text { medicament } \\
\text { o } \\
\text { - Longa } \\
\text { duração do } \\
\text { tratamento }\end{array}$ & $\begin{array}{l}\text { - Campanhas } \\
\text { insuficientes } \\
\text { sobre } \\
\text { tuberculose }\end{array}$ \\
\hline & & & & & & & Doentes de & - Não ter & - Não ter & & - Efeitos & - Observação \\
\hline
\end{tabular}




\begin{tabular}{|c|c|c|c|c|c|c|c|c|c|c|c|c|}
\hline \multirow[b]{2}{*}{$\begin{array}{c}\mathbf{N} \\
\mathbf{0}\end{array}$} & \multirow[b]{2}{*}{ Ano } & \multirow[b]{2}{*}{ Periódico } & \multirow[b]{2}{*}{ Autores } & \multirow[b]{2}{*}{$\begin{array}{l}\text { País de } \\
\text { Estudo }\end{array}$} & \multirow[b]{2}{*}{$\begin{array}{l}\text { Tipo de } \\
\text { Estudo }\end{array}$} & \multirow[b]{2}{*}{ Enfoque } & \multirow[b]{2}{*}{$\begin{array}{l}\text { População } \\
\text { de Estudo }\end{array}$} & \multicolumn{5}{|c|}{ Dimensões Relacionadas: } \\
\hline & & & & & & & & Paciente & $\begin{array}{c}\text { Sócio- } \\
\text { demografic } \\
\text { a } \\
\end{array}$ & Doença & Tratamento & $\begin{array}{l}\text { Sistemas e } \\
\text { Equipes de } \\
\text { Saúde }\end{array}$ \\
\hline & & & & & & & TB & $\begin{array}{l}\text { supervisão } \\
\text { do } \\
\text { medicament } \\
\text { o por } \\
\text { profissionai } \\
\text { s }\end{array}$ & $\begin{array}{l}\text { educação } \\
\text { formal }\end{array}$ & & $\begin{array}{l}\text { colaterais } \\
\text { dos } \\
\text { medicament } \\
\text { os }\end{array}$ & $\begin{array}{l}\text { da dose por } \\
\text { voluntários } \\
\text { - Não ter } \\
\text { supervisão } \\
\text { do } \\
\text { medicamento } \\
\text { por } \\
\text { - Tratamento } \\
\text { diretamente } \\
\text { observado } \\
\text { fora do } \\
\text { domicílio }\end{array}$ \\
\hline 13 & $\begin{array}{c}201 \\
0\end{array}$ & $\begin{array}{l}\text { International } \\
\text { Journal of } \\
\text { Preventive } \\
\text { Medicine }\end{array}$ & $\begin{array}{c}\text { Bagchi, } \\
\text { Ambe, } \\
\text { Sathiakum } \\
\text { a }\end{array}$ & Índia & $\begin{array}{c}\text { Transvers } \\
\text { al }\end{array}$ & Não Adesão & $\begin{array}{c}\text { Doentes de } \\
\text { TB } \\
\text { aderentes e } \\
\text { não } \\
\text { aderentes }\end{array}$ & $\begin{array}{l}\text { - Esconder } \\
\text { que é doente; } \\
\text { - Morar com } \\
\text { família } \\
\text { grande }\end{array}$ & $\begin{array}{l}\text { - Gastos para } \\
\text { ir ao serviço } \\
\text { de saúde; } \\
\text { - Longa } \\
\text { distância até } \\
\text { o serviço de } \\
\text { saúde } \\
\text { - Perder } \\
\text { tempo de } \\
\text { trabalho }\end{array}$ & $\begin{array}{l}\text { - Consumo de } \\
\text { tabaco } \\
\text { - Consumo de } \\
\text { bebida } \\
\text { alcoólica }\end{array}$ & $\begin{array}{l}\text { - Tratamento } \\
\text { longo } \\
\text { - Melhora } \\
\text { dos sintomas }\end{array}$ & \\
\hline 14 & $\begin{array}{c}201 \\
0\end{array}$ & $\begin{array}{c}\text { The } \\
\text { International } \\
\text { Journal of } \\
\text { Tuberculosis } \\
\text { and Lung } \\
\text { Disease }\end{array}$ & $\begin{array}{l}\text { Kliiman, } \\
\text { Altraja }\end{array}$ & Estônia & Coorte & Não Adesão & $\begin{array}{c}\text { Doentes de } \\
\text { TB }\end{array}$ & $\begin{array}{l}\text { - Ser } \\
\text { presidiário }\end{array}$ & $\begin{array}{l}\text { - Estar } \\
\text { desempregad } \\
\text { o } \\
\text { - Viver em } \\
\text { áreas } \\
\text { urbanas } \\
\text { - Ser } \\
\text { morador de } \\
\text { rua. }\end{array}$ & $\begin{array}{l}\text { - Consumo de } \\
\text { bebida } \\
\text { alcoólica } \\
\text { - Apresentar } \\
\text { tuberculose } \\
\text { multirresisten } \\
\text { te (devido ao } \\
\text { maior tempo } \\
\text { de } \\
\text { tratamento) }\end{array}$ & & \\
\hline 15 & $\begin{array}{c}201 \\
0\end{array}$ & $\begin{array}{c}\text { Rev Esc } \\
\text { Enferm USP }\end{array}$ & $\begin{array}{l}\text { Rodrigues } \\
\text { et al. }\end{array}$ & Brasil & $\begin{array}{c}\text { Pesquisa } \\
\text { Qualitativ } \\
\text { a }\end{array}$ & $\begin{array}{l}\text { Não Adesão } \\
\text { (pacientes com } \\
\text { coinfecção } \\
\text { tuberculose/HI } \\
\text { V) }\end{array}$ & $\begin{array}{c}\text { Profissiona } \\
\text { 1 de saúde } \\
\text { (Assistente } \\
\text { social, } \\
\text { enfermeiro, }\end{array}$ & & $\begin{array}{l}\text { - Baixa } \\
\text { condição } \\
\text { social e } \\
\text { econômica }\end{array}$ & $\begin{array}{l}\text { - Pacientes } \\
\text { com } \\
\text { coinfecção } \\
\text { - Consumo de } \\
\text { drogas }\end{array}$ & $\begin{array}{l}\text { - Efeito } \\
\text { colateral do } \\
\text { medicament } \\
\text { o da } \\
\text { tuberculose }\end{array}$ & $\begin{array}{l}\text { - Pouca } \\
\text { informação } \\
\text { por parte dos } \\
\text { profissionais } \\
\text { para os }\end{array}$ \\
\hline
\end{tabular}




\begin{tabular}{|c|c|c|c|c|c|c|c|c|c|c|c|c|}
\hline \multirow[b]{2}{*}{$\begin{array}{c}\mathbf{N} \\
\mathbf{0}\end{array}$} & \multirow[b]{2}{*}{ Ano } & \multirow[b]{2}{*}{ Periódico } & \multirow[b]{2}{*}{ Autores } & \multirow[b]{2}{*}{$\begin{array}{l}\text { País de } \\
\text { Estudo }\end{array}$} & \multirow[b]{2}{*}{$\begin{array}{l}\text { Tipo de } \\
\text { Estudo }\end{array}$} & \multirow[b]{2}{*}{ Enfoque } & \multirow[b]{2}{*}{$\begin{array}{l}\text { População } \\
\text { de Estudo }\end{array}$} & \multicolumn{5}{|c|}{ Dimensões Relacionadas: } \\
\hline & & & & & & & & Paciente & $\begin{array}{c}\text { Sócio- } \\
\text { demografic } \\
\text { a }\end{array}$ & Doença & Tratamento & $\begin{array}{l}\text { Sistemas e } \\
\text { Equipes de } \\
\text { Saúde }\end{array}$ \\
\hline & & & & & & & $\begin{array}{l}\text { médico, } \\
\text { psicólogo. }\end{array}$ & & & $\begin{array}{l}\text { - Presença de } \\
\text { HIV-aids }\end{array}$ & & $\begin{array}{l}\text { pacientes } \\
\text { sobre o } \\
\text { tratamento } \\
\text { da } \\
\text { tuberculose } \\
\text { - Estrutura } \\
\text { física do } \\
\text { serviço de } \\
\text { saúde não } \\
\text { garante a } \\
\text { privacidade } \\
\text { do paciente } \\
\text { - Ausência } \\
\text { de trabalho } \\
\text { em equipe } \\
\text { - Dificuldade } \\
\text { de acesso aos } \\
\text { serviços de } \\
\text { saúde }\end{array}$ \\
\hline 16 & $\begin{array}{c}201 \\
0\end{array}$ & $\begin{array}{c}\text { Rev Esc } \\
\text { Enferm USP }\end{array}$ & $\begin{array}{c}\text { Souza et } \\
\text { al. }\end{array}$ & Brasil & $\begin{array}{c}\text { Pesquisa } \\
\text { Qualitativ } \\
\text { a }\end{array}$ & Não Adesão & $\begin{array}{c}\text { Doentes de } \\
\text { TB }\end{array}$ & $\begin{array}{l}\text { - Falta de } \\
\text { vínculo com } \\
\text { os } \\
\text { profissionais } \\
\text { de saúde } \\
\text { - Falta de } \\
\text { informação } \\
\text { sobre os } \\
\text { resultados de } \\
\text { exames } \\
\text { - Descaso da } \\
\text { equipe de } \\
\text { saúde } \\
\text { - Falta de } \\
\text { informação } \\
\text { da } \\
\text { confirmação } \\
\text { da doença } \\
\text { - Melhora dos }\end{array}$ & & & & \\
\hline
\end{tabular}




\begin{tabular}{|c|c|c|c|c|c|c|c|c|c|c|c|c|}
\hline \multirow[b]{2}{*}{$\begin{array}{c}\mathbf{N} \\
\mathbf{0}\end{array}$} & \multirow[b]{2}{*}{ Ano } & \multirow[b]{2}{*}{ Periódico } & \multirow[b]{2}{*}{ Autores } & \multirow[b]{2}{*}{$\begin{array}{l}\text { País de } \\
\text { Estudo }\end{array}$} & \multirow[b]{2}{*}{$\begin{array}{l}\text { Tipo de } \\
\text { Estudo }\end{array}$} & \multirow[b]{2}{*}{ Enfoque } & \multirow[b]{2}{*}{$\begin{array}{l}\text { População } \\
\text { de Estudo }\end{array}$} & \multicolumn{5}{|c|}{ Dimensões Relacionadas: } \\
\hline & & & & & & & & Paciente & $\begin{array}{c}\text { Sócio- } \\
\text { demografic } \\
\text { a }\end{array}$ & Doença & Tratamento & $\begin{array}{l}\text { Sistemas e } \\
\text { Equipes de } \\
\text { Saúde }\end{array}$ \\
\hline & & & & & & & & sintomas & & & & \\
\hline 17 & $\begin{array}{c}201 \\
0\end{array}$ & $\begin{array}{c}\text { Scandinavian } \\
\text { Journal of } \\
\text { Infectious } \\
\text { Diseases }\end{array}$ & $\begin{array}{c}\text { Abuaku et } \\
\text { al. }\end{array}$ & China & $\begin{array}{c}\text { Transvers } \\
\text { al }\end{array}$ & Não Adesão & $\begin{array}{c}\text { Doentes de } \\
\text { TB }\end{array}$ & $\begin{array}{l}\text { - Sexo } \\
\text { Masculino } \\
\text { - Acima de } \\
65 \text { anos de } \\
\text { idade } \\
\text { - Viver em } \\
\text { áreas urbanas }\end{array}$ & & & $\begin{array}{l}\text { - } \\
\text { Retratament } \\
\text { o }\end{array}$ & \\
\hline & & & & & & Adesão + & & $\begin{array}{l}\text { - Ter a equipe } \\
\text { de saúde } \\
\text { próxima }\end{array}$ & & & $\begin{array}{l}\text { - Melhora } \\
\text { nos sintomas }\end{array}$ & \\
\hline 18 & $\begin{array}{c}201 \\
0\end{array}$ & $\begin{array}{l}\text { Saúde e } \\
\text { Sociedade }\end{array}$ & $\begin{array}{l}\text { Queiroz, } \\
\text { Nogueira }\end{array}$ & Brasil & $\begin{array}{c}\text { Pesquisa } \\
\text { Qualitativ } \\
\text { a }\end{array}$ & Não Adesão & $\begin{array}{c}\text { Doentes de } \\
\text { TB }\end{array}$ & $\begin{array}{l}\text { - Início do } \\
\text { tratamento } \\
\text { recebeu } \\
\text { algum } \\
\text { incentivo e } \\
\text { depois foi } \\
\text { cortado } \\
\text { - "Depressão, } \\
\text { desânimo, } \\
\text { cansaço", } \\
\text { quanto ao } \\
\text { diagnóstico } \\
\text { da } \\
\text { tuberculose }\end{array}$ & & & $\begin{array}{l}\text {-Diagnóstico } \\
\text { inicial } \\
\text { incorreto } \\
\text { (pneumonia, } \\
\text { sinusite, } \\
\text { bronquite, } \\
\text { etc) } \\
\text { - Efeito } \\
\text { colateral do } \\
\text { medicament } \\
\text { o }\end{array}$ & \\
\hline \multirow[b]{2}{*}{19} & \multirow{2}{*}{$\begin{array}{c}201 \\
0\end{array}$} & \multirow{2}{*}{$\begin{array}{c}\text { The } \\
\text { International } \\
\text { Journal of } \\
\text { Tuberculosis } \\
\text { and Lung } \\
\text { Disease }\end{array}$} & \multirow{2}{*}{$\begin{array}{l}\text { Cegolon et } \\
\text { al. }\end{array}$} & \multirow{2}{*}{ Inglaterra } & \multirow{2}{*}{$\begin{array}{c}\text { Transvers } \\
\text { al }\end{array}$} & Adesão + & \multirow{2}{*}{$\begin{array}{c}\text { Doentes de } \\
\text { TB }\end{array}$} & & - & & $\begin{array}{l}\text { - Não estar } \\
\text { hospitalizad } \\
\text { o com idade } \\
\text { entre } 45 \text { e } 64 \\
\text { anos }\end{array}$ & \\
\hline & & & & & & Não Adesão & & & $\begin{array}{l}\text { - Sexo } \\
\text { masculino } \\
\text { - Imigrantes }\end{array}$ & & $\begin{array}{l}- \\
\text { Retratament } \\
\text { o } \\
\text { - Estar } \\
\text { hospitalizad } \\
\text { o com idade }\end{array}$ & \\
\hline
\end{tabular}




\begin{tabular}{|c|c|c|c|c|c|c|c|c|c|c|c|c|}
\hline \multirow[b]{2}{*}{$\begin{array}{c}\mathbf{N} \\
\mathbf{0}\end{array}$} & \multirow[b]{2}{*}{ Ano } & \multirow[b]{2}{*}{ Periódico } & \multirow[b]{2}{*}{ Autores } & \multirow[b]{2}{*}{$\begin{array}{l}\text { País de } \\
\text { Estudo }\end{array}$} & \multirow[b]{2}{*}{$\begin{array}{l}\text { Tipo de } \\
\text { Estudo }\end{array}$} & \multirow[b]{2}{*}{ Enfoque } & \multirow[b]{2}{*}{$\begin{array}{l}\text { População } \\
\text { de Estudo }\end{array}$} & \multicolumn{5}{|c|}{ Dimensões Relacionadas: } \\
\hline & & & & & & & & Paciente & $\begin{array}{c}\text { Sócio- } \\
\text { demografic } \\
\text { a }\end{array}$ & Doença & Tratamento & $\begin{array}{l}\text { Sistemas e } \\
\text { Equipes de } \\
\text { Saúde }\end{array}$ \\
\hline & & & & & & & & & & & $\begin{array}{l}\text { maior que } 65 \\
\text { anos }\end{array}$ & \\
\hline 20 & $\begin{array}{c}201 \\
1\end{array}$ & $\begin{array}{c}\text { Revista } \\
\text { Brasileira de } \\
\text { Epidemiolog } \\
\text { ia }\end{array}$ & $\begin{array}{l}\text { Heck, } \\
\text { Costa, } \\
\text { Nunes }\end{array}$ & Brasil & $\begin{array}{c}\text { Transvers } \\
\text { al }\end{array}$ & Não Adesão & $\begin{array}{c}\text { Doentes de } \\
\text { TB }\end{array}$ & & $\begin{array}{l}\text { - Sexo } \\
\text { masculino } \\
\text { - Idade entre } \\
20-29 \text { e } 30- \\
39 \text { anos } \\
\end{array}$ & - Aids & $\begin{array}{l}- \\
\text { Retratament } \\
\text { o }\end{array}$ & \\
\hline 21 & $\begin{array}{c}201 \\
1\end{array}$ & $\begin{array}{c}\text { BMC Public } \\
\text { Health }\end{array}$ & Ayisi et al. & Quênia & $\begin{array}{c}\text { Pesquisa } \\
\text { Qualitativ } \\
\text { a }\end{array}$ & Não Adesão & $\begin{array}{c}\text { Doentes de } \\
\text { TB }\end{array}$ & $\begin{array}{l}\text { - Falta de } \\
\text { apoio familiar } \\
\text { - Falta de } \\
\text { comunicação } \\
\text { com os } \\
\text { profissionais } \\
\text { - Falta de } \\
\text { compromisso } \\
\text { do doente } \\
\text { com o próprio } \\
\text { tratamento } \\
\text { - Descoberta } \\
\text { de que o } \\
\text { tratamento é } \\
\text { extenso }\end{array}$ & & & $\begin{array}{l}\text { - Efeito } \\
\text { colateral dos } \\
\text { medicament } \\
\text { os pela fome } \\
\text { crônica } \\
\text { - Melhora } \\
\text { dos sintomas }\end{array}$ & $\begin{array}{l}- \\
\text { Medicament } \\
\text { os não são } \\
\text { entregues } \\
\text { com } \\
\text { antecedência } \\
\text { - Falta de } \\
\text { informação } \\
\text { quanto ao } \\
\text { tempo de } \\
\text { tratamento } \\
\text { da } \\
\text { tuberculose }\end{array}$ \\
\hline 22 & $\begin{array}{c}201 \\
1\end{array}$ & $\begin{array}{l}\text { BMC Public } \\
\text { Health }\end{array}$ & $\begin{array}{l}\text { Muture et } \\
\text { al. }\end{array}$ & Quênia & $\begin{array}{c}\text { Caso } \\
\text { Controle }\end{array}$ & Não Adesão & $\begin{array}{c}\text { Doentes de } \\
\text { TB } \\
\text { aderentes e } \\
\text { não } \\
\text { aderentes }\end{array}$ & $\begin{array}{l}\text { - Falta de } \\
\text { conhecimento } \\
\text { sobre } \\
\text { tuberculose } \\
\text { - Faltar de } \\
\text { compromisso } \\
\text { s agendados } \\
\text { para receber o } \\
\text { tratamento } \\
\text { - Não receber } \\
\text { informação } \\
\text { sobre } \\
\text { tuberculose } \\
- \\
\text { Profissionais } \\
\end{array}$ & $\begin{array}{l}\text { - Viajar para } \\
\text { receber o } \\
\text { tratamento }\end{array}$ & & $\begin{array}{l}\text { - Efeito } \\
\text { colateral dos } \\
\text { medicament } \\
\text { os }\end{array}$ & $\begin{array}{l}\text { - Falta de } \\
\text { medicamento } \\
\text { - Acesso } \\
\text { limitado aos } \\
\text { serviços } \\
\text { - Longa } \\
\text { espera para } \\
\text { receber } \\
\text { tratamento }\end{array}$ \\
\hline
\end{tabular}




\begin{tabular}{|c|c|c|c|c|c|c|c|c|c|c|c|c|}
\hline \multirow[b]{2}{*}{$\begin{array}{c}\mathbf{N} \\
\mathbf{0}\end{array}$} & \multirow[b]{2}{*}{ Ano } & \multirow[b]{2}{*}{ Periódico } & \multirow[b]{2}{*}{ Autores } & \multirow[b]{2}{*}{$\begin{array}{l}\text { País de } \\
\text { Estudo }\end{array}$} & \multirow[b]{2}{*}{$\begin{array}{l}\text { Tipo de } \\
\text { Estudo }\end{array}$} & \multirow[b]{2}{*}{ Enfoque } & \multirow[b]{2}{*}{$\begin{array}{r}\text { População } \\
\text { de Estudo }\end{array}$} & \multicolumn{5}{|c|}{ Dimensões Relacionadas: } \\
\hline & & & & & & & & Paciente & $\begin{array}{c}\text { Sócio- } \\
\text { demografic } \\
\mathbf{a}\end{array}$ & Doença & Tratamento & $\begin{array}{l}\text { Sistemas e } \\
\text { Equipes de } \\
\text { Saúde }\end{array}$ \\
\hline & & & & & & & & $\begin{array}{l}\text { hostis, } \\
\text { antipáticos } \\
\text { - Falta de } \\
\text { dignidade }\end{array}$ & & & & \\
\hline 23 & $\begin{array}{c}201 \\
1\end{array}$ & $\begin{array}{c}\text { Jornal } \\
\text { Brasileiro de } \\
\text { Pneumologia }\end{array}$ & $\begin{array}{l}\text { Campani, } \\
\text { Moreira, } \\
\text { Tietbohel }\end{array}$ & Brasil & $\begin{array}{c}\text { Caso } \\
\text { Controle }\end{array}$ & Não Adesão & $\begin{array}{c}\text { Doentes de } \\
\text { TB } \\
\text { aderentes e } \\
\text { não } \\
\text { aderentes }\end{array}$ & $\begin{array}{l}\text { - Não residir } \\
\text { com } \\
\text { familiares }\end{array}$ & $\begin{array}{l}\text { - Ser mais } \\
\text { jovem } \\
\text { - Não } \\
\text { brancos } \\
\text { - Menor } \\
\text { escolaridade } \\
\text { ( } 7 \text { anos ou } \\
\text { menos) }\end{array}$ & $\begin{array}{l}\text { - Consumo de } \\
\text { drogas } \\
\text { - Consumo de } \\
\text { bebida } \\
\text { alcoólica } \\
\text { - Infecção } \\
\text { pelo HIV }\end{array}$ & & \\
\hline 24 & $\begin{array}{c}201 \\
2\end{array}$ & $\begin{array}{c}\text { Revista } \\
\text { Clinica } \\
\text { Espanola }\end{array}$ & $\begin{array}{c}\text { Molina } \\
\text { Rueda et } \\
\text { al. }\end{array}$ & Espanha & Coorte & Não Adesão & $\begin{array}{c}\text { Doentes de } \\
\text { TB }\end{array}$ & & $\begin{array}{l}\text { - Sexo } \\
\text { masculino } \\
\text { - Estrangeiro }\end{array}$ & $\begin{array}{l}\text { - Tuberculose } \\
\text { extrapulmona } \\
\mathrm{r}\end{array}$ & & \\
\hline 25 & $\begin{array}{c}201 \\
2\end{array}$ & $\begin{array}{c}\text { The } \\
\text { International } \\
\text { Journal of } \\
\text { Tuberculosis } \\
\text { and Lung } \\
\text { Disease }\end{array}$ & Marx et al. & $\begin{array}{l}\text { África do } \\
\quad \text { Sul }\end{array}$ & Coorte & Não Adesão & $\begin{array}{c}\text { Doentes de } \\
\text { TB }\end{array}$ & & $\begin{array}{l}\text { - Sexo } \\
\text { masculino } \\
\text { - Idade } \\
\text { adulta }\end{array}$ & & $\begin{array}{l}- \\
\text { Retratament } \\
\text { o }\end{array}$ & \\
\hline 26 & $\begin{array}{c}201 \\
2\end{array}$ & $\begin{array}{c}\text { Texto \& } \\
\text { Contexto- } \\
\text { Enfermagem }\end{array}$ & $\begin{array}{l}\text { Wendling, } \\
\text { Modena, } \\
\text { Schall }\end{array}$ & Brasil & $\begin{array}{c}\text { Pesquisa } \\
\text { Qualitativ } \\
\text { a }\end{array}$ & Não Adesão & Gestores & $\begin{array}{l}\text { - Doente que } \\
\text { foi preso com } \\
\text { outro nome } \\
\text { - Negação de } \\
\text { que está } \\
\text { doente }\end{array}$ & $\begin{array}{l}\text { - Doente que } \\
\text { saiu de casa } \\
\text { e virou } \\
\text { morador de } \\
\text { rua } \\
\text { - Falta de } \\
\text { estrutura } \\
\text { familiar }\end{array}$ & $\begin{array}{l}\text { - Consumo de } \\
\text { bebida } \\
\text { alcoólica } \\
\text { - Consumo de } \\
\text { droga }\end{array}$ & $\begin{array}{l}\text { - Efeitos } \\
\text { colateriais } \\
\text { do } \\
\text { medicament } \\
\text { o } \\
\text { - Melhora } \\
\text { dos sintomas } \\
\text { - Resistência } \\
\text { ao } \\
\text { medicament } \\
\text { o }\end{array}$ & \\
\hline 27 & $\begin{array}{c}201 \\
2\end{array}$ & $\begin{array}{c}\text { North } \\
\text { American } \\
\text { Journal of } \\
\text { Medical } \\
\text { Sciences }\end{array}$ & $\begin{array}{l}\text { Kebede, } \\
\text { Wabe }\end{array}$ & Etiópia & $\begin{array}{c}\text { Transvers } \\
\text { al }\end{array}$ & $\begin{array}{c}\text { Adesão } \\
\text { (pacientes com } \\
\text { coinfecção } \\
\text { tuberculose/HI } \\
\text { V) }\end{array}$ & $\begin{array}{c}\text { Doentes de } \\
\text { TB/HIV }\end{array}$ & $\begin{array}{l}\text { - Bom } \\
\text { relacionament } \\
\text { o com médico }\end{array}$ & $\begin{array}{l}\text { - Bom nível } \\
\text { educacional }\end{array}$ & & & \\
\hline 28 & 201 & PloS one & Mkopi et & Tanzania & Transvers & Adesão + & Doentes de & & - Sexo & & & \\
\hline
\end{tabular}




\begin{tabular}{|c|c|c|c|c|c|c|c|c|c|c|c|c|}
\hline \multirow[b]{2}{*}{$\underset{\mathbf{o}}{\mathbf{N}}$} & \multirow[b]{2}{*}{ Ano } & \multirow[b]{2}{*}{ Periódico } & \multirow[b]{2}{*}{ Autores } & \multirow[b]{2}{*}{$\begin{array}{l}\text { País de } \\
\text { Estudo }\end{array}$} & \multirow[b]{2}{*}{$\begin{array}{l}\text { Tipo de } \\
\text { Estudo }\end{array}$} & \multirow[b]{2}{*}{ Enfoque } & \multirow[b]{2}{*}{$\begin{array}{l}\text { População } \\
\text { de Estudo }\end{array}$} & \multicolumn{5}{|c|}{ Dimensões Relacionadas: } \\
\hline & & & & & & & & Paciente & $\begin{array}{c}\text { Sócio- } \\
\text { demografic } \\
a\end{array}$ & Doença & Tratamento & $\begin{array}{c}\text { Sistemas e } \\
\text { Equipes de } \\
\text { Saúde }\end{array}$ \\
\hline & 2 & & al. & & al & & TB & & $\begin{array}{l}\text { feminino } \\
-25 \text { anos de } \\
\text { idade ou } \\
\text { menos }\end{array}$ & & & \\
\hline & & & & & & Não Adesão & & & $\begin{array}{l}\text { - Entre } 35 \text { e } \\
44 \text { anos de } \\
\text { idade } \\
\text { - Sexo } \\
\text { masculino } \\
\text { - Distância } \\
\text { até o serviço } \\
\text { de saúde } \\
\text { maior que } 15 \\
\text { minutos á pé }\end{array}$ & & & \\
\hline & & & & & & Adesão + & & & & & & $\begin{array}{l}\text { - Acesso aos } \\
\text { medicamentc } \\
\text { s } \\
\text { - Hospital } \\
\text { para o } \\
\text { tratamento }\end{array}$ \\
\hline 29 & $\begin{array}{c}201 \\
2\end{array}$ & $\begin{array}{c}\text { Revista } \\
\text { Gaucha de } \\
\text { Enfermagem }\end{array}$ & $\begin{array}{l}\text { Sousa } \\
\text { Filho et al. }\end{array}$ & Brasil & $\begin{array}{c}\text { Pesquisa } \\
\text { Qualitativ } \\
\text { a }\end{array}$ & Não Adesão & $\begin{array}{l}\text { Doentes de } \\
\text { TB/HIV }\end{array}$ & $\begin{array}{l}\text { - Falta de } \\
\text { apoio familiar }\end{array}$ & $\begin{array}{l}\text { - Falta de } \\
\text { recurso } \\
\text { financeiro } \\
\text { para o } \\
\text { transporte } \\
\text { - Dificuldade } \\
\text { de ir até o } \\
\text { hospital } \\
\text { tomar o } \\
\text { medicament } \\
\text { o } \\
\text { - Falta de } \\
\text { alimentação }\end{array}$ & $\begin{array}{l}\text { - Consumo de } \\
\text { drogas } \\
\text { - Consumo de } \\
\text { bebida } \\
\text { alcoólica }\end{array}$ & $\begin{array}{l}\text { - Efeito } \\
\text { colateral dos } \\
\text { medicament } \\
\text { os } \\
\text { - Dificuldade } \\
\text { para tomar o } \\
\text { medicament } \\
\text { o }\end{array}$ & \\
\hline 30 & $\begin{array}{c}201 \\
2\end{array}$ & $\begin{array}{c}\text { Pan African } \\
\text { Medical } \\
\text { Journal }\end{array}$ & $\begin{array}{l}\text { Tachfout } \\
\text { et al. }\end{array}$ & Marrocos & $\begin{array}{c}\text { Caso } \\
\text { Controle }\end{array}$ & Adesão + & $\begin{array}{c}\text { Doentes de } \\
\text { TB } \\
\text { aderentes e } \\
\text { não } \\
\text { aderentes }\end{array}$ & $\begin{array}{l}\text { Conheciment } \\
\text { o do que é a } \\
\text { tuberculose } \\
\text { - Receber }\end{array}$ & $\begin{array}{l}\text { - Maior nível } \\
\text { de } \\
\text { escolaridade } \\
\text { - Estar } \\
\text { empregado }\end{array}$ & & $\begin{array}{l}\text { - Melhora } \\
\text { dos sintomas }\end{array}$ & \\
\hline
\end{tabular}




\begin{tabular}{|c|c|c|c|c|c|c|c|c|c|c|c|c|}
\hline \multirow[b]{2}{*}{$\underset{\mathbf{N}}{\mathbf{N}}$} & \multirow[b]{2}{*}{ Ano } & \multirow[b]{2}{*}{ Periódico } & \multirow[b]{2}{*}{ Autores } & \multirow[b]{2}{*}{$\begin{array}{l}\text { País de } \\
\text { Estudo }\end{array}$} & \multirow[b]{2}{*}{$\begin{array}{l}\text { Tipo de } \\
\text { Estudo }\end{array}$} & \multirow[b]{2}{*}{ Enfoque } & \multirow[b]{2}{*}{$\begin{array}{l}\text { População } \\
\text { de Estudo }\end{array}$} & \multicolumn{5}{|c|}{ Dimensões Relacionadas: } \\
\hline & & & & & & & & Paciente & $\begin{array}{c}\text { Sócio- } \\
\text { demografic } \\
a\end{array}$ & Doença & Tratamento & $\begin{array}{l}\text { Sistemas e } \\
\text { Equipes de } \\
\text { Saúde }\end{array}$ \\
\hline & & & & & & & & $\begin{array}{l}\text { mais } \\
\text { informações } \\
\text { sobre a } \\
\text { doença } \\
\text { - Morar } \\
\text { próximo ao } \\
\text { serviço de } \\
\text { saúde }\end{array}$ & & & & \\
\hline & & & & & & Não Adesão & & $\begin{array}{l}\text { - Falta de } \\
\text { informaçãao } \\
\text { quanto ao } \\
\text { tempo de } \\
\text { tratamento da } \\
\text { tuberculose } \\
\text { - Morar } \\
\text { distante do } \\
\text { serviço de } \\
\text { saúde } \\
\end{array}$ & $\begin{array}{l}\text { - Menor } \\
\text { nível de } \\
\text { escolaridade } \\
\text { - Não } \\
\text { exercer } \\
\text { atividade } \\
\text { remunerada }\end{array}$ & & $\begin{array}{l}\text { - Efeito } \\
\text { colateral do } \\
\text { medicament } \\
\text { o }\end{array}$ & $\begin{array}{l}\text { - Dificuldade } \\
\text { de acesso ao } \\
\text { serviço de } \\
\text { saúde }\end{array}$ \\
\hline \multirow[b]{2}{*}{31} & \multirow[b]{2}{*}{$\begin{array}{c}201 \\
2\end{array}$} & \multirow[b]{2}{*}{$\begin{array}{c}\text { Qualitative } \\
\text { Health } \\
\text { Research }\end{array}$} & \multirow[b]{2}{*}{$\begin{array}{c}\text { Van den } \\
\text { Boogaard } \\
\text { et al. }\end{array}$} & \multirow[b]{2}{*}{ Tanzania } & \multirow[b]{2}{*}{$\begin{array}{c}\text { Pesquisa } \\
\text { Qualitativ } \\
\text { a }\end{array}$} & Adesão + & \multirow[b]{2}{*}{$\begin{array}{c}\text { Doentes de } \\
\text { TB }\end{array}$} & $\begin{array}{l}\text { - Medo de } \\
\text { morrer por } \\
\text { conhecer } \\
\text { pessoas que } \\
\text { morreram por } \\
\text { não aderir ao } \\
\text { tratamento } \\
\text { - Apoio } \\
\text { familiar }\end{array}$ & & & & $\begin{array}{l}\text { - Receber } \\
\text { apoio social } \\
\text { - Receber } \\
\text { SMS para } \\
\text { lembrar-se } \\
\text { de tomar o } \\
\text { medicamento }\end{array}$ \\
\hline & & & & & & Não Adesão & & $\begin{array}{l}\text { - Crenças } \\
\text { com medicina } \\
\text { alternativa } \\
\text { - Medo de ser } \\
\text { diagnosticado } \\
\text { com HIV } \\
\text { ("muitas } \\
\text { pessoas com } \\
\text { tuberculose } \\
\text { têm HIV") } \\
\text {-Falta de }\end{array}$ & & $\begin{array}{l}\text { - Consumo de } \\
\text { bebida } \\
\text { alcoólica } \\
\text { - Consumo de } \\
\text { drogas } \\
\text { - Falta de } \\
\text { recurso } \\
\text { financeiro } \\
\text { para o } \\
\text { tratamento e } \\
\text { transporte }\end{array}$ & & \\
\hline
\end{tabular}




\begin{tabular}{|c|c|c|c|c|c|c|c|c|c|c|c|c|}
\hline \multirow[b]{2}{*}{$\begin{array}{c}\mathbf{N} \\
\mathbf{0}\end{array}$} & \multirow[b]{2}{*}{ Ano } & \multirow[b]{2}{*}{ Periódico } & \multirow[b]{2}{*}{ Autores } & \multirow[b]{2}{*}{$\begin{array}{l}\text { País de } \\
\text { Estudo }\end{array}$} & \multirow[b]{2}{*}{$\begin{array}{l}\text { Tipo de } \\
\text { Estudo }\end{array}$} & \multirow[b]{2}{*}{ Enfoque } & \multirow[b]{2}{*}{$\begin{array}{l}\text { População } \\
\text { de Estudo }\end{array}$} & \multicolumn{5}{|c|}{ Dimensões Relacionadas: } \\
\hline & & & & & & & & Paciente & $\begin{array}{c}\text { Sócio- } \\
\text { demografic } \\
\text { a }\end{array}$ & Doença & Tratamento & $\begin{array}{l}\text { Sistemas e } \\
\text { Equipes de } \\
\text { Saúde }\end{array}$ \\
\hline & & & & & & & & $\begin{array}{l}\text { informação } \\
\text { sobre a } \\
\text { doença }\end{array}$ & & & & \\
\hline
\end{tabular}


APÊNDICE II - FORMULÁRIO ESTRUTURADO

$\begin{array}{lllllll}\text { CARACTERIZAÇÃO DOS DOENTES E } & \text { O } & \text { TRATAMENTO DE }\end{array}$ TUBERCULOSE

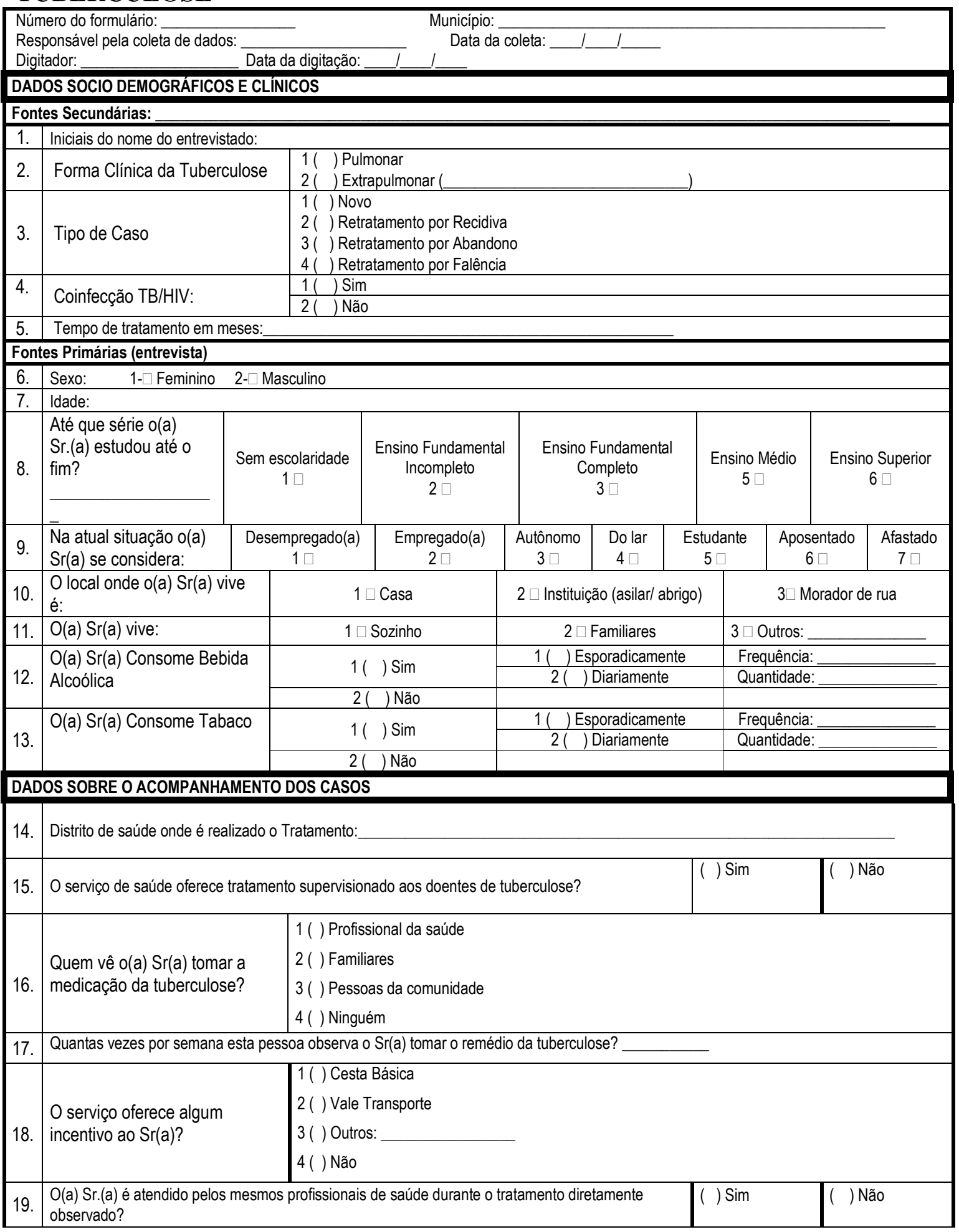




\section{APÊNDICE III - FORMULÁRIO ESTRUTURADO}

\section{CARACTERIZAÇÃO DOS PROFISSIONAIS DE SAÚDE QUE PARTICIPAM DO TRATAMENTO DE CASOS DE TUBERCULOSE}

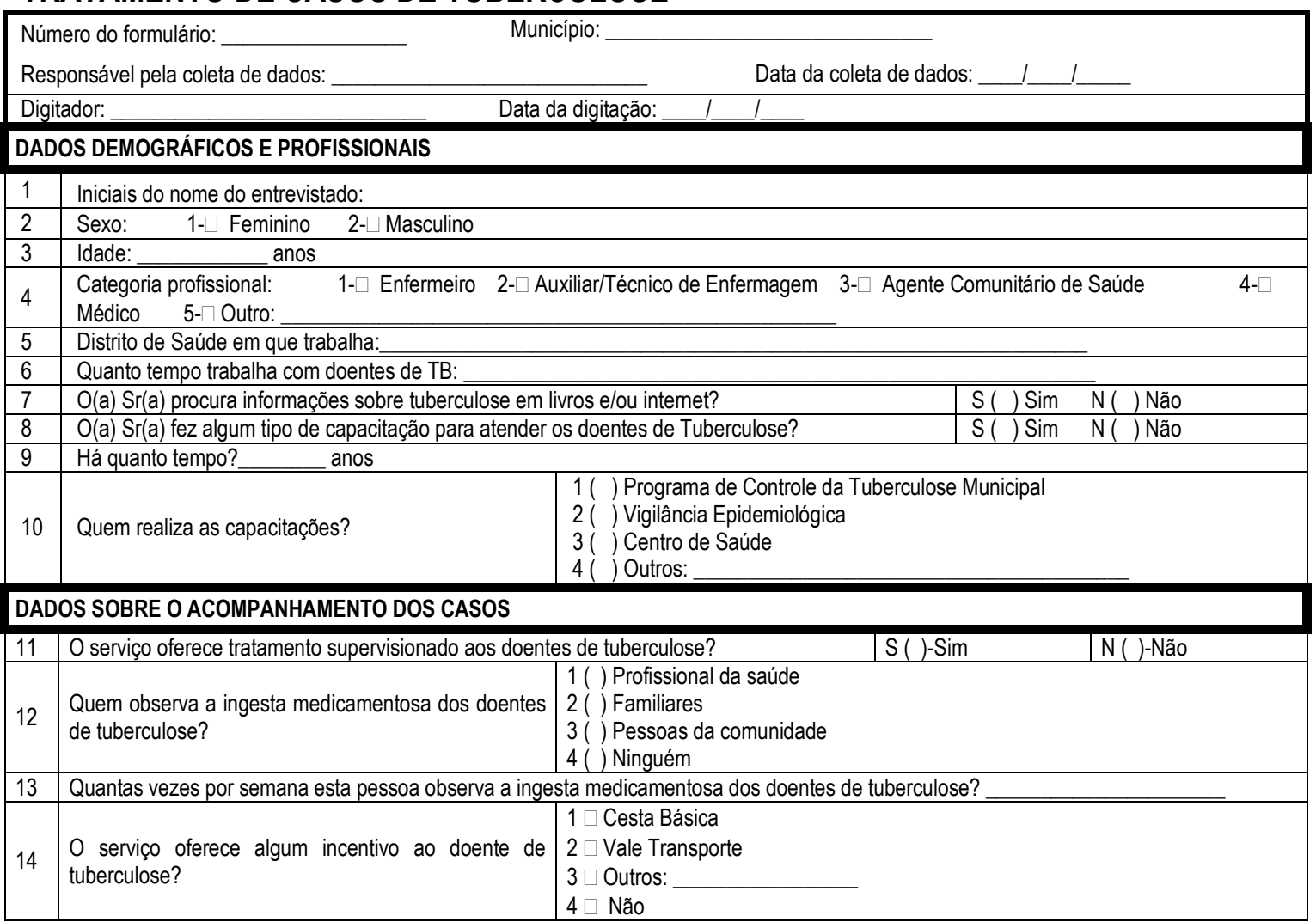




\section{APÊNDICE IV - FORMULÁRIO ESTRUTURADO}

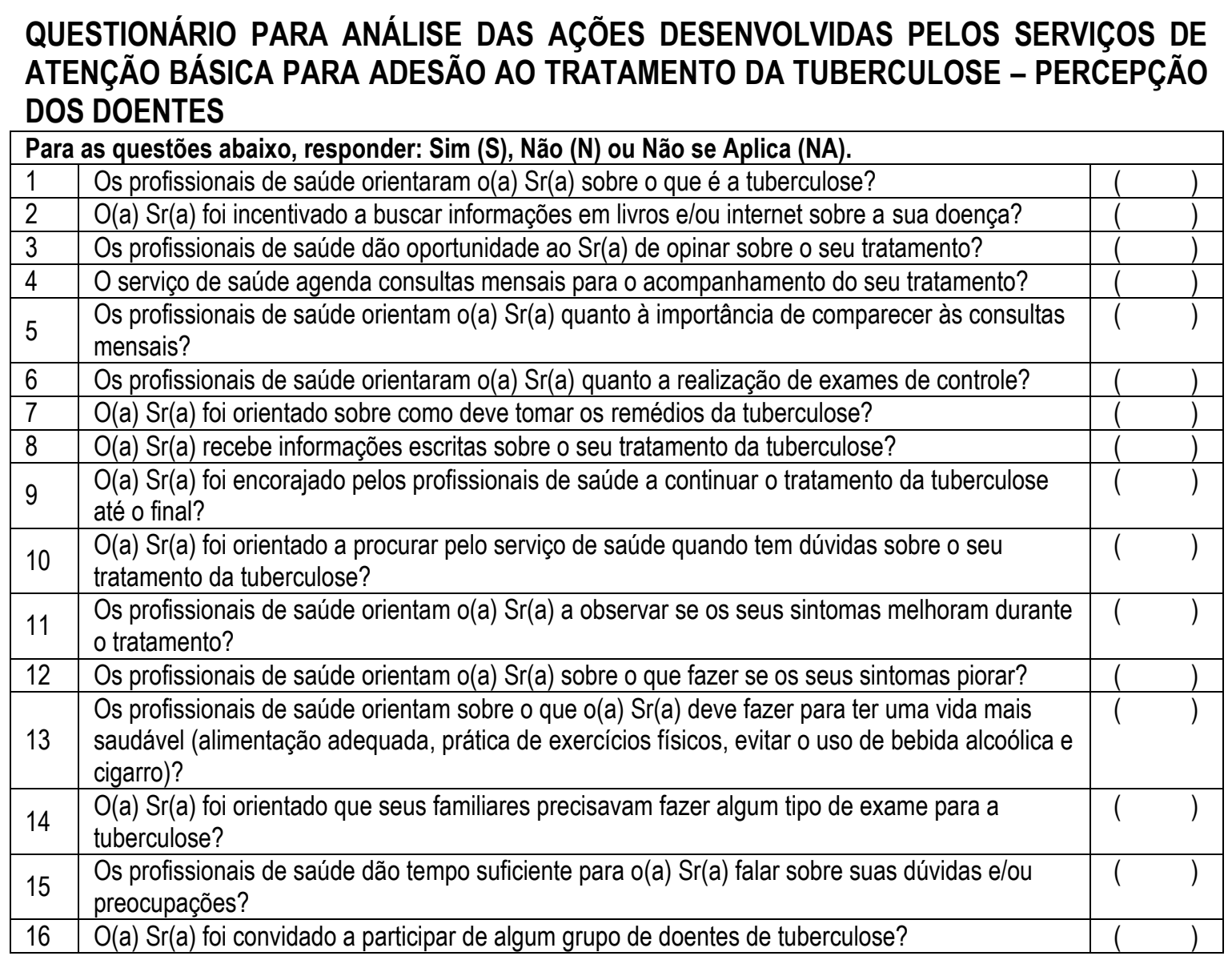




\section{APÊNDICE V - FORMULÁRIO ESTRUTURADO}

\section{QUESTIONÁRIO PARA ANÁLISE DAS AÇÕES DESENVOLVIDAS PELOS SERVIÇOS DE ATENÇÃO BÁSICA PARA ADESÃO AO TRATAMENTO DA TUBERCULOSE - PERCEPÇÃO DOS PROFISSIONAIS DE SAÚDE}

Para as questões abaixo, responder: Sim (S), Não (N) ou Não se Aplica (NA).

\begin{tabular}{|l|l}
\hline 1 & $\mathrm{O}(\mathrm{a}) \operatorname{Sr}(\mathrm{a})$ orienta o doente de tuberculose sobre o que é a tuberculose?
\end{tabular}

\begin{tabular}{|l|l|l|}
\hline 2 & $\mathrm{O}(\mathrm{a}) \mathrm{Sr}(\mathrm{a})$ orienta os doentes de tuberculose a buscar informações em livros e/ou internet & $(\quad$ )
\end{tabular}

2 sobre a doença?

$3 \quad \mathrm{O}(\mathrm{a}) \mathrm{Sr}(\mathrm{a})$ dá oportunidade ao doente de tuberculose de opinar sobre o tratamento dele?

$4 \quad$ O serviço de saúde agenda consultas mensais para o acompanhamento do tratamento do doente de tuberculose com tuberculose?

$5 \quad$ O(a) Sr(a) orienta o doente de tuberculose quanto à importância de comparecer às consultas mensais?

$6 \quad \mathrm{O}(\mathrm{a}) \mathrm{Sr}(\mathrm{a})$ orienta os doentes de tuberculose quanto à realização dos exames de controle?

$7 \quad \mathrm{O}(\mathrm{a}) \mathrm{Sr}(\mathrm{a})$ orienta o doente de tuberculose sobre como deve tomar os remédios da

7 tuberculose?

$8 \quad \mathrm{O}(\mathrm{a}) \mathrm{Sr}(\mathrm{a})$ entrega para o doente de tuberculose informaç̃̃es escritas sobre o tratamento dele?

\begin{tabular}{ll}
\hline 9 & $\mathrm{O}(\mathrm{a}) \mathrm{Sr}(\mathrm{a})$ encoraja o doente a dar continuidade no tratamento da tuberculose?
\end{tabular}

$10 \quad \mathrm{O}($ a) $\mathrm{Sr}(\mathrm{a})$ orienta o doente de tuberculose a procurar pelo serviço de saúde quando ele tem dúvidas sobre o tratamento?

11 O(a) Sr(a) orienta o doente de tuberculose a observar se os sintomas melhoram durante 0 tratamento?

$12 \mathrm{O}(\mathrm{a}) \mathrm{Sr}(\mathrm{a})$ orienta o doente de tuberculose sobre a conduta a ser tomada se os sintomas piorar?

13 O(a) Sr(a) orienta o doente de tuberculose sobre os hábitos que deve adotar para ter uma vida alcoólica e cigarro)?

$14 \quad \mathrm{O}(a) \operatorname{Sr}(a)$ orienta o doente de tuberculose para que os familiares dele também façam exames para ver se tem a doença?

$15 \quad$ O(a) Sr(a) dá tempo suficiente ao doente de tuberculose para ele falar sobre suas dúvidas e/ou preocupações?

$16 \quad \mathrm{O}$ (a) Sr(a) convida o doente de tuberculose para participar de algum grupo de usuários com tuberculose? 


\section{APÊNDICE VI - Termo de Consentimento Livre e Esclarecido}

Prezado (a) senhor (a),

Gostaria de convidá-lo (a) para participar de uma pesquisa sobre "Adesão ao tratamento da tuberculose: ações desenvolvidas pelos serviços de saúde em Campinas - SP”. Esta pesquisa está sendo realizada por uma equipe de pesquisadores da instituição: Escola de Enfermagem de Ribeirão Preto. Ela tem como objetivo Avaliar as ações desenvolvidas na atenção básica para promover a adesão ao tratamento da tuberculose na percepção dos doentes e profissionais de saúde em Campinas-SP.

Sua participação consistirá em responder a um formulário, podendo durar em média 30 minutos e ser realizada no local de sua preferência (serviço de saúde ou domicílio). As informações fornecidas contribuirão com a melhoria dos serviços de saúde na atenção a Tuberculose.

$\mathrm{Eu}$, tendo recebido as informações acima e ciente de meus direitos abaixo relacionados, concordo em participar.

A garantia de receber todos os esclarecimentos sobre as perguntas do questionário antes e durante a entrevista, podendo afastar-me em qualquer momento se assim o desejar, bem como está me assegurado o segredo das informações por mim reveladas;

A segurança de que não serei identificado, assim como está assegurado que a pesquisa não trará prejuízo a mim e a outras pessoas;

A segurança de que não terei nenhuma despesa financeira durante o desenvolvimento da pesquisa;

A garantia de que meu tratamento não será prejudicado se eu desistir de participar da pesquisa.

A garantia de que todas as informações por mim fornecidas serão utilizadas apenas na construção da pesquisa e ficará sob a guarda dos pesquisadores, podendo ser requisitada por mim a todo o momento.

Uma cópia assinada desta declaração deve ficar com o (a) Sr. (a).

Campinas, __, de de 2012.

Assinatura do entrevistado

Telefone:

Certos de estar contribuindo com o conhecimento em Tuberculose para a melhoria da saúde da população contamos com a sua preciosa colaboração.

Atenciosamente,

$\overline{\text { Prof }^{a} \text { Dr }^{\mathrm{a}} \text { Tereza Cristina Scatena Villa }}$

CONTATO: Escola de Enfermagem de Ribeirão Preto da Universidade de São Paulo.

Endereço: Avenida Bandeirantes, 3900 Campus Universitário - Ribeirão Preto - SP;

CEP 14049-900 - SP

Telefone (0XX16) 36023228

e.mail: tite@eerp.usp.br 


\section{APÊNDICE VII - Termo de Consentimento Livre e Esclarecido}

Prezado (a) senhor (a),

Gostaria de convidá-lo (a) para participar de uma pesquisa sobre "Adesão ao tratamento da tuberculose: ações desenvolvidas pelos serviços de saúde em Campinas - SP". Esta pesquisa está sendo realizada por uma equipe de pesquisadores da instituição: Escola de enfermagem de Ribeirão Preto. Ela tem como objetivo: Avaliar as ações desenvolvidas na atenção básica para promover a adesão ao tratamento da tuberculose na percepção dos doentes e profissionais de saúde em Campinas-SP.

Sua participação consistirá em responder um instrumento, podendo durar em média 20 minutos. As informações fornecidas contribuirão com a melhoria dos serviços de saúde na atenção a Tuberculose.

$\mathrm{Eu}$, tendo recebido as informações acima e ciente de meus direitos abaixo relacionados, concordo em participar.

A garantia de receber todos os esclarecimentos sobre as perguntas do formulário antes e durante a entrevista, podendo afastar-me em qualquer momento se assim o desejar, bem como está me assegurado o segredo das informações por mim reveladas;

A segurança de que não serei identificado, assim como está assegurado que a pesquisa não trará prejuízo a mim e a outras pessoas;

A segurança de que não terei nenhuma despesa financeira durante o desenvolvimento da pesquisa,

A garantia de que todas as informações por mim fornecidas serão utilizadas apenas na construção da pesquisa e ficará sob a guarda dos pesquisadores, podendo ser requisitada por mim a todo o momento.

Uma cópia desta declaração deve ficar com o (a) Sr. (a).

Campinas, __, de de 2012.

Assinatura do entrevistado

Telefone:

Certos de estar contribuindo com o conhecimento em tuberculose para a melhoria da saúde da população contamos com a sua preciosa colaboração.

Atenciosamente,

Prof $^{a}$ Dr $^{\mathrm{a}}$ Tereza Cristina Scatena Villa

CONTATO: Escola de Enfermagem de Ribeirão Preto da Universidade de São Paulo. Endereço: Avenida Bandeirantes, 3900 Campus Universitário - Ribeirão Preto - SP; CEP 14049-900 - SP

Telefone (0XX16) 36023228

e.mail: tite@eerp.usp.br 


\section{ANEXO I - Autorização do município de Campinas para a realização da pesquisa com os doentes de tuberculose.}

\section{PREFEITURA MUNICIPAL DE CAMPINAS \\ Secretaria Municipal de Saúde}

\section{AUTORIZACÄO}

Autorizo a realização da Pesquisa, em nivel de Doutorado, intitulada “AUTOCUIDADO E ADESĀO AO TRATAMENTO DA TUBERCULOSE, CAMPINAS SP", que tem por objetivo analisar o autocuidado e adesăo ao tratamento dos doentes de TB no municipio de Campinas - SP.

Declaro estar ciente que a Pesquisa (Aprovada no Comitê de Etica em Pesquisa EERP/USP em 03/03/2011) será desenvolvida por estudante do Programa de Pós. Graduaçăo em Enfermagem de Saúde Pública na Escola de Enfermagem de Ribeiräo Preto - Universidade de São Paulo, junto a usuários dos serviços de saúde do municipio de Campinas que estăo em tratamento de tuberculose e que apresentam os critérios de inclusāo estabelecidos pela pesquisadora. A pesquisa consistirá de: a) entrevista aos usuários que concordarem em participar da mesma; b) análise de dados epidemiológicos do municipio e será realizada sob a orientação da Professora Doutora Tereza Cristina Scatena Villa.

Campinas, 19 de janeiro de 2011

Adilson Rocha Campos

Secretäho Municipal de Saúde 


\section{ANEXO II - Autorização do município de Campinas para a realização da pesquisa com os profissionais de saúde.}

PREFEITURA MUMICIPAL DE CAMPINAS

Secretaria Municipal de Saúde

\section{AUTORIZACĀO}

Autorizo a realizaçắo da segunda etapa da Pesquisa intitulada "AUTOCUIDADO E ADESẢO AO TRATAMENTO DA TUBERCULOSE, CAMPINAS - SP", que tem por objetivo analisar o autocuidado e adesăo ao tratamento dos doentes de TB no municipio de Campinas - SP, tendo como objetivo especifico desta segunda etapa caracterizar os protissionais de saùde da atenção básica que acompanham os casos de tuberculose, segundo variáveis demográficas, profissionais e da organizaçāo da assistência aos doentes de tuberculose,

Declaro estar ciente que esta segunda etapa da Pesquisa (Adendo aprovado no Comité de Ética om Pesquisa EERP/USP em 01/06/2012) será desenvolvida por estudante do Programa de Pós-Graduaçăo em Enfermagem de Saúde Pública - Doutoradio, na Escola de Enffermagen cũe Ribeirāo Preto - Universidade de Sāo Paulo, consistindo nas atapas: entrevista com profissionas de saúde responsáveis pela atenção à tuberculose, coleta de dados de informaçâo e coleta de dados relacionados â cura dos pacientes, junto aos centros de Saúde do municipio, sob a orientação da Professora Doutora Tereza Cristina Scatena Villa.

Campinas, 15 de junitio de 2012

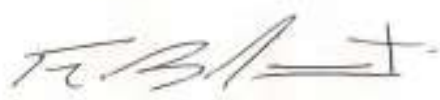

Fernando Luiz Brandāo do Nascimento

Secretário Municipal de Saúde 


\section{ANEXO III - Aprovação Comitê de Ética em Pesquisa}

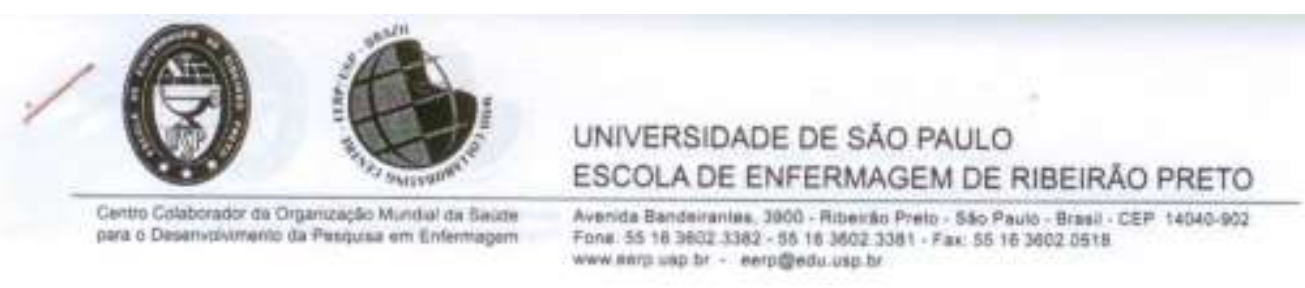

COMITEE DE ÉTICA EM PESQUISA DA EERP/USP

Of.CEP.EERP/USP - 056/2011

Ribeirão Preto, 04 de março de 2011.

Prezada Senhora,

Comunicamos que o projeto de pesquisa, abaixo especificado, foi analisado e considerado APROVADO AD REFERENDUM pelo Comitế de Ética em Pesquisa da Escola de Enfermagem de Ribeirâo Preto da Universidade de Săo Paulo, em 03 de março de 2011.

Protocolo:

$n^{0} 1264 / 2011$

Projeto:

ESTRATEGIA DOTS NO TRATAMENTO DA TUBERCULOSE: DESEMPENHO DA ATENCAAO BASICA EM MUNICIPIOS DA REGIĀO SUL, SUDESTE E NORDESTE DO BRASIL.

Pesquisador: Tereza Cristina Scatena Villa

Em atendimento à Resoluçâo 196/96, deverá ser encaminhado ao CEP o relatório final da pesquisa e a publicaça de seus resultados, para acompanhamento, bem como comunicada qualquer intercorréncia ou a sua interrupção.

$$
\begin{aligned}
& \text { Atenciosamente, } \\
& \text { fruita boxineto } \\
& \text { Prof'. Dra. Lucila Castanheira Nascimento } \\
& \text { Coordenadora do CEP-EERPIUSP }
\end{aligned}
$$

llma. Sra.

Prof", Dra. Tereza Cristina Scatena Villa

Departamento de Enfermagem Materno-Infantil e Saùde Pública

Escola de Enfermagem de Ribeirâo Preto-USP 


\section{ANEXO IV - Aprovação Comitê de Ética em Pesquisa}

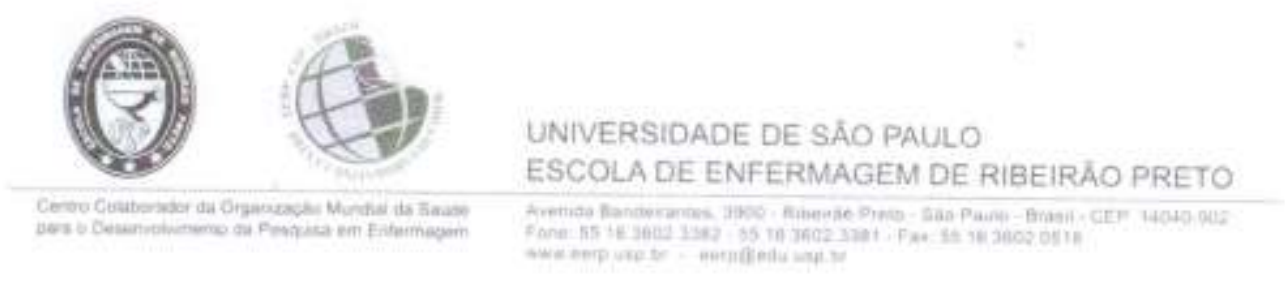

Ribeiräo Preto, 01 de junho de 2011

Protocolo: 1264/2011

Entrada: 01/02/2011

Pesquisadores: Tereza Cristina Scalena Villa

Projeto: Estratégia DOTS no tratamento da Tuberculose desempenho da atençăo básica em municipios da regiło sul, sudeste e nordeste do Brasil.

Trata-se da solicitaçăo de um adendo junto ao projeto acima citado, o qual fol aprovado por este CEP. O adendo consiste em um instrumento estruturado, elaborado com base nas definiçōes dos componentes básicos de avaliaçăo da qualidade dos servipos de saùde. 0 instrumento é composto por 62 questōes, com respostas dicotômicas e de mültipla escolha com resposta ûnica e múltipla.

A coleta de dados seră realizada em 3 etapas:

$1^{2}$ - Entrevista com o profissional de saùde responsável pela atençâo a tuberculose da Unidade de Saúde, que será realizada por um mediador qualificado mediante assinatura do TCLE;

24- Coleta de dados relacionados ás informaçóes do prontuário e à atualização do livro de registro e acompanhamento dos doentes e da ficha de registro diärio de tratamento;

3a- Coleta de dados retacionados à cura, abando e obbito coletados de fonte secundaria (TB-WEB ou SENAN).

- TCLE traz informaçbes sobre o objetivo do estudo, garante sigio da identidade do participante e que as informaçbes fomecidas serâo utilizadas unicamente para fins de pesquisa informa como sera realizada a coleta de dados, intorma que a participaçảo na pesquisa nâo trara risco a sujeito e que ele nấo fera despesas ou grafflicaçōes por participar. Adicionalmente, tra que as dúvidas poderáo ser esclarecidas mesmo após 0 termino da pesquisa, que o profissional pode negar-se a participar, garante a entrega de uma via do TCLE e fomece número de telefone e enderecp de e-mail para contato com a pesquisadora.

Pelo exposto, o Comile de Éfica em Pesquisa da Escola de Enfermagem de Ribeirâo Preto da Universidade de Săo Paulo considera o projeto APROVADO. 